HEAT TRANSFER IN A GAS-COOLED, HEAT-GENERATING POROUS SOLID

\author{
(Thesis !
}

Robert Pope Rannie 


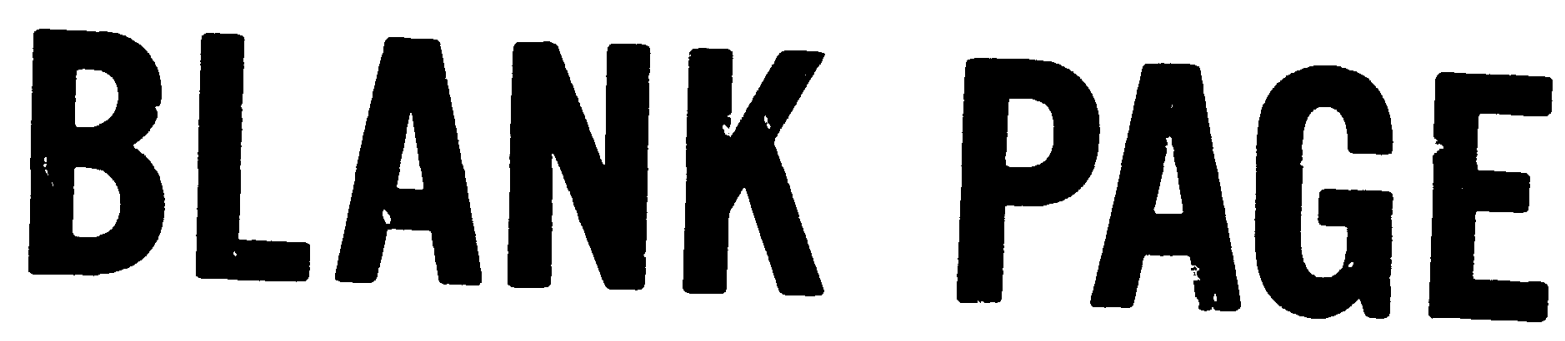


Printed in the United States of America. Available from National Technical Information Service

U.S. Depuremerit of Commerce

5785 fort Royal Road, Springfield, Nirginia 22151

Price. Printed Copy \$3.00-Microliche \$0.95

This report was prepared as an account of mork sponsored by tive United States Government. Neither the United Stsiss nor the United States Atomic Energy Commission, nor any of the:: employees, lior any of their contractors. subcontractors, or their employes, makes any warrant!, express or implied, or assumes any legal liability or responsibility for the accuracy, completeness or usef jiness of any information, apperattis, prodent or process disclosed, or represer:is that its use mould race infringe privacely owned rights. 


$$
\begin{gathered}
\text { ORNL-4808 } \\
\text { UC-38 - Engineering and Equipmer }
\end{gathered}
$$

Contract No. W-7405-eng-26

\section{MATHEMATICS DIVISION}

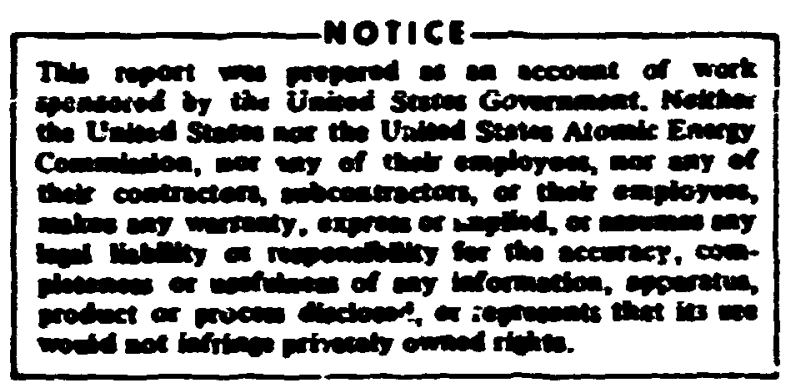

IEAT TRANSFER IN A GAS-COOIFD, HEAT-GEMIMATTNG POROUS SOLWD

Robert Pope Rannie

Submitted as a dissertation to the Graduate School of The Pennsylvania State University in partial fulfillment of the requirements for the legree of Doctor of Filszophy in Chemical Engineering.

\section{DECEMBER 1972}

\footnotetext{
OAK RIDGE NATIONAL IABORATORY

Oak Radge, Tennessee 37830

operated by

UNION CARBIEI CORPORATION

for the

U. S. ATOMIC ENERGY COMMISSION
}

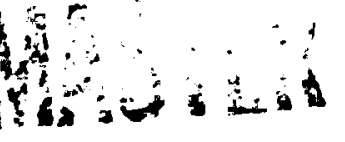




\section{ACKNOWLEDGMEINT}

To the many persons ari srganizations which have suppor sd the work on this thesis I should like to expres: my appreriation, and I would like to single out the following to express special opprepiation. I would like to thank thesis advisor, Dr. Wallis A. Llcya, for his guidance and particularly for his patience. I am indebted to Jerome Farber for his heip and assistance relating to the experimental apparatis which we shared. I would like to express my cippreciation to The Department of Chemical Engineering of the Pennsylvania Stste University and to the Oak Ridge Institute of Nuclear Studies for the awarding of the Scholarsinips and fellowships which supported the majority of doctoral studies. I very much appreciate the support I have received am the Oak Ridge National Laroratory in affording me time and facilities to complete this work. A special thanks is due to my colleagues and supervisors in the Mathematics Division of the Oak Ridge Naticnal Laboratory. The considerations of J. G. Sullivan in this connection are particularly appreciated. The thesis typing by Mathleen A. Christian is gratefully acknowledged. 


\section{ABSTRACT}

The use of porous materials in heat transfer has been increasing. The cquations shich describe heat transfer in forous materials with a fluid fiowing thrcugh the pores of the material are more complicated than those for heat transfer through solids and into fluids at a plane interface. Calculations of heat transfer in porous materials have been hindered by fairly widespread misconceptions about this type of heat transfer and by the lack of experimental data on the heat transfer relateà properties of porous materiais.

Among articles which have been published that discuss heat transfer in porous materials, there are some which are now arknowledged to contain errors. The erroneous conclusion or these articles, and other reasons, have fostered an assumption tinat in a fluid cooled porous material the sclid and fluid phase temperatures will be nearly identjcal.

The purpose of this study was to determine if an experimental apparatus cculd be built that could be used for gas phase chemical reactions in electrically heated porous tungsten and also to measure the heat trailsfer coefficient in the porous tungsten using nitrogen or helium gas as the coolart. The extent of the allaged similarity between the temperature of the solid and the fluid could thus be determines. It was proposed that the equations for heat transfer in a fluid cooled, heat generating porous solid be derived and used to analyze data from experimental measurements on the porous system. These equations were not to be based on or be restricted by the assumption of the essential equality of the solid and fluid temperature in the porous material. 
Appropriate experimental measurements were to be carricd out in order to measure four boundary conditions from which the ihree constants of the equations and the heat transfer coefficient could be deternined.

The equations were derived and incorporated into FORTRAN digital computer frograms that were used to accomplish the data reductivii. The experimental apparatus was successfully built and operated in spite of extensive deve:-opmental problems associated vith electrical contact resistance at the mounts of the porous tungsten. Due to the lack of data on the effective thermal conductivity of the porous tungsten, a fifth boundary condition was measured from which a conduction correction factor was determined for the porous tungsten.

The heat transfer coefficients that were measured in this study show good agreement with other experimental measurements of heat transfer coefficients. Correlations which had been suggested for heat transfer coefficients and which were not generally based on experimental data gave heat transfer coefficients that were larger than values measured in this study by two or three orders of magnilude.

The assumption of such large heat transfer coefficients could continue to support the idea that the temperature of the sislid and fluid are nearly identical. Even at the low Reynolds number $n 10^{-1}$ in this study, solid and fluid temperature differences of hundreds of degrees $F$ were observed. 
Acknowlegigment

Abstract

List of Tables..................... iz

List of Figures . . . . . . . . . . . . . . . . x

INTRODUCTION . . . . . . . . . . . . . . . . I

PURPOSE AND SCOPE . . . . . . . . . . . . . . 9

THEORY

Heat Transport in Porous Systems . . . . . . . . . . . II

Basic Heat Transport in the Experimental Porous System . . 18

Special Considerations for the Experimental Porous System • 21

EXPERTMENTAL WORK

Experimental Apparatus - General Description . . . . . 35

Electric Power Circuit .............. 36

Mechanical Assembly ............. 38

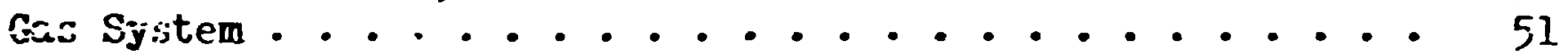

Instrumeniation ............... 53

Experimental Procedure .............. 59

DISCUSSION OF RESJiTS

Experimental Developments . . . . . . . . . . 61

Boundary Conditions and Method of Solution . . . . . . 64

S:umary of Results . . . . . . . . . . . . . 74

Nusselt-Reynolus Data Correlation .......... 78

Other Ncn-Experimental Correlations . . . . . . . . 85

Heat Balances and Temperature Profiles.......... 90

Conduction Correction Factor . . . . . . . . . . . 94

Analysis of Experinental Errors . . . . . . . . . 97

conclustons . . . . . . . . . . . . . . . 109

FUTURE WORK . . . . . . . . . . . . . . . . 111

APPENDIX A - Derivation of Equations . . . . . . . . 113

APPENDIX B - Experimental Data: Common Values and Physical

Ccnstants . . . . . . . . . . . . 121

APPENEIX C - Experimental Data: Individual Run Data . . . 125 


\section{BLANK PAGE}


vi:i

TABIE OF CCNTENTS (continued)

Pare

APPENDIX D - Kesults of Individual Run Analysis . . . . . 129

TABLE OF NOMENCLATURE

BIBLIOGRAPHY . . . . . . . . . . . . . . 137 


\section{LIST CF TABLES}

Tabl:

Numin:

Page

1 Common Parameters and Physinal Constants . . . . . . 122

2 Individial Run Data-Optical Pyrometer Temperature and Cylinder Position Pairs .......... 120

3 Individual Run Data-Thermometer and Thermocouple Readiners ................. 127

4 Indirichal Run Data-Cylinder Specificaticns, Heat Generation and Fluid Flow . . . . . . . . . 128

5 Individual 3un Analysis-Heat Ealances . . . . . . 130

6 Individual Ruri Analysis-Solid and Gas Temperatures . . . ' -3l

7 Individual Run Analysis-iteat Transfer Coefficient and Conduction Correction Factor . . . . . . . 132 
LIST' OF FICUKE.

Figure

Number

Pare

1 Heat Flow in a Differential Element of Porous

Material ................ 16

2 Equivalent Flat Wall Model of the Cylinder . . . . . 22

3 Drilled Channels and Porous Material . . . . . . 29

4 Factors Reducing Conductivity in Porous Materials . . . 31

5 Rectifier Power Circuit ........... 37

6 Pìotograph of the Experimental Equipment ...... 39

7 Photograph of the Mounted Tungsicn Cylinder without

Marinite Insulation ard Instrurentation . . . . . . 40

8 Insulated Studs Connecting the Bus Blocks ........ 43

9 Stainless Steel Pier and Graphite Washer ....... 45

10 Photograph of the Mounted Tungsten Cylinder with Marinite Insulation and Instrumentation .......... 47

11 Marinite Insulating Disks ........... 49

12 Photograph of the Assembled and Instrumented Tungsten Cylinder Showing the Jptical Pyrometer in Position for viewing ............... 50

13 Gas System-Schematic Diagram . . . . . . . . 52

14 Photograph of the Controls and Instrumentation of the Experimental Apparatus . . . . . . . . . . 54

15. Schematic of the Mounted and Instrumented Tungsten cylinder ................. 56

16 Tenperature Profiles and Heat Balances in the Forous Wall ................ . . 76

17 Niusse]t Number ve Reynolds Number for Systems of Porous Materials................ 77 


\section{INTRODUCIION}

The use and handling of jorous matcrials has been a concern of technology sinco its beginings. Beds of cranular materials and porous solids have extensive use in chemical and petroleum processing. $(4,26$, 32) While metals have long been avajiable in poisus forms, it is only within this century that powder meteillurgy he.s recome a significant technology. (19) Powder metallurgy has been used in the fabrication of high milting materials, such as tiungsten, and in the prewaration of bearing materials which are desirable because of their oil-retaining porous structure.

During the period around the second World War there was an increased incerest in heat transfer involving porous materials. The development in this period of the rocket engine with its severe problems in heat transfer led to consideration of film ccoling and trarspiration cooling. $(6,2 ;, 30)$ Transpiration cooling, which has also been referred to as "sweat cooling:" and "effusion cooling," is accomplished by the f'ow of a cooling fluid through a heat conducting material in a direction opposite to the flow of heat in the materia?. This technique of cooling by countercurrent flow of coolant and heat could in principle be accomplished with coclant passages of any size. Porous materials were used for some of these applications because they offered a large surface-to-voiume ratio and the low flow rates generally used did not create excessive pressure drops in the porous material. In addition the porous material had a high degree of homogeneity that could not be achieved by a systcm of tubes. 
The development of nuclear energy in this rcriod led to additional problems in heat transfer. One reason for thesi problems was that in nuclear reactor cores power densities were now available which were generally larger than those that had existed before the advent. of nuclear technology. One technique that ras bein suggested in connection with the nuclear powered rocket is to use a reactor core that is formed from jorous materials so that a large surface arsa will bc available for the transfer of heat to the propellant that is passing through the reactor core. (7)

The general advance of technology has led to systems with higher operating temperatures and more critical problems in heat transfer are now found in well establisher fields such as the cooling of turbirse blades. Another area of iriterest is in the use of a porous material as a reactor for chemical reactions. When the porous material is. heated internally by ohmic or nuclear heat generation it should ?rovide a reactor with a large surface area in a small volume capabie of permilting reactions with short contact times. An enhancement to the porcis reactor might be obtained by fabricating the reactor from fissionable material and operating it in or near the core of a niclear reactor where it would be subjected to a high neutron flux. The reacting fluid flowing through the porous reactor could then be subjected to direct fission fragment bombardment which wiuld serve as a catalyst for chemical reactions.

The number of areas which have an interest in hoat transfer in porous systems continues to increase as the understanding of this technology has increased and its application has spread. 
fit the present time there are at least two problems associated with carrying out calculations involving heat tranffer in porous systems. The first problem is a misconception regarding the solidfluid temperature difference in porous materials. The second probicm is the shortage of experimental data on heat transfer in porous sy:trims. The background of the first problem is the following. Many o: these new technologies which use porous systems have either come into existence or have received some major new impetus prior to extensive application of the digital computer as a tool for problem solving. This has created the problen of trying to solve the higher order, and somatimes partial, differential equations oi porous heat transfer by various simplifying technique :. Accordingiy each problem involvi:1g porous systems has been simplified by assumptions which wer $\cong$ designed to allow relatively easy solution of the equations for the particular case being studied. This procedure has createà a variety of apf roaches to the general problem of heat traisfer in porous systens and apparently has fosterea certain assumptions about porous systems which are not generally true. In any case, the variety of simplified approaches to the problem has not served to create a uniform set of definitions for porous systems.

The difficulty in solving third order equations does not lie simply in the need for an additional constant to be civaluated by the measurement of $a$ third boundary condition. Rather, the proble $\mathrm{n}$ occurs hecause of the coupled nature of the equations for heat transfer in porous systems. In a problen with heat conduction up to a boundary that was cooled by convective heat transfer it was generally possible to separate the solid and luid phases and treat cach as a separate 
problem with coupling thrciag the convective heat transfer coefficient. The differential equation for the heat transfer in the solid phase could be solved separately from the differential equation for the heat transfer in the fluid phase. For heat transfer in porous systems the heat transfer coefficient is irvolved in two different differintial equations which are combined to yield the third order heat transfer equations. The phases are now no longer separable in the sense of a fluid contacting a solid wall along a geometric plane. Moreover, the coupling of the phases is not in the algrbraic equations which are the solutions of the differential equaticos. The coupling is now in the differential equations themselves. Tis prevents the simpler solution of the problem in parts and the combination of the results. In addition the equations for the heat transfer coefficient are transcendental and trial and error solutions are necessary for this parameter. One early attempt to derive equations for the general problem of heat transfer in porous systems was that of Weinbaum and Wheeler. (34) This work assumed that the porous system sculd be considered to have pores made up of many small tubes or pipes running through the porous solid in the direction of fluid flow. The heat transfer ccefficient assumed in this work was therefore based on the flow of fiuids in pipes. This work had an error of sign in the derivation of the keat transfer equations and the authors erroneously concluded that in a great many systems the fluid would be heated to essencially the solid temperature in a very small percentage of the flow length of the fluid through the porous solid. It has been noted that this error was copied explicitly in at least one other work (1?) and several articles have 
referenced the articie of Weinbaum and Wheeler without taking not: of the error in their derivation.

Purtherwore, it will be show that this assumption ci essentially equal temperatures in the solid and fluid phases of a forous system has been widely used. While the assumption of equal solit and fluid temperatures might not be directly attributable to the artjcles cited, those erroneous conclusions may have grompted some autbors to make this same assumption in their work. In this connection it is noteworthy that in the chapter in Schneider (28) an porous systems he cites caly two references, one of which is Weirbaun and Wheeler; and the other of which is Green (13), who also assunes the equality of the phase temperatures. Schneider notes that the use of the assumption of the eqiality of the temperature of the two phases greatly simplified the analysis. If equality of phase temisature were true, or rather if this were an assumption that would be sufficientiy accurate, then it would be helfful since it effectively reduces the problem from one involving a third order equation to one $i$ - rolving cnly a second order cquation. In the absence of sophisticated computing facilities the desire to use the assumption of phase temperature equality is unclerstandable.

Bussard and DeLauer (7) essentially ascume identity of the solid and fluid phase temperatures citing Green as a reference. A more recent article by Weiner and Edwaris (35) treats simultaneou.; conduction, convection, and radiation in a porous bed by initially dirining the solid and fluid temperaturts to be the same. A still morc recent article by Koh and del Casal (2l) surprisingly still cites Weintaum and wheeler, and Green. While this work initially considers a temperature difference between the solid and the fluid, a significant portion of this work 
considers the case where the solid and fluid phase temperatures are assumed to be equal.

The protien of the incorrect sign in the derivajion of Weinbaum and Wheeler did not, however, go entirely unnoticed. B? and (2) and Grootenhuis (17) made a correct derivation of the problem. Bland derived equations wich coupled the flow equations with those for heat transfer by assuming a correlation for the heat transfer coefficient in the porous material. While this correlation, based on work by Grootenhuis (15) was probably reasonable, it does point out the lack of experimental data on porous systems, a fact which is explicitly noteü by Grootenhuis. These two works point up the second shortcoming of the state of this art which was the lack of experimental measurements on porous systems. The difficulties in solving higher order equations which more accurately aescribed the porous system often led to treatment of the porous systems by extrapolation from other models. Among others it was postulated that a porous solid was equivalent to many small tubes or that it resembled a packed bed. $(1,34)$ some of the concepts cf parameters in porous systems will now be considered.

Experimental values for the thermal conductivity of porous materials were generally u.known and Grootenhuis in fact comments on the general lack of experinental data in tris area. More recently, Koh and del Casal (21) have reiterated this complaint. The question of the thermal conductivity of porous materials is related to che question of how the area for heat conduction should be defined. Many of the authors $(7,28$, 34) siate that the cross sectional area available for thermal conductivity is based on the geometrical area for conduction. The geometrical area for concuction is generally taken to be as area evaluated by 
multiplying the complement of the volumetric porosity by the bulk cross sectional area of the porous material. A notable exception to this assumption is the work of Koh and del Casal (2l) on nickel Foametal.

A variety or assumptions are made with regard to the correlation to be assumed for the internal heat transfer coefficient as well as the method to be used to evaluate the area within the pores. Bland evaluates the heat transfer coefficient on the basis that the pores correspond to a system of small tubes. Moreover he relates this to pressure drop during flow measurements in that he calculates the size of a group of small pipes which would produce the observed pressure drop. He then uses these tul $\_$as the basis for both the heat transfer coefficient and the internal area of the porous material.

Grostenhuis has sought to determine an experimental correlation between a volumetric heat transfer coefficient and the flow rate. The volumetric heat transfer coefficient is the product of the clasicical heat transfer coefficient and the internal area per unit bulk volume of the porous material. Grootenhuis evaluates the internal surface area of any porous solid by assuming ihat specific surface varies as a linear function of one minus the porosity.

While the case of a heat generating solid phase in a normis sjstem has been considered in some articles (13), there do not appear to be many experimental studies in which this effect occurs. This suggests a need in this area since internal heat gencration is the mechanism which would be enployed in a porous nuclear reactor core and in a porous chemical reacior. Another difficulty in obtaining a well 
defined set of cquations for heat transfer in porous systems is due to the desire by sone authors to couple the heat transfer problcm with the fluid rlow problem. This is being done without firm data on the relation of fiow rates $t u$ the heat transfer coefficients in porous materials. With the large area of uncertainty in porous heat transfer it would probably be better if the problems of heat transier and fluid flow could be considered separately until better solutions for the individual problems are established.

Studies on heat transfer in porous systems have remained relatively scarce in the sense that there are relatively few articles in this general area which are applicable to the concept as it is examined in this study.

A relutively new ares of study involving heat transfer in porous materials is the heat pipe. (9) Present studies on the heat pipe are more concerned with fluid fiow through the capillaries of the wic: and problens of entrainment during vaporization than they are with problems of heat transfer through the porous wick. This is to be expect,ed because the heat transfor problems are not the most critical proilems found in heat pipes at the present tirse. However, it has been noted (8) that future developments in heat pipes will need to consider problems such as the heat transfer through the fluid and the wick in high performance heat pipes. 
TURPOSE AUD SCOPE

One purpose of this study was tc build and operate an experirental apparatus tinat could be used to perform research on jorous systims. The apparatus was to be used for studies of thr kinetics of gas phise chemical reactions in a heat-generating porous reactcr. It was al:;0 to be used to measure heat transfer coeficients in heat-generating porous materials.

The development and use of the apparatis for kinetic stidies has been describeil by Parber. (10) The present thesis will describe the development and use of the apparatus for the purpose of experimentally measuring heat transfer coefficients within a gas-cooled, heatgeneratirig porous solid. The method for the detcrmination of the heat transfer coefficient will use only a kimited number of assumtions and in particular this method will take into account some factors which, through neglect, omission, or error, appear to have led to certuin erroneous assumptions regarding heat transfer in porcus systems.

The present study also propose $s$ to examine correlations which have been suggested for porous materials, but which are based on extrapolation from nonporous nodels, in order to determine the agretment between these proposed correlations and experimcntal data.

The porous material used in both the kinetic sturiss of Farber and in this work was porous tungsten in the form of hollow cylinders approximately one and a half inches long, $3 / 8$ inch in outsije diameter with a wall chickness of $1 / 16$ inch. The heat generation within the purous tungsten was obtained from direct current that was supflicd from a selenium rectifier of the type used for conmercial electroplating 
operations. In the prisent stuly the heated tungsten was cooled by nitrogen or helium eas which flowed radially outwerd through the pores of the hol.low $t$ anesten cyinder.

Measurements of the porous system were taken when it wus in a state of dungmic equilibrium in which heat was being generated within the porous tingsten at the same time that heat was being removed by the heating of the gas that was llowing through the wall of the hollow cyinder. Under these conditions a number of boundary conditions of the porous system were determined. More boundary conditions were measured tian were required by the order of the differential equations that describe the porous system and the unkiows heat transfer coefficient could then be found from the overdetined system of equations. Analysis of the experimental data was carried out using thiru order differential equations to desrribe the porous syst $2 m$. The use of equations of this order assured trai t\}:e analysis would not impose any constraint on the heat transfer coefficient such as results when, for example, cifferential equations of a lower order are used to lestribe tide porcus system.

Porous systems have been described by models that consider the porous material to consist of many sinall pipes or to resemble a packed bed. Correlations obtained from these models will be compred tc experjuentally measured cata. 
THEORY

Heat Transport in Porous Systim:

There are many materials whish have beeil described as porcus, which literally means that the materiai contains a number of small openings. This concept of pcrosity will be retained in this study but additional qualifications will be added. In porous materials. dimensions of the pores are usually small relative to the extensive dimensions of the material. Also the pores are asially uniformly distributed throughout the material. When the term porous is applied to a material, that material is still considered to be uniform but its extensive properties (mass, heat capacity, conductivity, etc.) are now treated as inaving been reduced by some factor. Oil-bearing strata, a fluidized bed, urethane foam, a car radiator, and turbine blades formed by sintering powered metal are examples of porous materials.

Porosi'y is a parameter used to describe porous materials. It specifit the fraction of a particular extensive property that is missing from the porous material. Volume is the extensive property generally referred to when porosity is used. In this serise porosity is a measure of the amount of void in a porous solic. Volume porosity has the dimerisions of cubic feet of void volume per cubic feet of bulk volume. These dimensiors have been specified for porosity in other references. There are other kinds of porosities such as solid-areanormal-to-conduction per bulk area and solid-length-parallel-toconduction per bulk length. The first of these porosities is generally assumed to have the same nume:ical value as one finus the volume porosity while the second is generally assumed to have a numerical value of one. 
On this basis, the effective area for conduction through a porous solid woild be numerically equal to the bulk area for conduction multiplied by one minus the volume porosity. However, an example will show that all porosities are not the same as the volume porosity. Two materials may have the sabis volume porosit.y but the one may be a bed o: hard spheres that touch only at the points of contact while the other is a solid block (f material that has a number of parailel holes drilled through it. The conductivity through the drilled block parallel to the drilled holes and the conductivity through the bed of hard spheres would certainly be quite different. There would probably also be a difference in the conductivity through the drilled blork parallel to the holes and the conductivity through the drilled block perpendicular to the holes. Porous materials have a certain degree of homogeneity due to the uniformity of their $F:$ structure. However, the ability to analyze porous materials by the method used in this study is dependent on the following considerations. Porous naterial is cleariy heterogrneous when it is examined at a level corresponding to the dimensions of the particulate structure. A rigorous analysis of the heat transier through a number of such particles would be analogous to an attempt to analyze the heat transfer in the bricks of a regenerator by defining finite difference equations for $a 11$ of the bricks in the regenerator.

The analysis can be greatly simplified if the porous system can be analyzed on a scale that is at least one or two orcuers of magnitude larger than the dimensions of the particles of the porous structure. In this case it may now be possible to consider the porous material to be homogeneous and possessed of extensive properties that are reduced in magnitude. 
This method for analyzing systems has a clear precedent in the ordinary heat conduction problem in which the problem of defining enerey transfer bitween atoms is avoided by assuming that the conduction problems will consider the material on a scale where the significant dimensions of the conducting material are much larger than the dimensions of the atoms comprising the material. Thus, treating solid material made of atoms, and porous material made of particles as both being homogeneous involves only a quantitative and not a qualitative difference.

A real porous system will $2 a$ mixture of solids and voids. A significant number of these voids may be connected to form passages. The voids may contain a fluid. The model of the porous system used in this study treats the porous system as one composed of two phases that occupy the sare buik space but in which each phase is present at a reduced density. The solid phase and the fluid phase are each considered to be homogeneous, continuous, uniformly dispersed through each other, and in contact with each other. In this model the extensive properties of each phase are proportional to the volume fraction of that phase in the porous system.

In order to justify the assumption that a real heterogeneous porous system can be considered to be homogeneous, the Biot number should be determined for the particles in the material. The Biot number is $\mathrm{hr} / \mathrm{k}$ where $h$ is the heat transfer coefficient at the surface of the particle, $r$ is the radjus, or characteristic dimension of the particle, and $k$ is the thermal conductivity of the solid material comprising the particle. The Biot number is the ratio of the midplane thermal internal resistance to the surface film resistance. (3) The Biot number is exactly the ratio of the conduction temperature oradient over the convection 
temperature gradient for the case of a plane of thiskness $r$ with thermal ccnductivity $k$ and heat transfer coefficient $h$ at one surface. The Biot number is twice this ratio for a slab, a cylinder, or a sphere when the solid material is uniformly generating heat. (24) With the exception of the factor of two, the Biot number can be used to determine the ratio of the temperature difference from the center of the particle to the edge of the particle divided by the terreture difference from the edge of the particle to the bulk temperature of the fluid stream.

The Biot number for the particles of a porous material may be used to determine the temperature gradients which will be created within the particles by the convective heat transfer coefficient of the system. The assumption has been made that the solid phase temperature varies uniformly across the wall of the porous material. This means that a certain temperate gradient will. exist across the width of a single particle of the porous material. In order to justify treating the porous system as if it were homogeneous the central and surface temperatures of the particles should vary less than an wount that could perturb the $t=m p e r a t u r e$ gradierit which may be imposed on the porous material. The temperature change within the particles should also be small enough not to significantly effect any temperature dependent physical parameters of the particle material since they have been zssumed to be independent of temperature in this mode:-

Heat transfer in porou, systems, as def:ned in this study, involves a stationary porous solid phase and a fluid jhase that is riowing through the connected pore structure of the porous solid. Heat is being generated within the solid phase material. Three wodes of heat transport are involved. Heat is being transferred through the solid phase 
by conduction and is being transferred with the fluid phase by mass transport. In addition to these two modes, heat is beine exchanged between the solid and fluid phases by convective heat transf $-\mathrm{r}$ across the solid-fluid interface. This interface is the internal surface area of the porous solid.

The configuration which may be used to stidy heat trarsport in heat generating porous systems consists of a generating, conducting, infinite, porous flat plats cooled with a nusgenerating, nonconductine fluid flowing through the connected pores in the plate. The flow shrough the plate is taking place in the one finite dimension. Figure 1 shows the heat flows used to derive the equations for steady state heat transfer in such a system.

The quantities $q_{1}$ and $q_{3}$ represent respectively the beat conducted into and out of the element $\mathrm{dx}$ of the solid phase of the porous system. Since no conduction through the fluid phase is considered there is no ccmparable effect in the fluid phasa. This assumes the heat transferred by conduction in the fluid is negligible compared to other heat transport effects in the fluid phase. The quantities $q_{5}$ and $q_{6}$ represent the heat transported into and out of the element $d x$ of the fluid phase of the porous systom by fluid fluw. Since there is no movent of the soifd phase there is no comparable effect in the solid phase. The puantity $I_{2}$ represents the neat generated in the element $d x$ of the solid phase of the porous system due to ohmic heating. Since there is no ohmic heating of the iluid phase there is no comparable effert in the fluid phase. The guantity $q_{1}$, represents the heat transferred by convective heat transfer frot: the solic phase to the flidid phase. This transfer takes place across the interphase boundary existing in the dx element. 


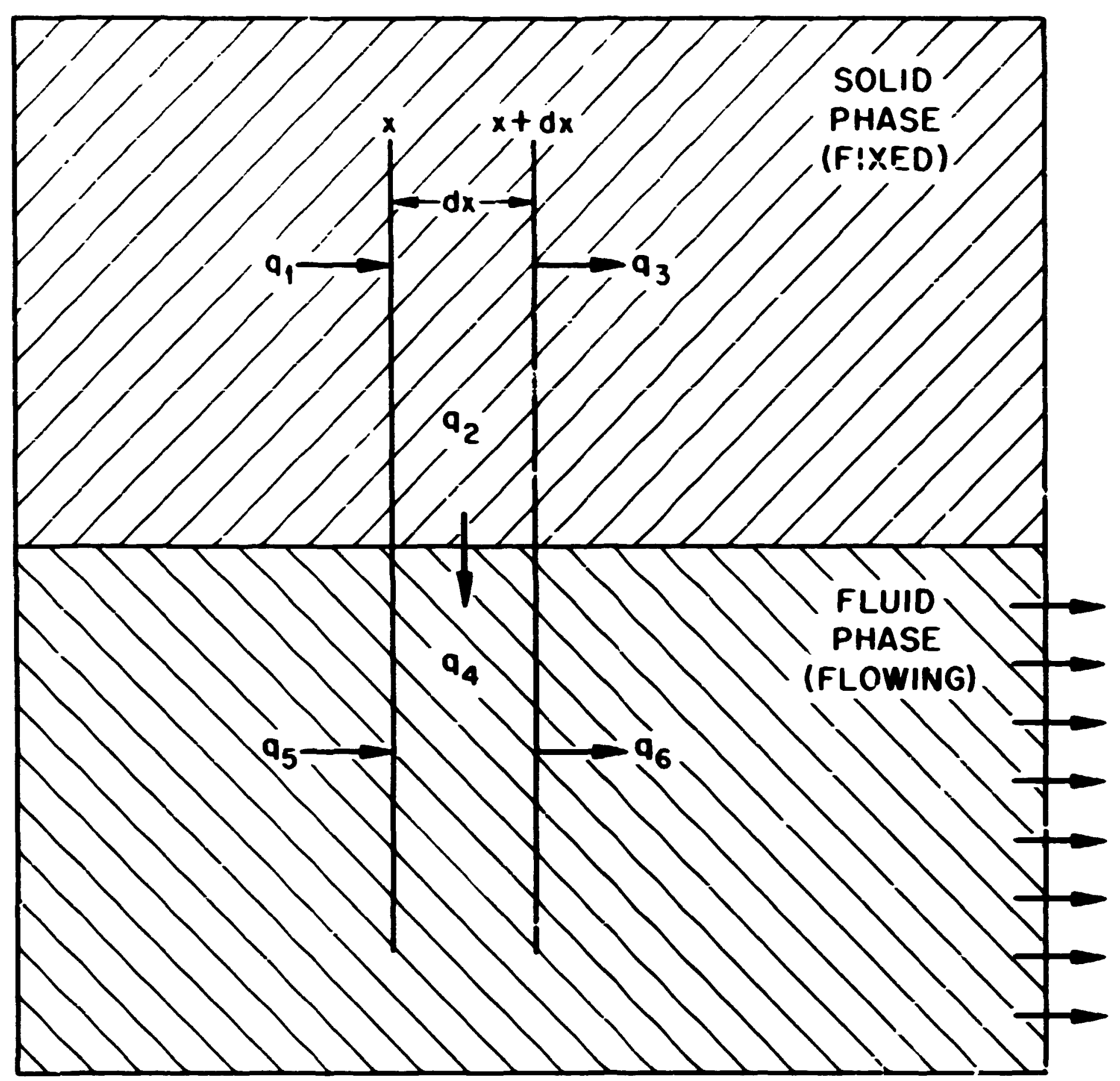

$a_{1}=$ HEAT IN TO SOLID BY SOLID CONDUCTION.

$a_{2}=$ HEAT GENERATED IN SOLID.

$a_{3}=$ HEAT OUT OF SOLID BY SOLID CONDUCTION.

$a_{4}=$ HEAT TRANSFERRED FROM SOLID TO FLUID BY CONVECTIVE HEAT TRANSFER.

$q_{5}=$ HEAT IN TD FLUID BY FLUID TRANSPORT.

$a_{6}=$ HEAT OUT OF FLUID BY FLUID TRANSPORT.

Figure 1

Heat Flow in a Lifferential Element of Porous Material 
Heat balances around the soliu and fluid differential elements yield the two related differential equations

$$
k y_{2}\left(d^{2} T / d x^{2}\right)+r Y_{3}=h e(T-t)
$$

and

$$
h \varepsilon(T-t)=\operatorname{Tep}_{2}(d t / d x)
$$

The full derivation is given in Appendix $A$.

The physical parameters are treated as being independent of tempersture, and are therefore handled as constants in the equations. The solution of this systen of differential equations gives for the solid and fluid phase temperature distributions

$$
T(x)=c_{1} e^{r_{1} x}+c_{2} e^{r_{2} x}+c_{3} e^{r_{3} x}+j x
$$

and

$$
t(x)=B_{1} e^{r_{1} x}+B_{2} e^{r_{2} x}+B_{3} e^{r_{3} x}+j x
$$

where the $r_{n}(n=1,2,3)$ are the roots of the operator equation in $m$

$$
a^{3}+b a^{2}-c a=0
$$

and where

$$
\begin{aligned}
& b=h_{c} / \mathrm{FCp}_{2} \\
& \mathrm{c}=\mathrm{he} / \mathrm{k \gamma _{2 }} \\
& \mathrm{j}=\Gamma_{\mathrm{Y}_{3}} /{\mathrm{PCp \varepsilon _{2 }}}_{2} .
\end{aligned}
$$

The Bs are related to the Cs by 


$$
B_{n}=c_{n}\left(\frac{b}{r_{n}+b}\right) \quad(n=1,2,3)
$$

Equations (3) and (4) are the form of solution that is sharacteristic of generating porous systems. The solid phase temperature and the fluid phase temperature are found to depend on a complementary function involving three undetermined coefficients end on a perticular integral involving the ohmi: heat generation. The three und $\epsilon$ ierwined coefficients arise since third order differential equations are produced in solving the system of two differential equations (1) and (2). The corstants of integration $\left(c_{1} ; c_{2}\right.$, and $\left.c_{3}\right)$ can be found from three boundary conditions involving $T, t$, or their derivatives with respect to $x$. If the various physical parameters involved in formulating (1) and (2) are known, the porous system would now be fully described.

For a porous plate whose $x$ dimension is $l$ ft., the simplest boundary conditions, and ones which provide a cravenient means for the stidy of porous heat transfer, are $t_{\mid x=0}=t_{0}$ (specifying the inlet fluid temerature which sets the temperature regime of the system), $d r /\left.d x\right|_{x=0}=0$ and $d T /\left.d x\right|_{x=i}=0$ (adiabatic walls on the porous solid).

Due to the nature of the experimental apparatus used in this study it was not possible to use these simple forms of the heat transfer equations to analyze the experimental system.

\section{Basic Heat Transport in the Experimental Porous System}

While the infinite flat plate system with the simple boundary conditions just described provites the nost ideal model for describir. porous heat transfer, systems used for experimental studies are of 
necessity less ideal. For this reason it was necessary to consider the experimental system bring used and to modify and extend the heat transport equations accordingly.

The porous solid used in this experimental study was tingsten. The porous tungsten was manufactured by sintering tungsten powder at a texperature where physical bonding of the particles occurred without eliminating the porous nature of the conpacted powder. The powder used to form tne porous turigsten was 20 aicron pouder. The porosity of the sintered tungsten was approxinately one half. The characteristic diameter both of the solid structure and the void space was taken to be that of the poider dianeter.

The thernal conductivity of solic tingsten is approximately $10^{2}$ B.t.u./hr.- ${ }^{\circ}$ F-ft. It will be shown the convective heat transfer coeficient at the particle surface in this study is much less than 1.0 B.t.u./hr.-OP-sq.ft. ana since 20 microns is approximately $6 \times 10^{-5} \mathrm{f}^{4}$. the Biot nuber $(\mathrm{hr} / \mathrm{k})$ for these particles is approximately $3 \times 10^{-7}$. This shows that even with a solid to fluid teperature difference on the order of $10^{3} \mathrm{~F}$, as found in this study, intraparticle temerature variation is of the urder of $10^{-4} \circ \mathrm{P}$ and the central and surface particle temperatures are effectively the same. No significant change in temperature dependent physical paraneters would take place in this small a temperature difference and this temperature difference is also negligible compared to a gradient of a few degrees of teuperatire per particle which the temperature gradient across the porous material may impose.

The size of the Biot number indicates that this rorous solid is very well suited for consideration as i homogeneous porous solid. 
Consi leration of the porous tungsten in a homogeneous sense is further enhanced by the fact that the characteristic dimensions of the sinterci tungsten (a hollow cylinder) ranged from an axial length of 1.5 in. down to a wail thickness of 0.07 in. Thus, the porous material has dimensions at least two orders of magnitude larger than the characteristie disfotes of either the particles or the voids of the porous material.

The fluid fiowing through the connected pores of the porous tungsten was either nitrogen or belium gas. The Reynolds number in the pores was approximately $10^{-1}$ and the Peclet number was therefcre of approximately this same order or magnitude.

The systen is operating at solid phase temperatures around ij00 0F. Radiative heat transfer considerations involving the fluid phase may be reglected due to the transparency of nitrogen and heliun to radiation. Radiative heat trancier at the boundarits of the porous tungsten cylinder are considere: but interparticle radiative heat transfer ray be neglected since the fine porous structure effectively makss the cylinder a wall consisting of approximately $10^{2}$ radiation shields. Purther justification for neglecting this effect will be presented later.

In orler to define the experimental porous systom it is necessary that the parameters used in equations (1) and (2) be known and that three boundary conditions te measured. This would al jow evaluation of :he Cs, and therefore the Bs, so that the system would be completely defined. Horsver, the volumetric heat transfer coefficient is an inknown parameter in this study. The method of findine this parameter will be to mezsure four boundary conditions rather than three and then 
so]ve a system of four equations in four unknowns. The four unknowns will be the three coefficients and the volumetric heat transfer coefficient.

Special Considerations for the Experimental Porous System

\section{Coordinate Trarsformations}

The experimental porous system used in this study was a thin-walled, hollow porous tungsten cylinder. Study of this system ras facilitated by treating the hollow cylinder as a flat piate. Since the rario of the radii of the cylinder was :-pproximately 1.5 , the error introduced : $y$ the use of the arithetic mar area rather than the logarithic nean area was less than 2 percent. Additional justification for this simplifying assumption will be found in the discussion of resilts.

The transformation frod cylindrical to rectangular cosrdinates was performed as shown in Figure 2. The cylinder radius correspunded to the $x$ dimension of the porous system in wich tcmpcrature was related to $x$ position according to equation (3). The radial vall thichness was taken to be equal to the rectangular wall thickness. The cylinder axis corresponded to the rectangular $z$ dimension. The axial cylinder length was taken to be equal to the rectangular 2 length.

The cylinder angular dimension corresponded to the $y$ dimension of a rectangular system and due to symetry no temperature variation in the $y$ dimension was considered. The $y$ dimension of the rectangular model is therefore limited by adiabatic walls. Further, the magnitude of the $y$ dimension was taken to be the quotient of the volume of the hoilow cylinder divided by the product of cylinder wall thickncss and axial cylinder length. The volume of the porous tungsten, the axial 


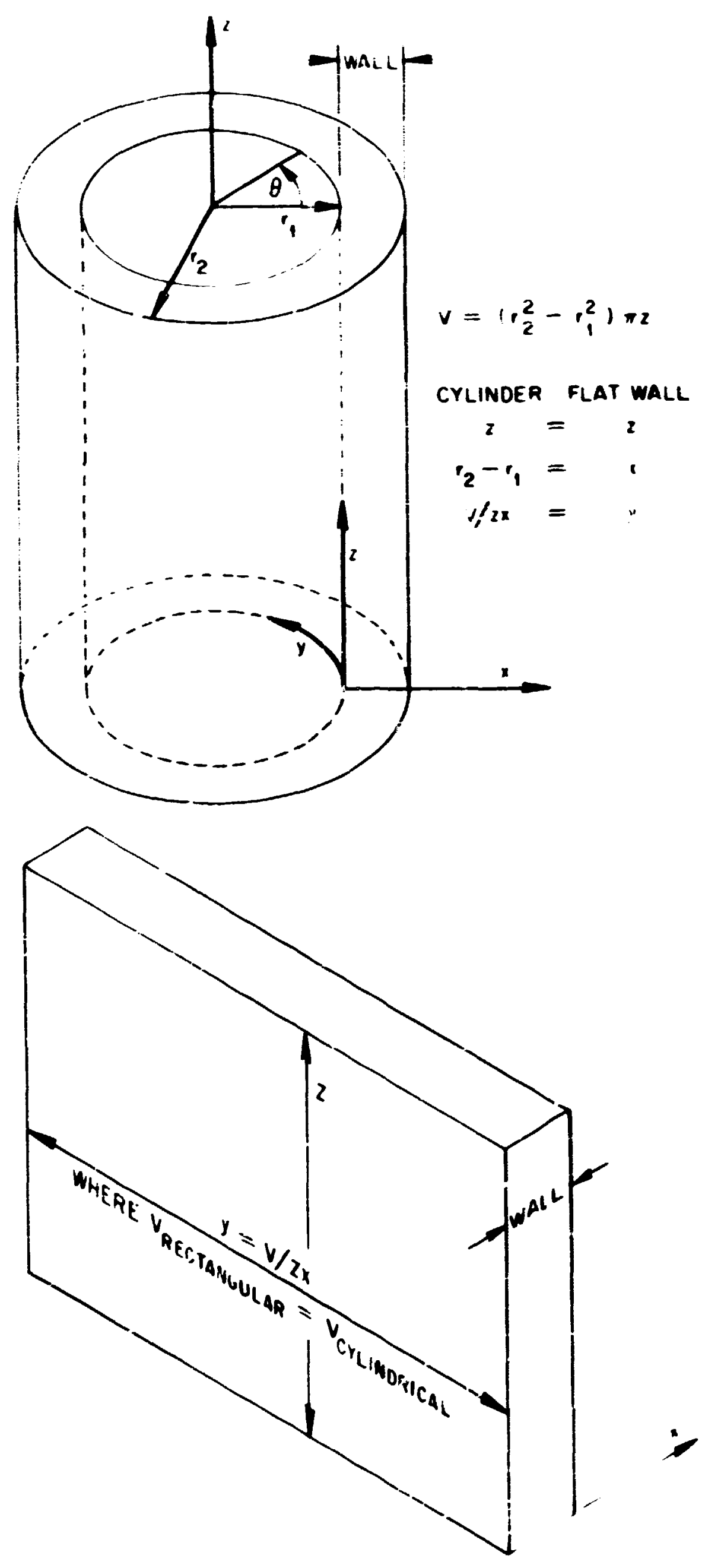

Firure 2

Equivalent Flat wall Model of the Cylinder 
length, and the wall thickness thus remain unchanged across the cocrdinate transformation. 


\section{Gylinder Axis Temerature Gradient}

Decause of the experimental difficultics in preventing a temprature gradi:nt aione the cylinder axis, it was necessary to formulate differential equations that took the axial or $z$ dimension solid phise? temperature gradient into account.

The fluid phase $z$ dimension temperature gradient is not considercd since fluid phase heat corduction has alreddy bren negiected and since ne $z$ direction fluid flow is considered. The extensian of equitions (1) and (2) to the two dimensional cases for the solid phase gives

$$
k Y_{2} \nabla^{2} T+r_{Y_{3}}=h \in(T-t)=F C p \delta_{2} d t / d x
$$

A solution of equation (7) is obtained by assuming the $x$ and 2 components of $\mathrm{T}$ are separable, i.e.,

$$
T(x, z)=x(x) z(z)
$$

and further that

$$
\frac{d^{2} z}{d z^{2}}=-\lambda^{2} z
$$

or

$$
\mathrm{Z}^{\prime \prime}=-\lambda^{?} \mathrm{Z}
$$

Equations (9) and (10) are satisfied for the case where the function $Z$ is a Fourier series. The solution of equation (7) gives

$$
T=\sum_{i=1}^{\infty} x_{i}(x) z_{i}(z)+j x
$$

wher.

$$
x_{i}(x)=c_{11} e^{r_{i 1} x}+c_{i 2} e^{r_{i 2} x}+c_{13} e^{r_{13} x}
$$

and the $Z_{i}(z)$ are the terms of the fourier series. 
Experimentaly the observation of the outer surface of the tungsten cylinder will be linited to a fixed rumber of points. These points correspond to the holes in the Marinite disks thrcugh which the tungsten surface is viewed with in optical pyrometer. Since there are five holes in the Marinite ii.jks the $z$ axis temperature distribution will be represented by a truncated series using the first five terms of the Fourier series. This should be very adequate approximation of the axis temperature function in view of the fact that the norm for the $z$ axis temperature gradient is zero and a few terms of the series are typically used to characterize perturbations. Equation (11) there a becomes

$$
T=\sum_{i=1}^{5} x_{i}(x) z_{i}(z)+j x
$$




\section{Temperature Dependence of Electrical Resistivity}

With one exception, all physical parameters in the porous system were taken to be temperature independent and a parameter value corresponding to the mean temperature of the material was used. The one excepticr was the elecirical resistivity of tungsten. A linear temperature dependence was used to describe this parameter. The volumetric heat generation term $\Gamma_{Y_{3}}$ was replaced by $G(T)$ where

$$
G(T)=G_{0}+\alpha T \text {. }
$$

The differential equations describing the porous system are now

$$
k v_{2} \nabla^{2} T+G(T)=h e(T-t)=F C p \delta_{2} d t / d x
$$

The solution becomes, using the first 5 terms of the series,

$$
T=\sum_{i=1}^{5} x_{i}(x) z_{i}(z)-\cos \alpha
$$

The use of the first five terms appears to give a satisfactory description of the axial temperature profile as will be discussed later.

The volumetric heat eneration terms now occur not only in the constant term in equation (17), but also in the operator equation, (5), which now takes the form of

$$
m^{3}+b m^{2}-\left(c-\left(\alpha / k y_{2}\right)+\lambda^{2}\right) m-b\left(\lambda^{2}-\left(\alpha / k y_{2}\right)\right)=0
$$


A similar sclution exists for $t$. The complete derivations are giver in Appendix A.

The reason for the use of a temperature dependent physical parameter is to facilitit.e the computations involved. The necessary calculaticiss could be performed without allowing the temperature dependence. However, introduction of this dependence loes not increase the order of the equations involved and thereby makes better use of data available to describe the tungsten. The mean solid temperature is used to evaluate appropriate zric and first order terms for electrical resistivity as used in equatior: ( 1 ':).

The computations that involve the electrical resistivity (and thermal conductivity) are perfozmed in order to evaluate the electrical (and by implication the thermal) conductance of the porous tungsten at the operating temperature of the tungsten cylinder. The need for this evaluation will now be considered. 


\section{Length Over Area Conduction Correction Factor}

A porous material is considered to have intensive properties that have been reduced in proportion to the extent, and the natiie, of the porosity. The thermal and electrical conductivity are two such properties of particular interest in this study.

If the pores in a porous material were a series of un:form straight, parallel holes rurning through the solid in the direction of energy flow (Figure 3a.) then the conductance, whirh involves the length, area, and conductivity, could be evaluated simply by applying a volumet -ic $^{-}$ porosity correction factor to the area in the form

$$
K_{\text {eff }}=k_{\text {bulk }} \frac{A\left(1-S_{3}\right)}{L}
$$

where

$K_{\text {eff }}=$ effective conductance

$k_{\text {bulk }}=$ bulk conductivity per unit (aree over length)

$\mathrm{L} \quad=$ bulk length for sonductance

A $\quad=$ bulk area for conductance

$s_{3}=$ volume purosiiy, cu. ft. void/cu. ft. bulk

However the real nature of most porous solids, including the ones in this study, is more nearly as shown in Figure 3b. In particular, in the case of sintered materials formed from powders, the channels are in fact formed from the interstices between the powder grains. This implies that the effective length of the conduction path and the effective area of the conduction path can no longer be described by the simple relation shown in equation (19). A new equation is needed to describe the Stilation, thas 


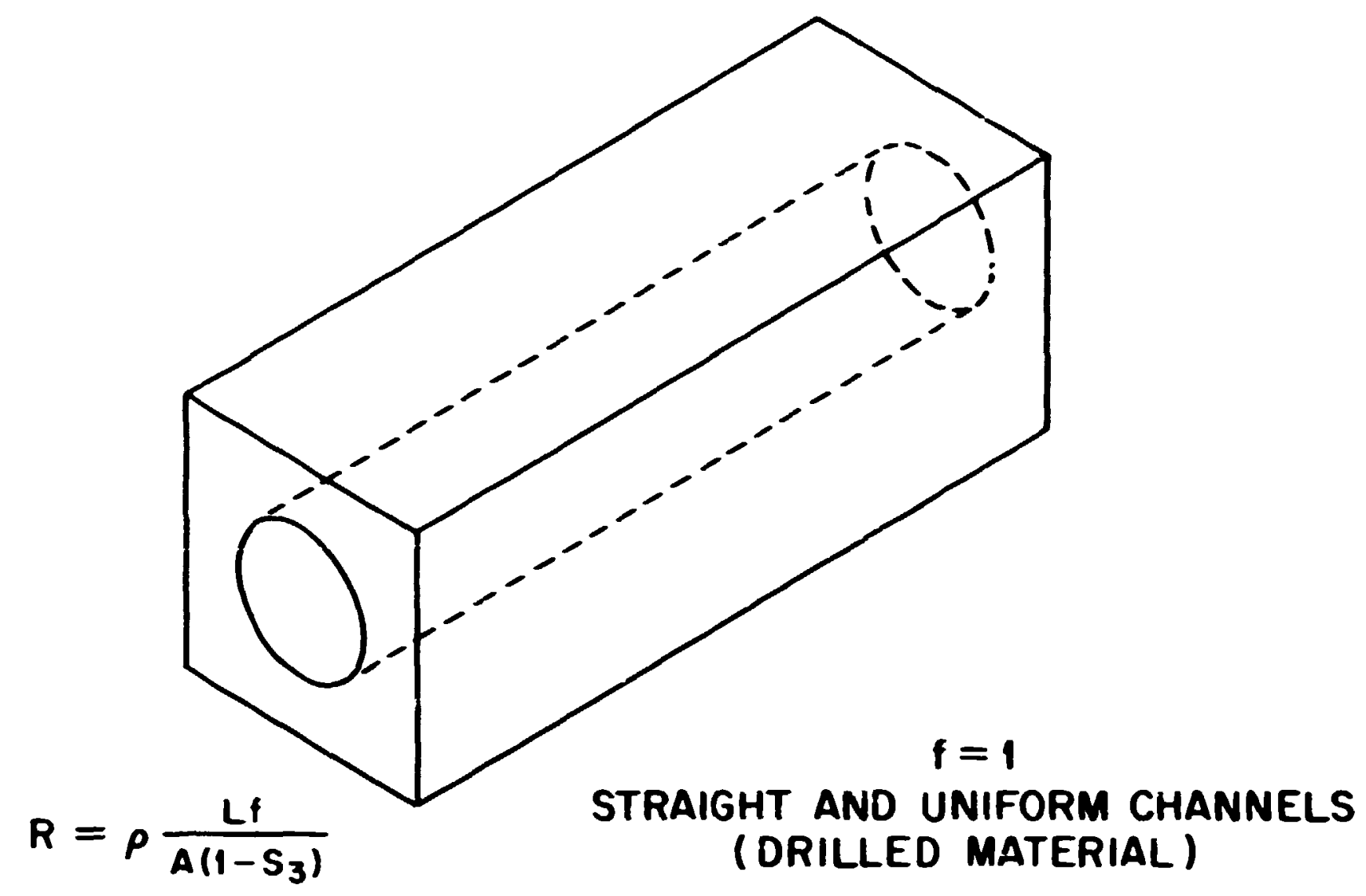

(a)

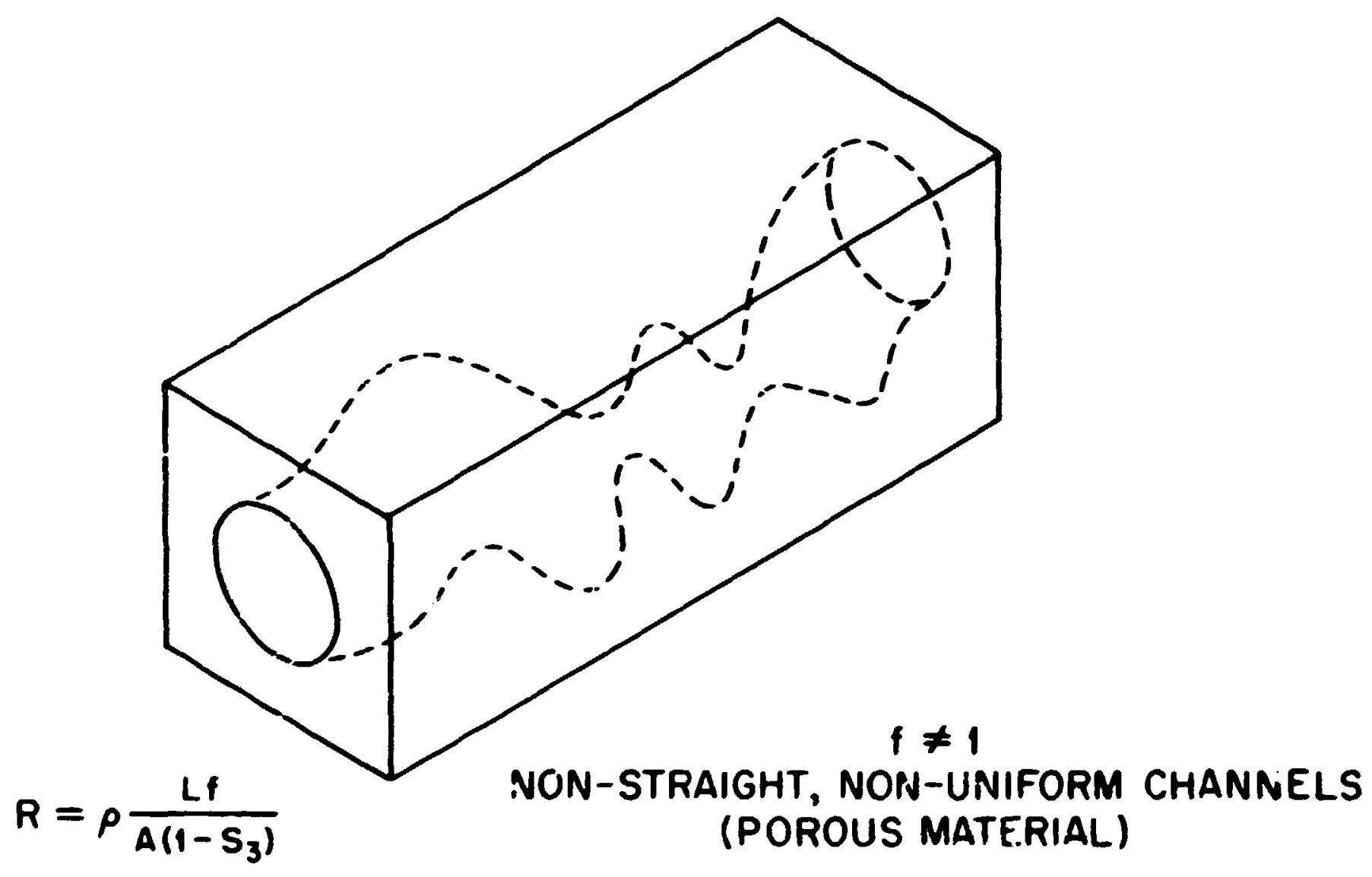

(b)

Figure 3

Drilled Crannels and Porous Material 


$$
K_{\text {eff }}=k_{\text {bulk }} \frac{A\left(I-S_{3}\right) f_{A}}{L f_{I}}
$$

where

$\mathbf{f}_{\mathrm{L}}=\mathbf{a}$ correction factor to obtain the effective length for conduction. $\mathbf{f}_{\mathbf{A}}=\mathbf{a}$ correction factor to obtain the effective area for conduction (excluding the volume porosily factor).

A schematic representation of these factors is shown in Figure 4. This figure shows a hypothetical, idealized, porous solid composed of siaggered rods and having a volumetric porosity of one haif. The orientation of the rods that comprise the material are not parallel to the direction of conduction. The actual length over which energy travels in moving a distance $L$ in the direction of conduction is 1.33L. This length factor will reduce tre conduction by a faetor of 0.75 , i.e. $\mathrm{f}_{\mathrm{L}}=1.33$

The cross sectional area of these rods will be assumed to vary. The are: for conduction will "neck down" at points of contact between particles. The simplest example of this effect may be seen by assuming that 1 of every 5 rods has a complete break at some point along its length. Since this removes this rod as a conductor the available area for conduction is reduced by 0.8, i.e. $f_{A}=0.8$.

Since the effective conduction is propertional te the area and inversely proportional to the length, these two factors combined will reduce the conduction by a factor of 0.6 . In combination with the volume porosity factor of 0.5 the overall effective conductivity now becomes 0.3 that of the conductivity of solid material and the porous material may now be consjdered as a homogeneous material, characterized by extensive properties such as bulk area and bulk length but possessed 
VOLUME POROSITY $\left(S_{3} i=0.5\right.$

( HALF OF THE VOLUME IS "RODS"

HALF OF THE VOLUME IS "VOID")

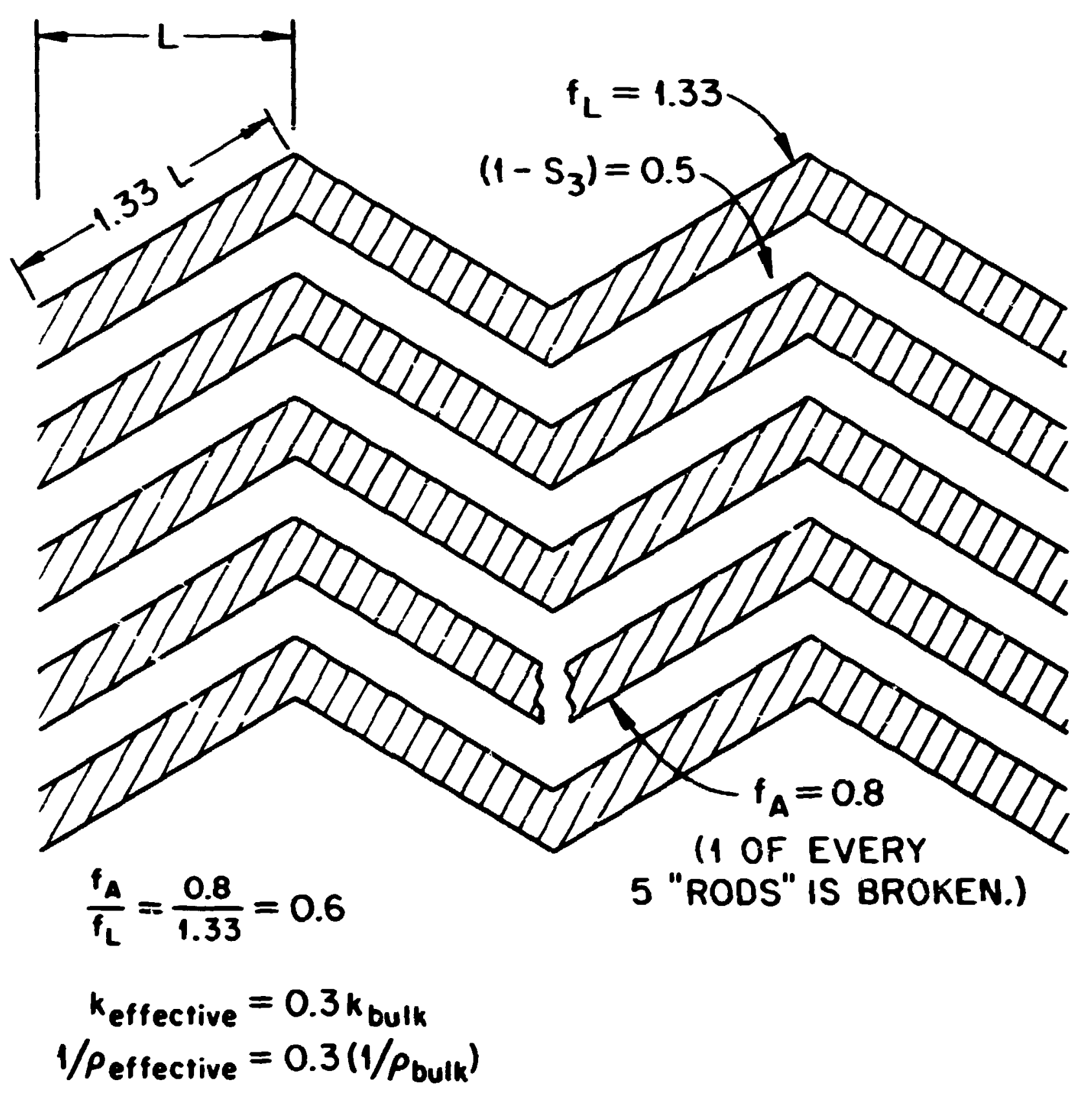

Figure 4

Factors Reducing Corductivity in Porous Materials 
of a reduced conduct: vity. The effect of this factior on the eiaiuation of the heat transfer coefficient will be considered laier.

The volume porosity is readily obtained from measurements of weig'nt and yolume of the porous material. While the length and area ractor: are separable in the example of Figure 4 they may not be as easiiy separated in real materials. Determination of the combined lengthover-area confuction correction factor could be found from experimental steady state measurements of the conductivity of the porous material. In principle the length correction factor could be found from experimental unsteady state (iransient) measurements of the conductivity of the porous material. However, since ihis strdy deals only with steady state problems, the two factors may be considered together as the lengthover-area correction factor, $f_{L / A^{\prime}}$ which equals $f_{L^{\prime}} / f_{A}$

Information on the effective thermal and electrical conductivity of the porous tungsten used in this study was not available from the manufacturez. Apparatus for independent thermsl and electrical conductivity measurements at the operating temperature of $1500^{\circ} \mathrm{F}$ was not available. According?y, the length-over-area conduction correction factor for electrical conduction was determined during each run at the actual operatinf temperature from experimert.al data taken during the run.

This type of sorrection factor is applicable to both the electrical and the therial conduction problem. It is assumed that the length-overarea correction factor for thermal conduction is equal to that for electrical conduction. This appears to be a valid assumption in view of the direct analogy between the thermal and electrical conduction mechanisms. 
The similarity of the mechanisms for thermal and electrical conductivity is not found in similar temperature ccefficients for thermal and electrical conductivity. The temperature coefficient of thermal conductivity (k) for tungsten is in fact regative while the temperature coefficient of electrical resistance ( $p$ ) for tungsten is positive. This behavior is in fact necessary in order that the Lorenz number $\left(\mathrm{KP}_{\mathrm{p}} / \mathrm{T}^{\circ} \mathrm{K}\right)$ remain essent: lly constant which is known to be the case for metals. (24) The Loreriz number for tungsten varies by only one percent ovcr a range of $800^{\circ} \mathrm{K}$ thet includes the temperatures found in this study.

The thermal and electrical conductivity are thus related as shown in the Lorenz equation and the agents that are responsible for this relation are the free electrons of the metal. (1)

There have been experimental measurements that tend to verify the assumption that a similar correction factor may be used for thermal and electrical conduction in porous metals. (16) The chapter in Scnneidei (28) on Experimental Analogic Method gives extensive treatment to electrical analogy in heat conduction protlems noting that this analug has a direct mathematical similarity to heat conduction and is the best known and most widely used analog for these types of problems.

\section{Fifth Boundary Cond:tion}

It was pointed out that the volumetric heat transfer coefficient, he, was to be found along with the three unknown coefficients that resulted from solution of the differential equation. Measurement of four boundary conditions allowed evaluation of he The combined lengthover-area conduction correction factor is a paraneter that occurs in the electrical and thermal conduction terms in the original differential 
equation. decribing the porous syet.m. It is treated as a vilue that is unknown an:? is to be found frum :he? measurement of a figth tounriary sondition. This lifth boundary condition is the average temsursure cof the solid phase of the porous tungsten cylinder in the rcgion between the two voltage probes $\left(\overline{\mathrm{T}}_{\mathrm{AB}}\right)$. Measuremert of five boundary conditior.s will now permit, the evaluation of the three unknown coefficients, ne, and the length-over-area conduction correction factor.

The length-over-area conduction correction factor becrmes anoihs $r$ parameter the value of which is initially assumed and which is then used in iterative calcuiation until the calculated value matc: is the assumed value. 


\section{EXPERIMENTAL WORK}

Exneriminta? Apnaratus - resora? Mescription

The experimcnt:il apparatus consisted of equipment that could ceneriate heat within porcus tungsten and that could also remove the heat with gis flowing through the pores of the tungsten. The heat was generated within the poious tungsten by direct curr ent that was supplied by a rectifier. The direcic current circuit from the rectifier used copper tus bars of 1 sq. in. cross section to carry the current io the porous tungsten. The heat $g$ ?nerating porous tungsten was cooled by passing nitrogen or helium gas through the pores of the tungsten.

The experimental runs were carried out by establishing a heat generation rate and a coolant fiow rate. When the apparatus reached a state of iymamic equilibrium, weasurements were made of parameters that defired five boundary conditions. The heat transfer coefficient 1 ithin the porous tungsten and the conduction corrcction factor ior the porous tungsteii were calculat $2 d$ from these boundary conditions.

The study was carried out with hollow porous tungsten cylinders fabricated by sintering 20 micron tungsten powder. Thess tungsten cylinders vere obtained from the Kulite Tungsten Co.: Ridgefield, New Jersey. The cylinders were approximately 1.5 in. Iong. They were hollow, having an O.D. of approximately $0.4 i 5$ in. and an I.D, of approximately 0.275 in. The cylinders had a weight of approximately 18 grams and a volume porosit: of approximately 45 percent. 
Ficctric Powr Circuit

The elictric power used to heat the tungsten cylinder was obtaincd from a selenium rectifier manufactured by the Rapid biectric Campany, Serial N.mber 68025. The power was direct current flowing in a circuit that passed axially through the tungsten cylinder. All heating effects were due to ohmic (resistance) heating. The electric power circuit is shown in Figure 5.

Iisput to the rectifier was 230 volt, 60 cycle, $;$ phase, alternating current (A.C.). Output from the rectifier ranged from D to 12 volts, and from 0 to 6000 amperes, direct current (D.C.). Control of the output voltage on the rectifier, as manufactured, was obtained by means of three, 7-position tap switches. Fach of these tap switches controlled the output from the high voltuge transformer for one phase of the input alternating current. 'ithe direct current output voltage was proportional to the outnut of the high voltage transformers.

A modification was made to the rectifier circuit in order to obtain continuous, as opposed to stepwise, control of the output voltage. Three 230 volt Variacs were inserted in the rectifier input circuit between the 230 volt laboratory power supply and the three high voliage transformers. The three Variacs were connected along a comon axis and were operated in tandem. Continuous output vollage rezulation was obtrined by using the combination of Variacs and tap sifitenes.

The electric power supply was monitored by means of several instruments. The rectifier $d$ been delivered uith a D.C. voltmeter and a D.C. ammeter to monitor the output current. Three A.C. andeters were connccted to inr: three output lines from the thres Variacs in order to 


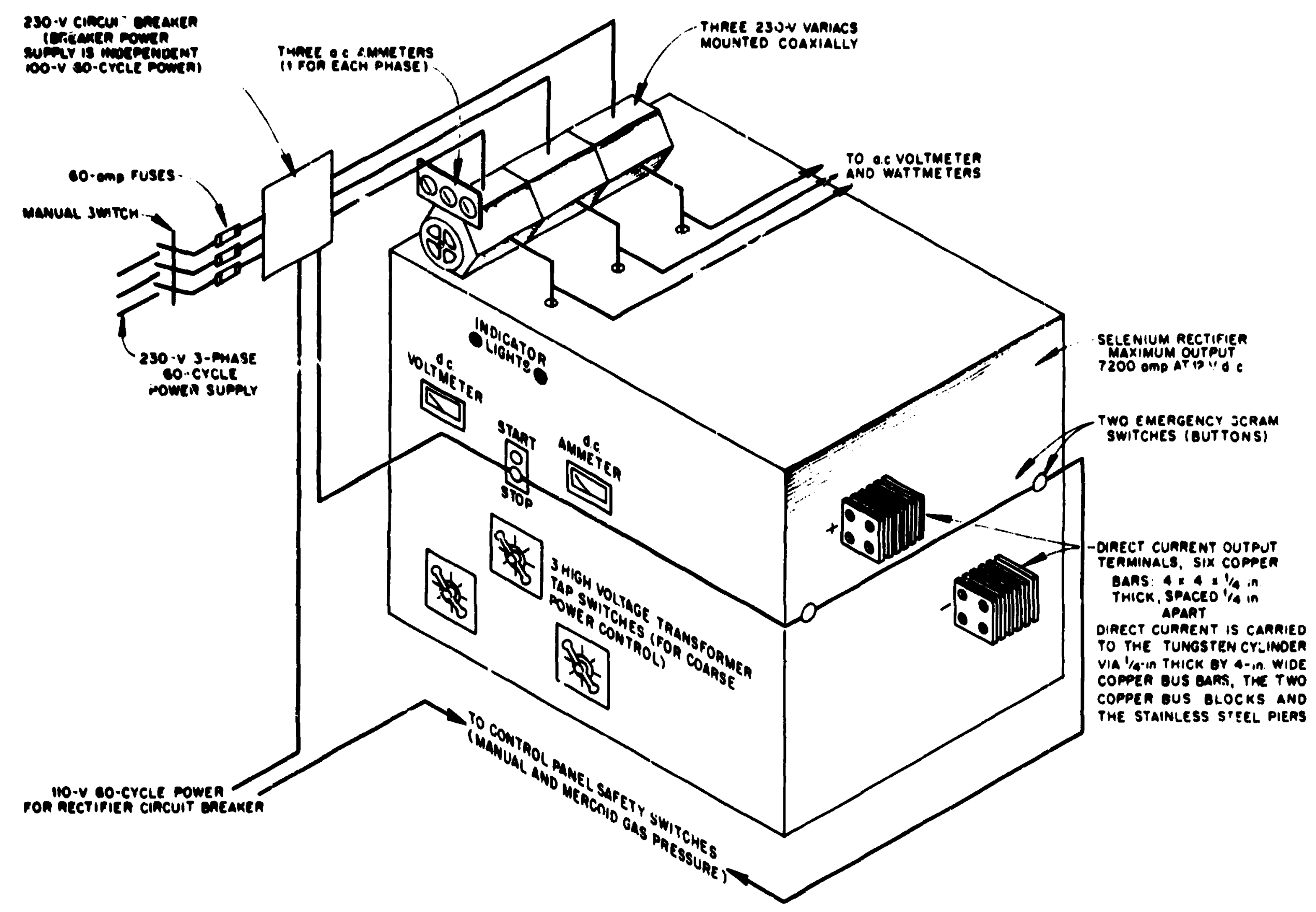

F1f dre 5

Rectifier Power Circuit 
monitor the current in these circuits. An A.C. voltmeter was set up to selectiveiy monitor the voltage across each pair of A.C. input 'ines. Two A.C. wattmeters were connected across the three lines supplying power from the Variacs to the high voltage transformer of the rectifier. The wattmeters were equipped with phese reversal swiiches and were used to monitor the power inpui to the rectifier. Frobes were connected to the direct current circuit at several locations in order to take measurements of voltage at these points in the circuit. The probes attached across the D.C. ammeter shunt sere used to measure the D.C. current with high accuracy by means of a high precision potertiometer.

\section{Mechanical Assembly}

The direct, current was carried from the rectifier terminals to the tungsten cylinder through bus bars consisting of several solid copper bars bo?ted together. The bus bars were $1 / 4$ in. thick, 4 in. wide and from $8-1 / 2$ in. to 12 in. long. See Figure 6.

A copper bus block was bolted to the terminus of each bus bar. These two bus blocks served as the platforms for the mounting of the tungsten cylinder. These bus biocks were solid copper, 1 in. thick, 4 in. wide, and 5 in. long. See Figure 7. Fach bus block had a 1/3 in. diameter hole drilled through it at the center sf the block. A high pressure fitting was silver soldered into one face of each bus block in a position over the $1 / 8$ in. dianeter hole in the bus block. The faces of the blocks containing this fitting faced away from the tungsten cylinder and were known as the outside faces of the bus blocks. These high pressure fittings had an I.D. of $1 / 8$ in. A hollow stainless steel 


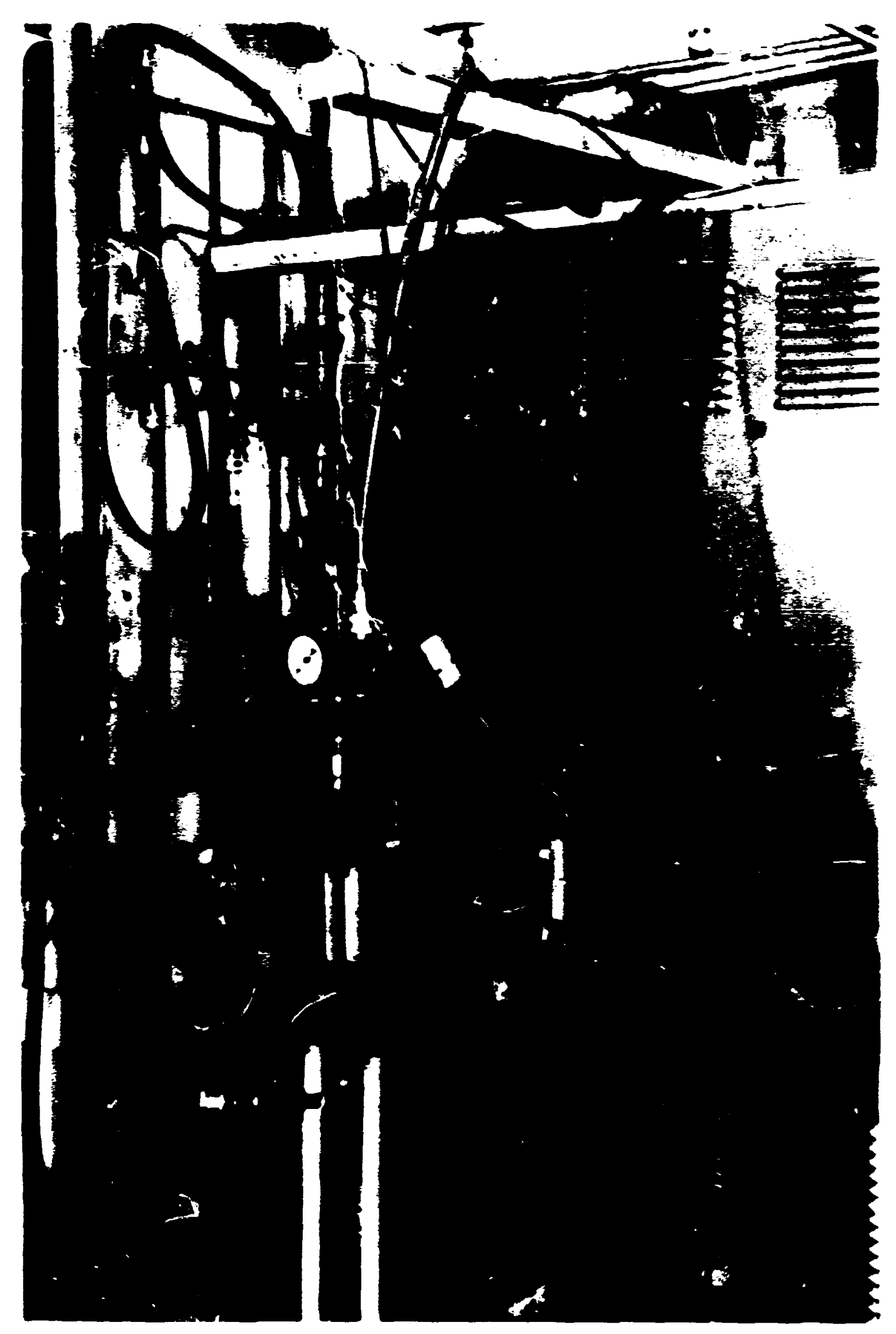

Figure 6

Thotograpn of the Experimental Equipment 


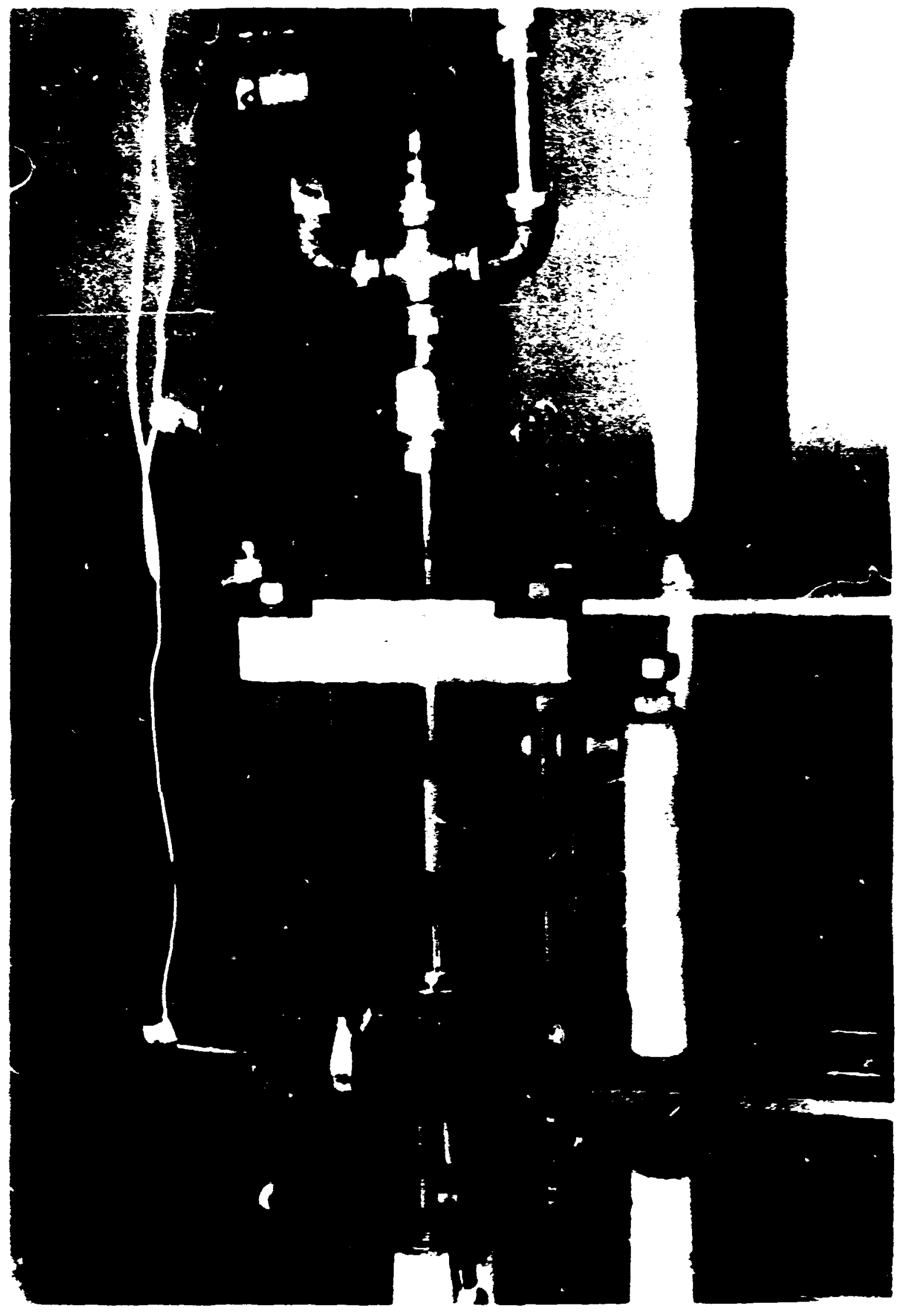

Figure 7

Photograph of the Mounted Tungsten Cylinder Without Marinite Insulation and Instrumentation 
pier was bolted to the other fice of each bus block. The faces of the blosks crito which the piers were bolted face toward the tungsten cylinder and are known as the inside faces of the bus blocks. The I.D. of the piers was $1 / \mathcal{E}$ in.

There was a groove in the end of each pier that held a graphite washer. The hollow jorous tungsten rylinder rested on the graphite washers. Access to the interior of the tungsten cylinder was through the $1 / 8$ in. diameter hole running through the high pressure fitting, the bus black, and the pier. See Figure 7.

The direct eurrent used to heat the tungsten cylincier flowed from the rectifier through tic circuit consisting of the copper bus bars, the copper bus block, the staizlors steel pier, the graphite washer, the tungsten cylinder, and then back to the rectifier through the other iasner, pier; blcck and bus bars.

The mechanizal connection between the: two bus blocks was provided by four $3 / 8$ by 16 stainless steel studs, each 10 in. long. These studs passed through four mat,ching $1 / 2$ in. diamete: holes in the four corners of each bus blocix. These studs were electriczlly isclated from the bus blocts by means of Mucarta sleeves and washers. A Mucarta sleeve 1-3/32 in. long, $1 / 2$ in. O.D. and $z / 8$ in. I.D. was placed in each of the four holes in both bus blocks. Each sleeve protiuted from either side of the bus block by from $1 / 16$ to $1 / 32$ in. Mycarta washers, $1 / 16$ in. thick, $1-1 / 8$ in. $0 . D$. and $1 / 2$ in. I.D. were placed on the bus block, around the portion of the Mcarta sleeve that protride.2 from the surface of the bus block. The insulating Mcarta washers were held in place by steel washers 5/64 in. thick, 7/8 in. 0.D. and 25/64 ir. I.D. Stecl nuts 
surmcist,ing the steel washers were used to form a rigid connection between the four stainless steel studs and the upper bus block.

The stainless stee'. studs were not connected rigidly to the lower bus block. Through a system of compression springs provision was made for small relative movements of the two bus blocks parallel to the comon axis of the stainless steel studs. The compession springs were formed from steel wire 0.080 in. in dianeter with an axial length of $2-3 / 15$ in. and with an I.D. of $1 / 2$ in. Steel washers vere nodified by the addition of collars $1 / 2$ in. $0 . D$. and $7 / 16$ in. I.D. These collars were brażel to the steel washers. The compression spring was positioned on the stud with the collar of a collared washer inserted into each end of the sfring. Tris assembly formed toe interface between the lower Hearta washer and the steel nut. See Pigure 8 . The springs provide the pressure lised to hnla the tungsten cylinde $\mathrm{in}$ place. Since the wounting was spring loajed, it allowed for therwal expansion of the tungsten cylinder and other parts under essentially constant Icad.

Since thare was no rigid connection between the studs and the lower bus block a lightly loaded spring system was used to keep the Hycarta washers in place on top of the lower bus block. These Hycarta hold-down springs were formed from $3 / 64$ in. stock, and were 5/16 in. Inng with an I.D. of $19 / 32$ in. Additional collared washers were prepared by brazing a collar onto regular steel wazhers. The collar wes $19 / 32$ in. 0.D., 25/64 in. I.J) and $1 / 8$ in. long. The collars with the hold-down springs were positioncd on the studs above the lower bus block as shom in Figui'e 8. 


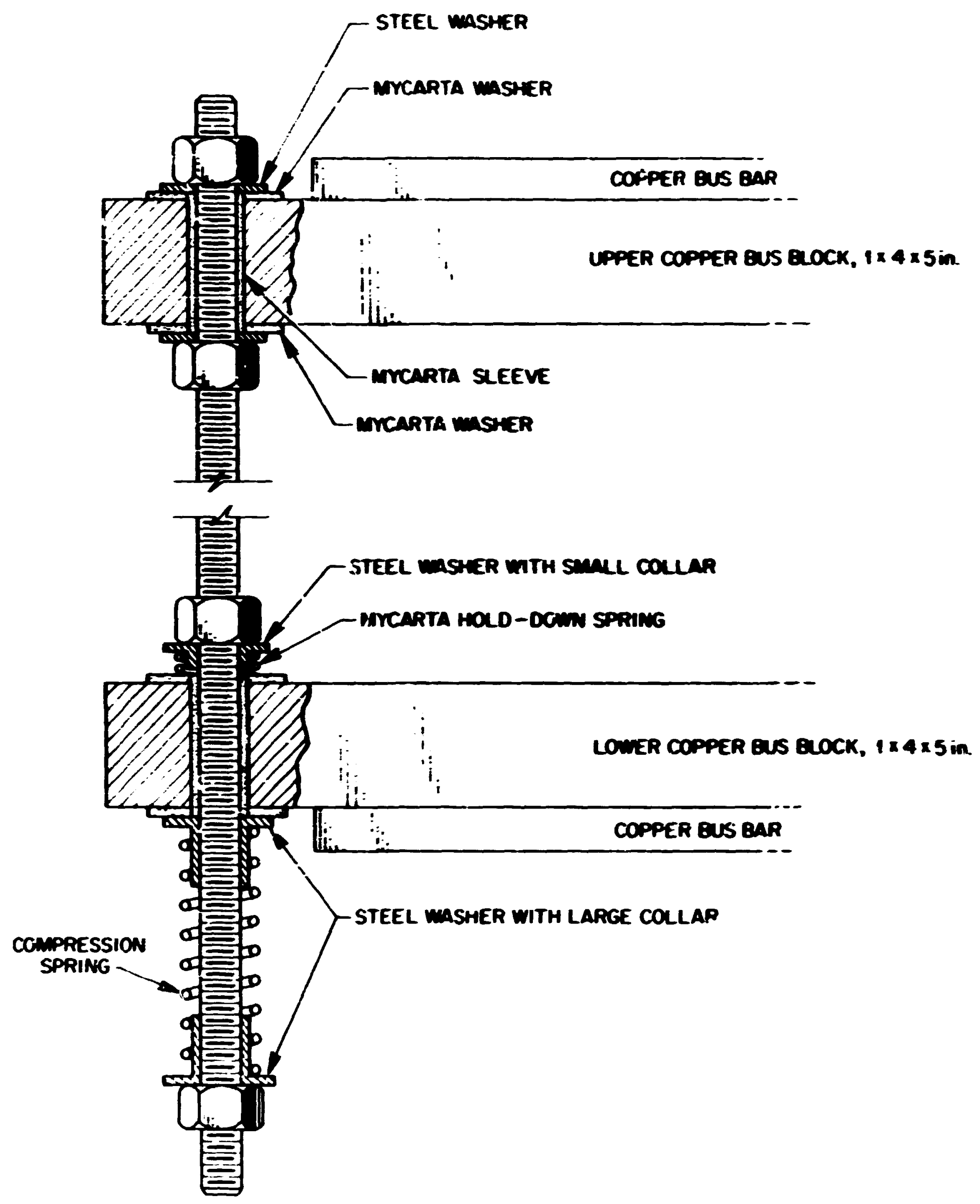

Figure 8

Insulated Studs Connecting the Bus Blocks 
Figure 9 shows the stainless steel piers that vere used to lold the tunesten cylinder during operation. A neoprene 0 -ring $11 / 32$ in. 0.0. , 13/64 in. I.D. and .070 in. thick was seated in a spotface at the base of the pier to provide the gas seal between the pier and the bus block. The spotface was created using an $11 / 32$ in. drill to a vall depth of .012 in. The lorest step on the fier was $i-3 / 4$ in. in dianeter, $1 / 16$ in. thick, and ccutained three boles tha: were used to bolt the stainless steel piers to the bus block by means of three $5 / 32 \times 32$ bolts each $5 / 16$ in. lang. The three holes in this step of the pier vere $11 / 6$ in. in dianeter on a $1-1 / 2$ in. bolt circle. The rext step of the pier was 1 in. in dianeter and $5 / 16$ in. thick. This step served as the base for the Marinite insulating disks. The eajor portion of the pier was $1 / 2$ in. in dianeter and $1-1 / 2$ in. 10ng. A $1 / 8$ in. dianeter bole was drilled through the length of each pier. The top of the pier contained a trench thai was used as a seat for the graphite rasher. The trench was approximately 0.264 in. I.D., 0.438 in. 0. . and $1 / 16$ in. deep. The outer wall of the trench was $1 / 32$ in. lower than the inner wall. Four theisocoiple wells $1 / 16$ in. in diameter were drilled along the cylinder axis.

The graphite washers were prepared from liuber 2 Graphitar by drilling a $17 / 6$ in. $(\cong 0.265$ ir. $)$ hole in a quantity of stock which was then turned to 0.425 in. 0.D. Washers were cut off from this stcck with a thickness of apprcxiniately $1 / 16$ in. and they were subsequently ground to thiskness of from $0.035 \mathrm{in}$. to $0.060 \mathrm{in}$. as needed. Figure 9 shows these washers in position in the trench at the end of the stainless stecl pier. 


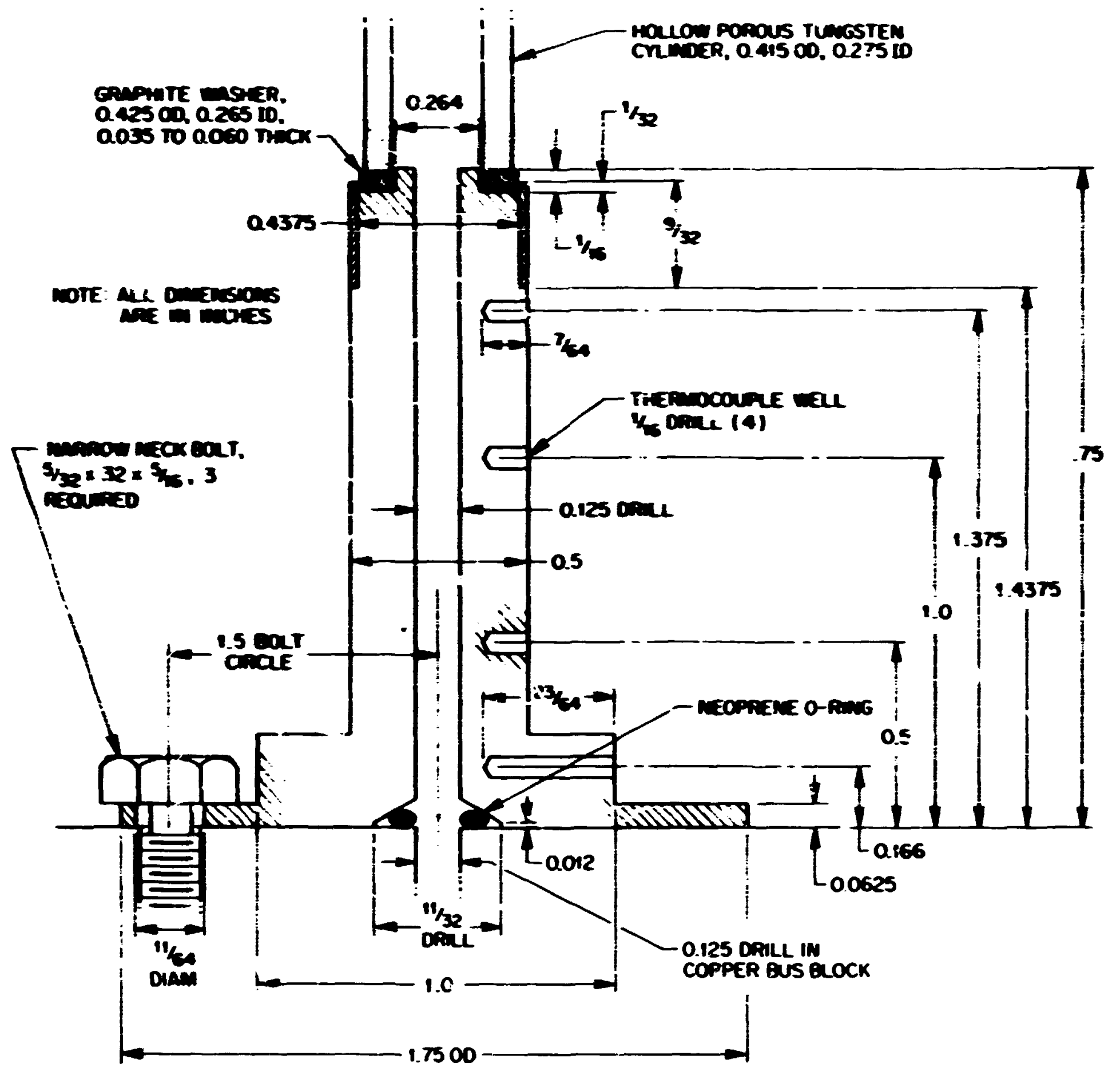

Ficure 9

Stainless stecl Pier and Graphite Washer 
The weight of the bus i? ochs is supported by twe 1 in. O.D. woodes jowels which rest on the floor and support the lower bus block. The weight of the upper bu: bars is supported by a short 1 in. O.D. wooder. dowel located between the upper and lower bus bars approximately onethird of the distance from the rectifier terminals to the bus oloriss.

Figure 7 shows the tungsten cylinder mounted between the stainless stee 1 piers but, withuit the insulating Marinite disks or various instruments in position. In addition to the two dowels that support the bus blocks, two other dowels may be seen in Figure 7. A wcoden dowel below the lover bus bar and the short wooden dowel between the upper and lower bus bars are cnly used to raise the upper bus bar and bus block during the positioning of the tungsten cylinder. These two dowels are remavec during operation of the experimental apparatus. This may be seen by comparing Figure 7 with Figure 6 or with Figure 10.

Figure 10 shows the assembly of the tuiststen cylinder with the insulating Marinite disks in posjtion. The Marinite disks are $1-3 / 4$ in. O.D. and $1 / 2$ in. I.D. There are ten aisks which are numbered 1 through 10 counting from the bottom up. Disks 1 through 3 and 8 thre'gh 10 are each $1 / 2$ in. thick. These disks enclose the lower and upper stainless, steel piers. Disks 4 thro. gh 7 are each $3 / 8$ in. thick. These disks enclose the tungsten cylinder.

The Marinite disks function in severai capacities. They provide thermal insulation around the tungsten cylinder. Mhey keep a blanker of the coolant gas arowin the tungsten cylinder during operation thereby kceping atmospheric oxygen away fron the hot tungsten suriace. They provide the mounting to hold the stainless steel hypodernic needlos that 


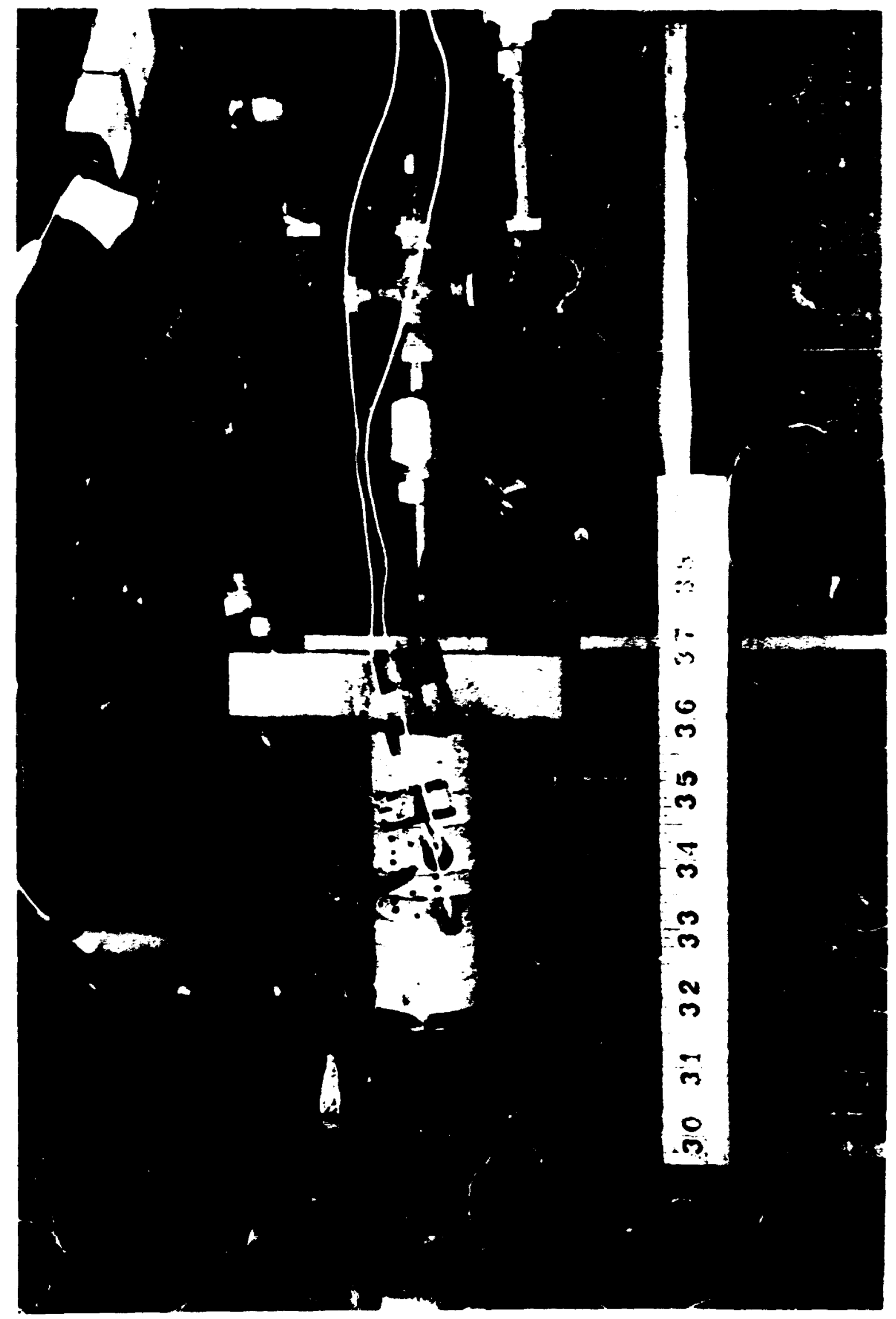

Figure 10

Photograph of the Nounted Tungsten Cylinder with Marinite Insulation and Instrumentation 
s:rire to measur: the voltafe drop across ine length of the tingsten :ylinder. They provide the mounting to hold the stainless stecl sheathed thermciouple number 16 in position against the exterior of the tungsten cylinder.

Ther: are a number of small holes in the disks which serve a variety of purposes. There are $1 / 16$ in. diameter holes in disiks 1,2 , 3, and 3 which a:low therrucouples $2,3,4$, and 5 to fass through the Marinite disks and be inserted in the 1/16 in. dianeter thermocouple wells in the stainless ste€l piers. There are two 0.028 in. diameter holes in Marinite disks 4 and $i$ foi the stainless steel hypodermic needles and a $1 / 15$ in. diameter hole in disk 6 for the stainless steel sheathed thermocouple number 16. Dis'ss $4,5,6$, and 7 nave a serses of 1/16 in. diameter holes drilled through them in the plane of the disn. These holes are drilled at angles such that tiey prevent direct radiative heat loss from the tungsten cylinder to the surrounding room. The holts allow the effluent coolant gas to leave the region around the tungsten cylinder. Se€ Figure 11.

There are five $1 / 16$ in. diameter holes in disks $4,5,6$, and 7 (two in disk 7) drilled radially in the plane of the disk. These holes afford the means of observing the surface of the tungsten cylinder with an opticai pjrumeter. See Figre i2. There are holes in disk number 5 where thermoccuples 6 ara $\vec{i}$ are positioned at two different radii within the Marinite disk. 


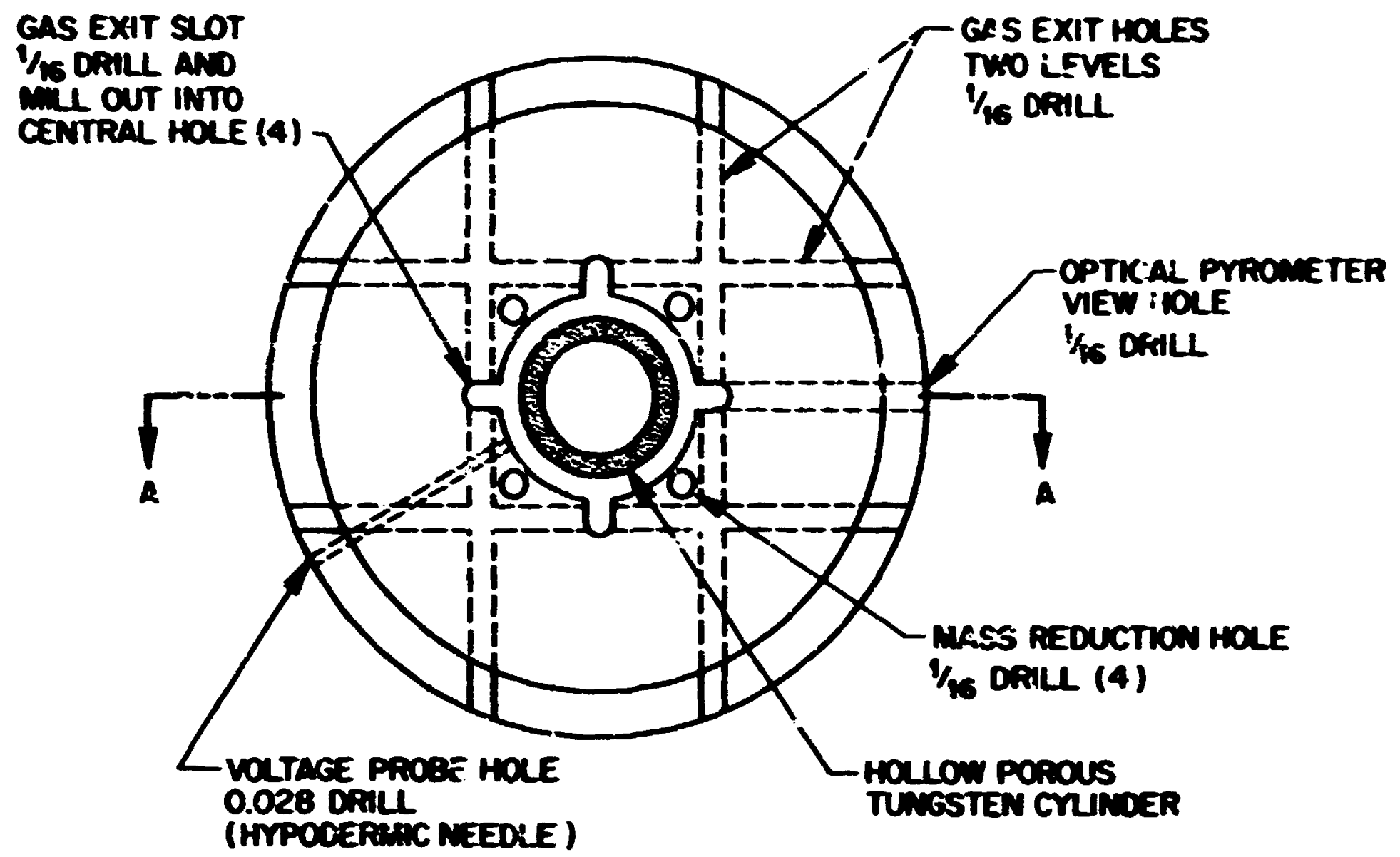

TOP VEW

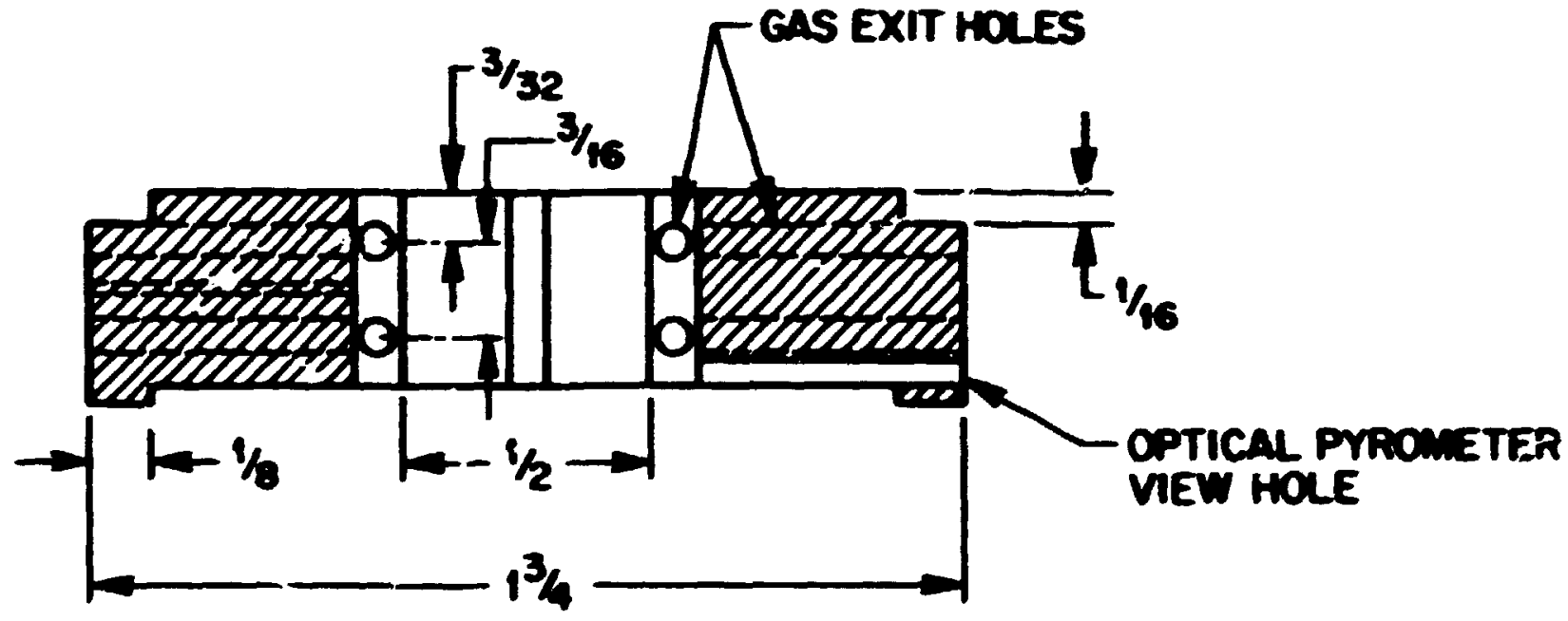

SECTION A-A

Pigure 11

Marinite Insu].ating Disks 


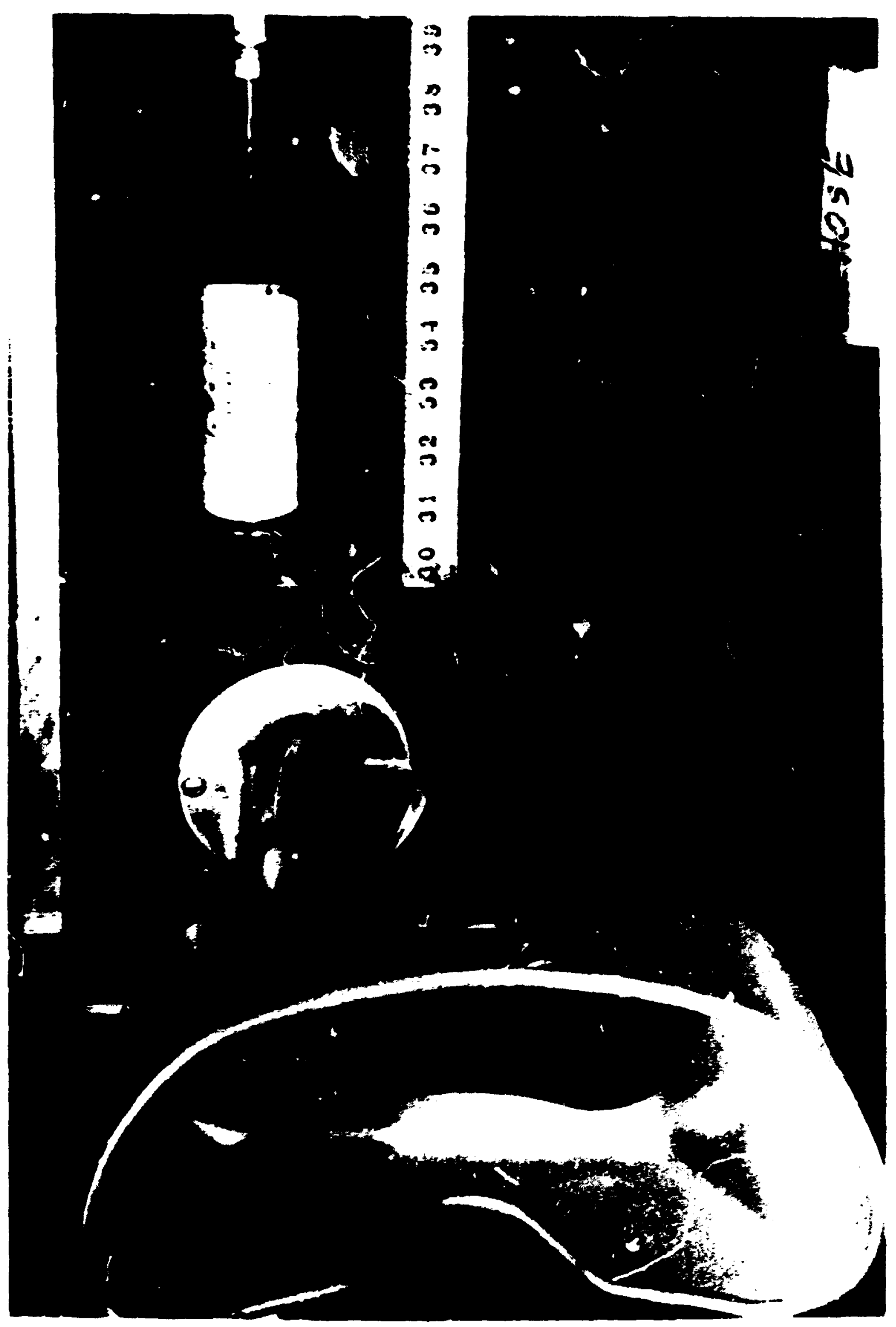

Figure 12

Phougraph of the Assembled and Instrumented Tungsten Cylinder Showing the Optical Pyrometer in Position for Viewing 


\section{Gas Systen}

The gas used to cool the tungsten cyinder was either high purity nitrogen or belium. The pressure of the gas was regulated and provision was made "or measuring the prscsure, flow, and iemperatiure of the gas. A pressure sensing switch was insluded in the system to shut off the electric power to the apparatus in the event of a loss of pressure in the gas system. The layout of the gas system is shom scheraticilly in Pigure 13.

Gas was supplied from comercial $2000 \mathrm{1b} / \mathrm{sq}$. in. compressej gas cylinders. From the cylinder the gas passed through a pressure regulator : here the gas pressure was reauced to approximscely $15 \mathrm{lb}$./sq.in. gauge. After passing thrcugh two ccnt=ol valves, the gas passed through two rotameters in series and from there into the interior of the hollow tungsten cylinder via the high-pressure fitting on the lower bus block.

The connections between the various components of the gas system were made by high-pressure air hose coupled by means of quick-disconnect fit.tings. Gas pressures were measured by means of Bourdon type pressure galiges on the gas cylinder pressure regulator, a pressure gauge on the output of the first rotameter, and a pressure gauge connected to the hoilow tungsten cylinder at the high-pressure fitting on the upper bus blnck. For precision pressure measurement up to approximately $80 \mathrm{~cm}$. of mercury above atmospheric pressure, a mercury manometer was conriezted throuch a valve to the output from the second rotameter. A Mercoid pressure controlled switch was connected to the high-pressure fittind on the upper bus block. The function of this Mercoid switch was to turn off the rectifier power in the event gas pressure was lost within 


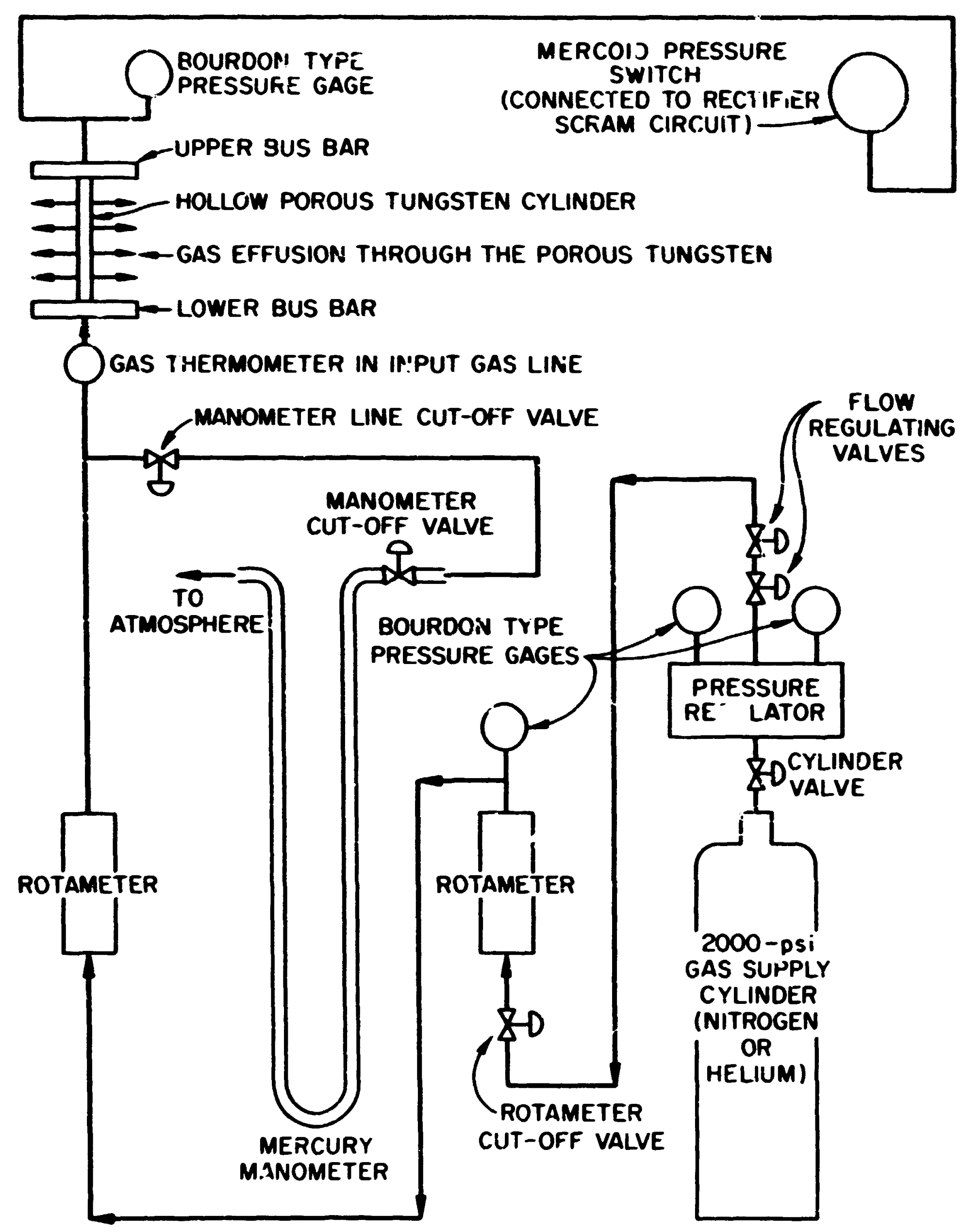

Figure 13

Gas Systcm-Schematic Diagram 
the holiow porous tungsten cylinder durine an experirental run. Several components of the gas system can be seen in Figure 14. The gas lines and other parts of the gas system can be seen in Figrire 6.

Gas temperature was measured by means of a gas thermometer in the gas inlet line at a foint just before the gas entered the ?ower bus block. Sze Figure 6. Calibration of the two rotsmeters used to measuure the gas flow was done by means of a wet test meter.

The integrity of the gas system was verified periodically by replacing the hollow porous tungsten cylinder yrth a hollow cylinder of solid brass and by replacing the graphitar washers with neopre!s: 0-rings. Gas was introduced into the now closed system at a pressure in excess of that used in actual operation. The system was then isolated from the gas supply and observed for pressure loss over a period of several minutes. The absence of pressure loss during this period vorified the integrity of the gas system for the purposes of this study.

\section{Instrumentation}

A number of instruments were used to measure parameters of the experimental system. Temperatures were measured by means of thermocouples, thermometers and an optical pyrometer. Twc potentiometers were used to measure the thermocouple voltages and the voltage drop across portions of the direct current heating circuit. Measurements of the gas flow were made by means of rotameters, pressure gauges, and a mercury manometer. Other instruments were used dur ng asse ably of the experimental apparatus in preparation for mus and to monitor the operation of the rectifier. 


\section{Mut mancters: ind The racioun!cs}

Temperatures were asured at several icratson: vithin the foperimental apparatus. The temperature of the coolant fluid was m-isured Jy an immersion thermometer in the gas inlet line just br: low the lower bus block. See Figures 6 and 1j. Chrome-alumel thermocouples vith in ici-water reference junrtion . sre used to measure temperalures at 11 points within the spparatus. Temperatures vere measured at the points designated in Figure 15 as 1 through 8,14 , and 16.

Two potentiometers vere used to measure the voltage produced in the thermocouples. A portable, laboratory type potentioneter with self contained batteries, standard cell, and galvanoweter was used for rough measuremonts, and for measurements when the temperature of the system was changing rapidly. When the system was close to dynamic equilibrium a Leeảs and Northrup K-3 precision potentiometer was usea in conjunction with a Leeds and Northrup ballistic galvanometer for more precise meisurements. An external standard cell was used for the calitration of the $\mathrm{K}-3$ potentiomet:r and an external 2-volt storage battery was used to provide the bridge power supply. A double pole, double throw switch enabled either poientiometer to be connected to the output of a 20 position thermocouple selector switch.

\section{Ortical Pyrometer and Cathetometer}

Measurement.s of the surface temperature of the tungsten cylinaer were taken with a Leels and Northrup potentiometer type optical pyromcter, model number $8621-c$. This optical pyrometer was attached to the telescope mount of a cathetometer by means of an especially desiened mount. The optical pyrometer mounted on the cathetometer is shrim in 


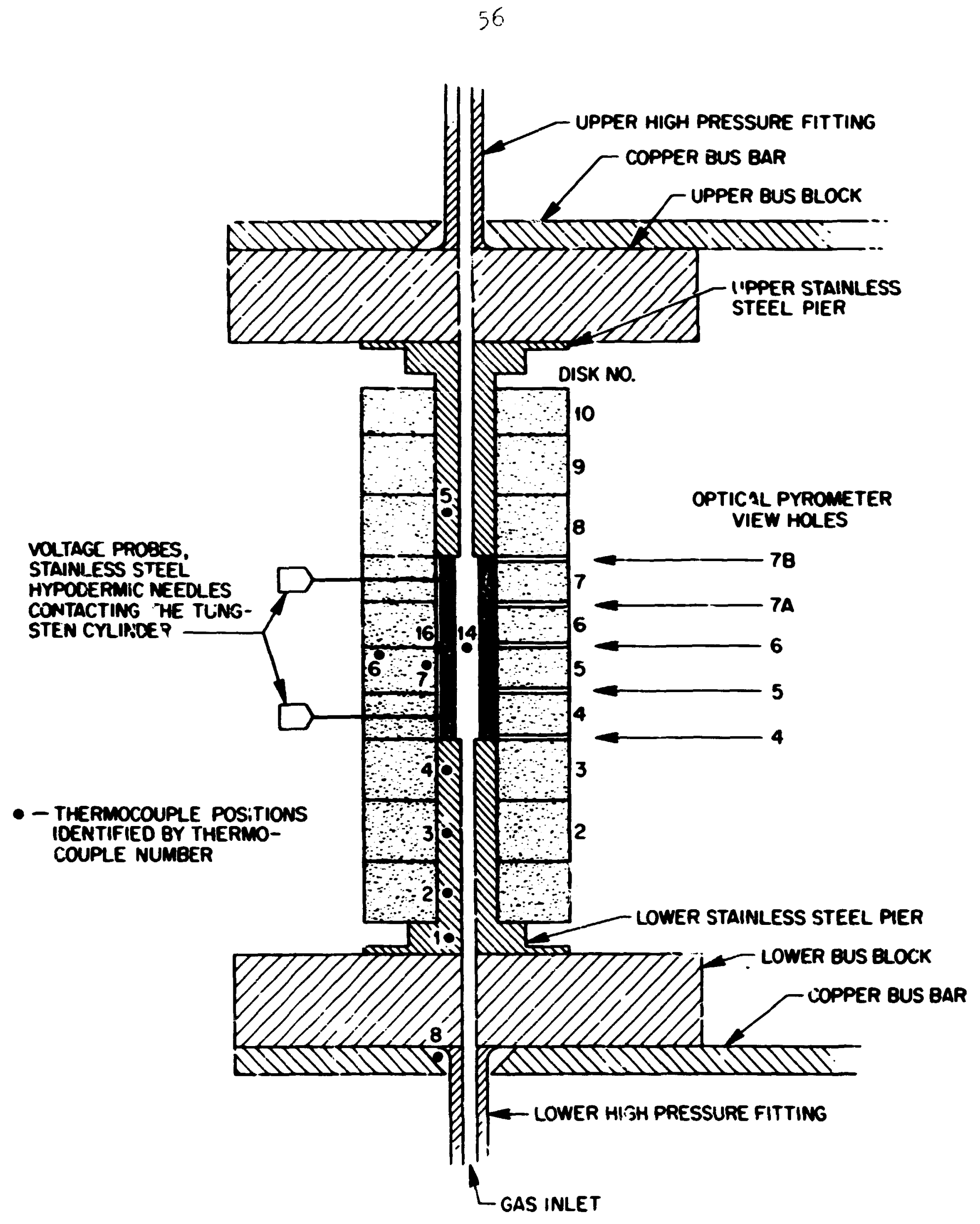

THERMOCOUPLES 1-8 ARE BARE CHROME-ALUMEL

THERMOCOUPLES 14 AND 16 ARE STAINLFSS STEEL SHEATHEU CHROME-ALUMEL

THERMOCOUPLE 14 ENTERS IHROUGH THE UPPER HIGH PRESSURE FITTING

\section{Figure 15}

Schematic of the Mounted and Instiumented Tingsten Cylinder 
Figure 6. The lens of the optical pyrcueter was 11 in. from the sureface of the porous tungsten cylinder. The surface of ine iunfsten cylinder was observed throuch five radial holes in the Minite disks that enclosed the tungster sylinder. See Figures 11 and 12 . Thesc holes were $1 / 25$ in. in diameter and $5 / 3$ in. long. The relatire vertical position of the optical pyrometer at, each of the five observation holes was measured in hundredths of $\mathrm{cm}$. from the cathetometer scale. These temperature and position measurements, in conjunction with the reliztive vertical position of the lower end of the tungsten cylinder, descrived the tungsten cylinder surface temperature distribution along the cylinder axis.

\section{Voltage and Amperage Probes}

The ohmic power generation in the tungsten cylinder was determined by measuriig the direct current flowing through the tungsten cylinder and the voltage drop over a known fraccion of the cylinder length. The two potentioneters used for thermocouple roltage measurements were also used to measure the current flow and voltage drop in the tungsten cylinder. Amperage was determined by measuring the voltage drop across the smmeter shunt provided within the rectifier. The shunt factor of the ammeter was 120. amperes/millivolt.

The voltage drop along the tungsten cylinder was measured using twu hypodermic needles as probes. The needles were stainless steel, size B-D 22, which had an 0.D. of 0.028 in. The original $2 i$ length of the needje: was cut down to $7 / 8$ in. which also served to blunt the necdles. Thesc probes passed through two radiai holes in the Marinite disks that had been drilled with a number 70 dril.1 (0.028 in. 0.D.). 
These holes were in disks 4 and 7 . Sce Figures 10, 11, and 15. The necdles touched the tuncsten cylinder at two points approximately 1.1 in. apart. This generally represented approximately $3 / 4$ of the total cylinder length. The precise separation of the two visible contact points on the tungsten cylinder was measured following a run.

The ohmic power teneration in the region of the cylinder between the probes was calcilated directly from the current and prole voltage drop. Through the use of other dats the ohmic power generation in the entire tungsten cylinder was calculated. A linear extrapolation of the power generation between the probes to that of the entire cylinder was a good first estimate of the total power generation.

\section{Other Instrumentation}

A Leeds and Northrup Kelvin Bridge, model 4340, that measured resistances on the order of 100 microhms was used to measure the resistance between the two bus blocks measured through tise tungsten cylinder and graphite washers. The Kelvin Bridge is shown in Figure 14. These measurements were made during the mounting of a tungsten cylinder in preparation for a run and provided a useful moans of determining empirically when the :ungsten cylinder and graphite washers were in uniform and stable contact with the piers. Figure $?$ shows tine tungsten cylinder mounted on Eraphite washers between the stainless steel piers. The two leads from the Kelvin Bridge are connected to terminals on the upper and lower bus blocks. Fo: a run the leads from the Kelvin bridge are disconnected from the bus block terminals: as may be seen in Figure 10. Power for the Kelvin Bridge was supplied by a 12-volt storage battery. 
The Kelvin Bridese was not used durine runs when the rectifier was in operation.

The portable, laboratory type potentiometer was used in conjunction with the Kelvin Bridge to measure resistance in the circuit formed by the bus blocks, piers, washers, and the tungsten cylinder. Use of the Kelvin Bridge was necessary because the resistance of the circuit made up of the tungsten and graphite was too small to be measured by an ordinary vacuum tube volt-ohm-milliameter by a factor of from 100 to 1000 .

\section{Experimental Procedure}

The experimental procedure is described below.

1. Prior to the start of a run the ends of the tungsten cylinder were ground ilat and perpendicular to the axis of the cylinder, as needed, in order to remove any rough spots that may have resulted from thermal stresses during the shutdown from the previous run. The dimensions of the cylinder were measured and the cylinder was weighted. The flat faces of the graphite washers were ground in order to achieve surothness as well a: to obtain the desired washer thickness.

2. The tungsten sylinder was assembled in the apparatus and an acceptable contact resistance was established using empirical measurements with the Kelvin bridge as a guide.

3. When the tungsten cylinder had been mounted in a configuration which afforded a good probability for a successful run, the final instrumentation was installed or the tungsten cylinder. This included putting into place Marinite insulators, thermocouples, voltage probes, internal and external sheathed thermocouples, and the Marinite disk hold-down springs. 
4. The gas flow was staried through the cylinde:. If no gas leak developed at the ends of the cylinder, electric heating of the cylinder was begun. The heating of the cylinder was allowed to proceed slowly until heat generation rate and gas flow rate were reached at which measirements of the system were to be made.

5. With the system at or near dynamic equilibrium, measurements were maje of those variables necessary to evaluate :.e heat transfer coefficient. In the event thet an adeouate approach to equilibrium could not be obtained, due to contact resistance problems, it was then necessary to shut of the electric power, cool the system with the coolant gas, and begin again at step 1 or step 2.

6. When sufficient measuremests had been made at one electric power level and gas flow rate the system could be shifted to another equilibrium condition by aitering either the electric power level, or the gas flow rate, or both. When the new equilibrium had been obtained, measurements couid be resumed at step 5 .

7. When the measurenents had been finished the system was shut down by turning off the electric power and letting the gas flow until the cylinder temperature had been reduced to near room temperature. 


\section{DISCUSSIOA OP RESULTS}

\section{Experimental Developments}

The major difficulty in devsloping the experimental apparatus which was used in the studi by farber (10) and in this work was obtaining and maintaining uniform mechanical and electrical contact between the porous tungsten cylinder and its mounting. Wechanical contact was needed to obtain a gas seal between the tungstr.n cylinder and the stainless steel piers. Electrical cantact was needed in order to maintain the heat generation within the tungsten cylinder.

Early attempts at mounting the tungs $\cdots$ cylinder between the copper bis blocks using stainless steel disks (approximately $1 / 4$ in. thick) demorstrated a number of problems. The tungsten cylinder iended to weld to the stainless ster 1 . The electrical metal to wetal contact resistance was very unpredictable. Cas leakage occurred at the metal to metal interfaces. A significant axial temperature grarient indicated that there was an appreciable hes- loss from the cylinder into the stainless disks and the copper bus blocks. The consideration of the axial heat rlux introduced a significant increase in the complexity of the analysis needed tc evaluate the heat transfer ccefficients. While it was not possible tu entirely eliminate the consideration of the axial heat flux it was desirable to reduce this effect as mach as possible.

All of the preceding problems were alleviated to the degree ne:essary to obtain successful operation of the experimental apparatus by the: troduction of graphite washers between the tungsten cylinder and the stainless steel mounts. The stainless steel mounts were modified from disks to piers and a washer seat was cut in the end of the pier 
which served to position the graphite vasher. The outer lip of the washer seat was lower thain $t_{1: 2}$ upper surfacc of the graphite washer when the wasice was in place in the pier. This prevented contact and therefore welding between the tungsten cyilinder and the pier alore the outside wall of the tungsten cylinder. Ho major weldine problems developed between the interior lip of the graphite washer groove and the inside wall of the tungsten cylinder even though this lip protrudid above the upper surface of the graphite vasher by approximately 0.015 in.

The relatively soft washer reduced the unpredictability in the contact resistance, and essentially eliminated gas loss at the ends of the cylinder. This was verified by replacing the hollow pcrous tunesten cylinder with a hollow solid brass cylinder of the same dimensions. The brass cylinaier was mounted between the piers using the graphite washers to provide the seal between the cylinder and the piers. Tre gas system was pressurized to a value abore that found within the tungsten cylinder during experimental runs. The gas system was closed and found to show no pressure loss for a test period of several minutes.

The washers also provided a high electrical resistance and therefcre ser: $i$ as a heat source at the ends of the tungsten cylinder. This served to flatten the axial temperature gradient by reducing heat loss from the tungsten into the piers. Even with the use of the graphite washers the remaining unpredictability of the contact resistance resulted in significant axial temperature gradients. During the experimental muns the axial heat flux into the -nds of the tungsten cylinder ranged from 7 to 108 percent of the heat generated within the cylinder by electric heating. 
Since the experimental apparatus was described by third order dirierential equations the determination or the heat transfer coefficient in the porous tunesten required the evaluation of a totai of five boundary conditions. These five boundary corditions allowed evaluation of the five unknow coefficients. These coefficjents were the three coefficients of integration of the differential equation. the heat transfer coefficient and the conduction correction factor for thermal and electrical conduction. 
Boundary Conditions and Method of Solution

\section{First Boundary Condition}

In measuring the first boundary condition radial symetry vas assusred for the tungsten cylinder which resulted in no consideration of $y$ dimensional parameter variation for the flat plate model of the hollow cylinder. The flat plate wadel was considered to be limited in the $y$ dimension by adiabatic walls.

The axial surface temperature variation was observed vith an optical pyrometer inrsugh five $1 / 16$ in. diameter holes in the enclosing Harinite disks. These temperature-position pairs were analyzed to obtain the coefficients of a truncated Pourier series (five terms) that providad a description of the $z$ dimensional temperature variation. The optical pyrometer holes in the Marinite disks were assumed not to perturb the assumption of radial symmetry. It was also assumed that the small radiation loss from these holes allowed them to be treated as viewing holes for a black body. While this as umption would be strictly true only in the case of a body which has unitary emissi-jity or from which there was no net heat transfer to the walls of its enclosure, it was believed that the radiative shielding of the Marinite disks, the roughness of the porous tungsten surface, and in particular the slight oxide or nitride coating on the tungsten surface would all combine to justify the assumption of unitary emissivity.

Tabies of correction factors for optical pyrometric temperature measurements show that in the temperature range of $800^{\circ} \mathrm{C}$ to $1000^{\circ} \mathrm{C}$ the error in the tempcrature measurcd is from $5^{\circ} \mathrm{C}$ to $8^{\circ} \mathrm{C}$ for a spectral emissivity of 0.9 and from $19^{\circ} \mathrm{C}$ to $27^{\circ} \mathrm{C}$ for a spectral emissivity of 0.7 . 
All radiation considered in this study was assumed to be gray body radiation.

The observations of the outside wall of the tungsten cylinder gave the solid phase temperature as a function of $z$ position and provided one boundary condition, $\left.T(z)\right|_{x=\ell^{\circ}}$ 


\section{Second Boundary Condition}

A network of holes were drilled in Marinite disks number 4 through 7 which surrounded the tungsten cylinder in order to provide an exit for the coolant gas which was emerging from the outer surface of the tungsten cylinder. Thus there was no axial gas flow along the outside wall of the tungsten cylinder ard convective heat loss from the cylinder was neglected. In order to evaluate the radiative heat loss from the tungsten to the Marinite, a second series of Fourier coefficients were developed which described the $z$ dimension variation of $\left(T^{\circ} R\right)^{1 / 4}$. These coefficients were needed in order to obtain a mean value of $\left(T^{\circ} R\right)^{4}$ that was needed to evaluate the radiative heat transfer. The mean of $\left(T^{\circ} R\right)^{4}$ is not necessarily equal to the fourth power of the mean of $T^{0} R$.

The inside wall temperature of the Marinite was determined indirectly by measuring the temperature at other points in the Marinite disks and solving a heat balance involving the heat flow radially outward through the Marinite disks. Thermocouple number 7 was located in a $1 / 16$ in. diameter vertical hole in Marinite disk number 5. This was one of four holes which were drilled in each of the four central disks to reduse the mass of the Marinite disks and improve their insulating properties. The hole containing thermocouple number 7 was separated from the inside wall of the Marinite disk by less than $1 / 16$ in. of Marinite. Thermocouple number 6 was located near the outer edge of Marinite disk number 5.

The heat flow through the Marinite and the inside wall temperature of the Marinite disk was evaluated by two methods. The first method was to solve a conduction heat balance using the temperatures of thermocouples 6 and 7 which were fmbedded in the Marinite disk. This was the 
simpler methor but some mechanical deterioration of the Marinite disks resulted in cracking of tre thin web between the inside w: 11 of the Marinite disk and the hole containing thermocouple number 7 . This thermocouple was then exposed to some direct radiation from the tungsten cylinder as well as to some of the effulent coolant gas from the tungsten cyinder.

In order to avoid the possible inaccuracies which could result, from the exposure of thermocouple number 7 to this variety of temperature sources, $z$ combined radiation and conduction heat balance was sclved using the temperature of the tungsten cylinder, the thermal conductivity of the Karinite disks and the temperature at thermocouple nimber 6 in the Marinite disk. This resulted in a quartic equation which when solved provided the inside wall temperature of the Marinite disk. The radiative heat loss from the tungsten surface could now be eveluated.

Since there was only one pair of thermocouples imbedded in the Marinite disiks, the values obtained for the inside wall temperature of the Marinite at the axial position corresponding to the imbedded thermocouples was taken to be the mean temperature for the entire inside wall of the Marinite disks. No axial heat flux in the Marinite was considerea. This was probably a good estimate because thermocouple number 6 was 10cated axially near the center of the tungsten cylinder. Also any axial temperature gradieni in the Marinite would tend to be flattened by the heating of disks number 3 and 8 due to the heat these two disks received from the region at the tops of each of the stainless steel piers. The graphite washers produced a heat source in this region of the pier wich served to reduce conduction heat loss from the tungsten cylinder. This heat was transferred to disks number 3 and 8 which were at the ends of 
the four disks which actually enclosed the tunesten cylinder.

Since the heat loss from the tungsten surfacc to the enclosing Marinite disks could nos be calculated, the second boundary condition, $\mathrm{dT} /\left.\mathrm{dx}(\mathrm{z})\right|_{x=\ell}$, could now be evaluated.

\section{Thi-d Boundary Condition}

The thira boundary condition was the temperature $c^{-}$the fluid at the point of entry into the norous wall from inside the hollow cylinder, $\left.t(z)\right|_{x=0}$ No $=$ axis variation in the inle:t fluid temperature was con. sidered. This temperature corresponded to the use of a single: constant term il a Fourier series. It was considered necessary to take into account the heat absorbed by the gas from the time it entered the lower bus block at essentially room temperature unitl it entered the inside wall of the porous tungsten cylinder.

The passare of the gas into the interior of the hollow cylinder involved two preheating prases. The first occurred as the gas passed up through the relatively cool bus block into the lower pie: One end of the pi rr was at a temperature comparable to that of the tungsten. The thermocouple wells $i_{\text {a }}$ the lower pier provided a temperature profile along tlie entry path of the gas. The temperature of the pier at the end of the pier where the gas left was estimated to be eqial to the temperature of the lower end of the tungsten cylinder This assumption was made in spite of the fact that the graphite washer in the end of the pier $\mu$ obably produced $a$ hot spot in this region but the tungsten end temperature was "he only value available.

The calculations for the preheating of the gas were based on the assumption that iaminar flow had been estatlished in the $1 / 8$ in. 
diameter gas inlet passace in wh:ch the Reynolds number was on the order of $10^{-1}$. Equations cited by McAdams $\left(2 h_{t}\right)$ were used to estimate the value of the heat transfer coefficient in the $1 / 8 \mathrm{in}$. entry passage. A series of preheating calculations were carried out assuming a linear variation of the temperature in the bus block and the pier between each of the thermocouple wells. The gas preheating in the pier for nitrogen was found to be from 120 to 230 degrees F. The pier preheisting for Helium was from 360 to 740 degrees $F$.

The other gas preheating consideration was the assumption that after the incoming gas lef't the pier it wouid absorb all of the heat transferred to the sheathed stainless steel thermosouple number 14 by radiation from the inside wall of the tungsten cylinder. This was considered the most reasonable assumption since the nature of the flow over this thermocouple was not well known. While the axial flow of the gas entering the rylinder and absorbing heat from the inside cylinder wall and the coaxial sheathed thermocouple could conceivably produce an axial gas temperature profile, this factor was neglected. Since axial flow effects were neglected no considaration was given to any heat loss from the inside wall of the tungsten cylinder directly into the incoming gis. The error analysis at a iater pcint in this work will show that these assumptions are justified.

\section{Fourth Bouridary Condition}

The fourth boundary condition was the temperature gradient in the tungsten at the insige wall. of the tungsten cylinder, $d T /\left.c i x(z)\right|_{x=0}$. The temperature gradient was evaluated by two metnods. The first method was to solve a radiative heat balance between the inside wall of the 
tungsten cylinder and the itainlcss steel sheathed thermocolple number 14. This method required an estimate of the tempcrature of the inside wall of the tungsten cylinder.

It was found that the tungsten eylinder wall temperature profile was very flat and that the inside wall temperature was within a few degrees of the outside wall temperature at any given position along the cylinde: axis. Accordingly the $z$ axis temperature profile at the inside wall of the tungsten cylinder was taken to be the same as that of the outside wall.

Estinates of the radiative transfer from the tungsten wall to the coaxial thermocouple were complicated by the fact that the thermorouple sheath exiended into the interior of the tungsten cyiinder for only abu-t half of the length of the tungston cylinjer. This problem was circumvented by assuming a pseudo thermocouple in the form of a coaxial cylinder that extended the entire length of the tungsten cylinder. This pseudo thermocouple had the same surface area as the portion of the real thermocouple inside the tungsten cylinder, and the pseudo thermocouple had a correspondingly smaller radius.

The mean of $\left(T^{\circ} R\right)^{4}$ at the inside wall of the tungsten cylinder was used in the radiative heat transfer calsulations. The entire length of the pseudo thermocouple was assumed to be at the temperature of thermocouple number 14. From the rough, oxidized, and blackened condition of the sheathed thermocouple its emissivity was estimated to be 0.95 and unitary emissivity was again assumed for the tungsten.

The second method for evaluating the temperature gradient at the inside wall of the tuncsten cylinder was to remove the sheathed thermocounlc number 14 . This created a radiative black box inside the tungstien 
cylinder in which lite net temperature gradient at the inside wall of the tungsten cylinder would be zero. However, since there was generally an axial temperature gradient alone the outside wail of the tungsten cylinder, and since this gradient was propagated thrugh the tungsten wall, there would generally be the same axial grauient along the inside wall of the tungsten cylinder. The inside wall of the cylinder would not then be strictly adiabatic but it was assumed to be so since the effect of the radiative exchange inside the cylinder woulc tend to reduce the axini temperature gradients.

The use of this second method for establisning the fourth boundary condition was reasonable and even desirable since it eliminated the need for the radiative heat transfer calculations and also eliminated the need for one of the two gas priheating considerations.

\section{Fifth Boundary Condition}

The conduction correction factor to be used in the equations for therma? and electrical conduction was not known. In order to evaluate this factor along with the volumetric heat transfer coefficients and the three constants of integration it was necesse.ry to measure a fifth boundary condition. The fifth boundary condition was the amount of heat generated in the length of the tungsten cylinder bet:seen the two roltage probes. By e.ssuming that the thermal and electrical conciuction correction factors are the same and knowing the temperature dependence of the electrical resistivity, the leigth-over-area conduculon correction factor can be evaluated when the temperature distribution in the tungsten cylinder is known. 


\section{Method of Solution}

Since the heat transfer coefficient and the conduction correction factor were contained in transcendental equations the method of solution for the five unknown coefficients was the following. First, an initial estinate was made of the heat trarsfer coefficient and the conduction correction factor. Then, even though the equations defining the experimental system assume that all parameters except for the electrical resistivity are temperature independent, parameters vere used which correspond to those for the mean temperature of the material for which the paraneter applies. An initial estimate of the solid phase temperature of the porous tungsten was obtained from an average of the five opticai pyrometer temperature readings. An estimate was made of an average fluid cemperature during the passage of the fluid through the porous turgsten. Initial values of parameters such as thermal conductivity and heat eapacity are estimated. Evaluation of the heat transfer coeificient ind the conduction co:rection factor require that values be chosen for these parameters. When these values are inserted in the first three boundary conditions a set of equations results which can be solved explicitly for the three constants of integration. The constants of integration are then used along with the assumed heat transfer coefficient and the conduction correction factor to calculate the fourth and fifth boundary conditions. The calculated values of the fourth and fifth boundary conditions are then compared to the experimentally measured boundary conditions. Successive values for the heat transfer coefficient and the conduction correction factor are chosen until sets of assumcd values are found which yie]d calculated boundary conditions that bracket thr: exfcrimentally determincd fourth and fifth bondary conditions. 
Successive iterations are then carried out ir. order to obtain convergence to within a frescribed limit. Convergence to a tolerance of one part in $10^{4}$ was facilitated ty the use of digital computer program: and ky the fact that the conduction correction factor was not particularly sensitive to changes in the heat transfer coefficient. The conduction correction factor was evaluated in the first two to three iterations after which the iterations on the heat transfer cipeficient could proceed.

When the computer program obtained a bracket on the heat transfer coefficient the method of filse position was used with a quadratic rather than a linear fitting wethod. Use of this technique usually gave convergence in from two $\sim$ five iterations. The stacility of the conduction correction factor wes result of its essentially singular cependence on the solid f hase temperature wich defines the electrical Fower gereration equations. It has been noted that the porous tungsien wall had a very flat temperature profile so that the initially observed temperan:ire profile of the outer wall of the cylinder was very nearly the profile for the entire thickness of the tungsten wall. 
Sumary of Results

The data from 39 experimental runs are tabulated in Tables 2 through 4 which are in Appendix C. Daca in these tables represent the values which served as input to the coeputer programs which calculated the heat transfer coefficient and other parameters for each experimental run. Table 1 tabulates parameters which were comon to all runs as well as physical constants. This table is in Appendix B. Tables 5 through 7 contain the heat transfer coefficient and other values calculated fron the analysis of the experimental runs. These tables are in Appendix $D$. All runs are designated by a two digit number ranging from 05 through 82. These numbers were originally related to the date $n$ which the run was made but are used only as reference.

Three different norous tungsten cylinders were used in this study. The four runs 05 tirrough 08 were carried out using cylinder $C$. The twenty-four runs 14 through 37 and 62 through 82 were carried out using cylinder D. The ten runs 45 through 54 were carried out using cylinder E. All of the cylinoiers weighed approximately 18 grams at the start of a series of runs. The volume porosity of all the cylinders was approximately one half based on the dimensions of the hollow cylinders, their weight, and the density of solid tungsten.

The coolant gas for the twenty-seven runs 05 through $5^{\prime}+$ was nitrogen and the coolant gas for the eleven runs 62 through 82 was belium. The nitrogen flow rates varied from approximately 7 to 19 standard cubic feet of gas per hour and the helium flow rates varied from approximately 8 to 30 standard cubic feet of gas per hour.

The stainless steel sheathed thermixcouple number 14 was inserted into the interior of the tunf:sten cylinder for approximately one half of 
the leneth of the tungsten cylinder during 17 of the runs using nitrogen as the coolant. In this configuration heat was transferred from the interior wall of the tungste: cylinder to the thermocouple by radiation where it was absorbed by the inconing coolant gas. The gas was thus preheated by this mount of heat after leaving the end of the pier and before entering the porous vall.

Therwocouple nuber 14 was withdram from the interior of the tungsten cylinder during 10 of the runs using nitrogen as the coolant. In this configuration thernocouple number 14 was not involved in heat excharge in the interior of the tungsten cylinder. The interior wall of the cylinder was assuned to be adiabatic in these runs. All of the rins using helium were made with thermocouple nuber 14 inserted into the interior of the cylinder.

The evaluation of a heat transfer coefficient in the generating purous tungsten was possible in 30 of the runs. These values are presented in Table 7. A Nusselt number and a Reynolds number are calculated for these runs and presericed in Table 7. Figure 16 shows typical solid and fluia temperature profiles within the wall of the porous cylinder. The heat fluxes involved in the evaluatius of these profiles are also shorn. Figure 17 presents the Russelt-Reynolds correlation in graphic form. Other experimental data ccrrelations for heat transfer in forous meterials are show :n Figure 17. Correlations which have been suggested for heat transfer in norous systizs are also shown. 


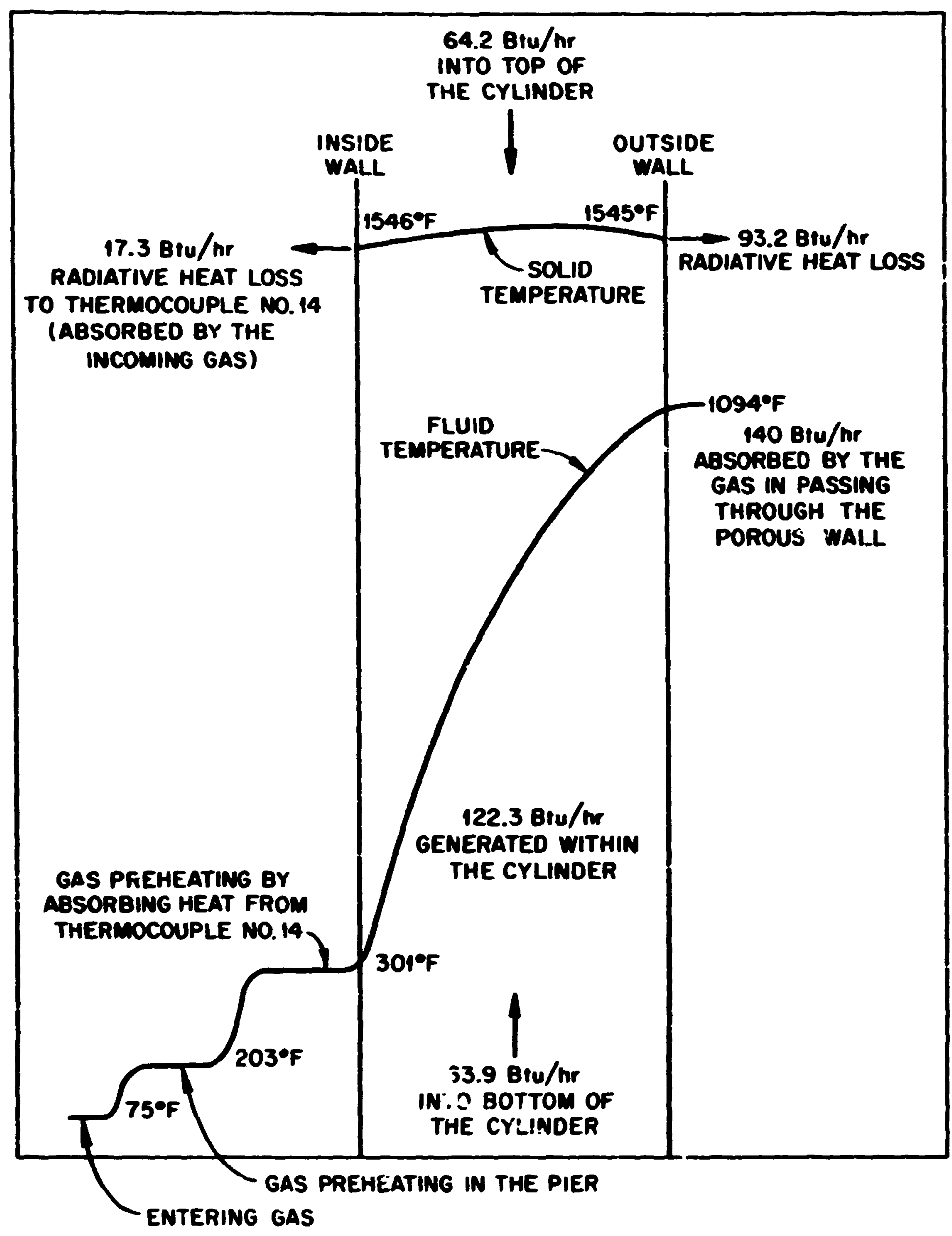

Figure 16

TEmperature Profiles and Heat Balances in the Porous Nall 


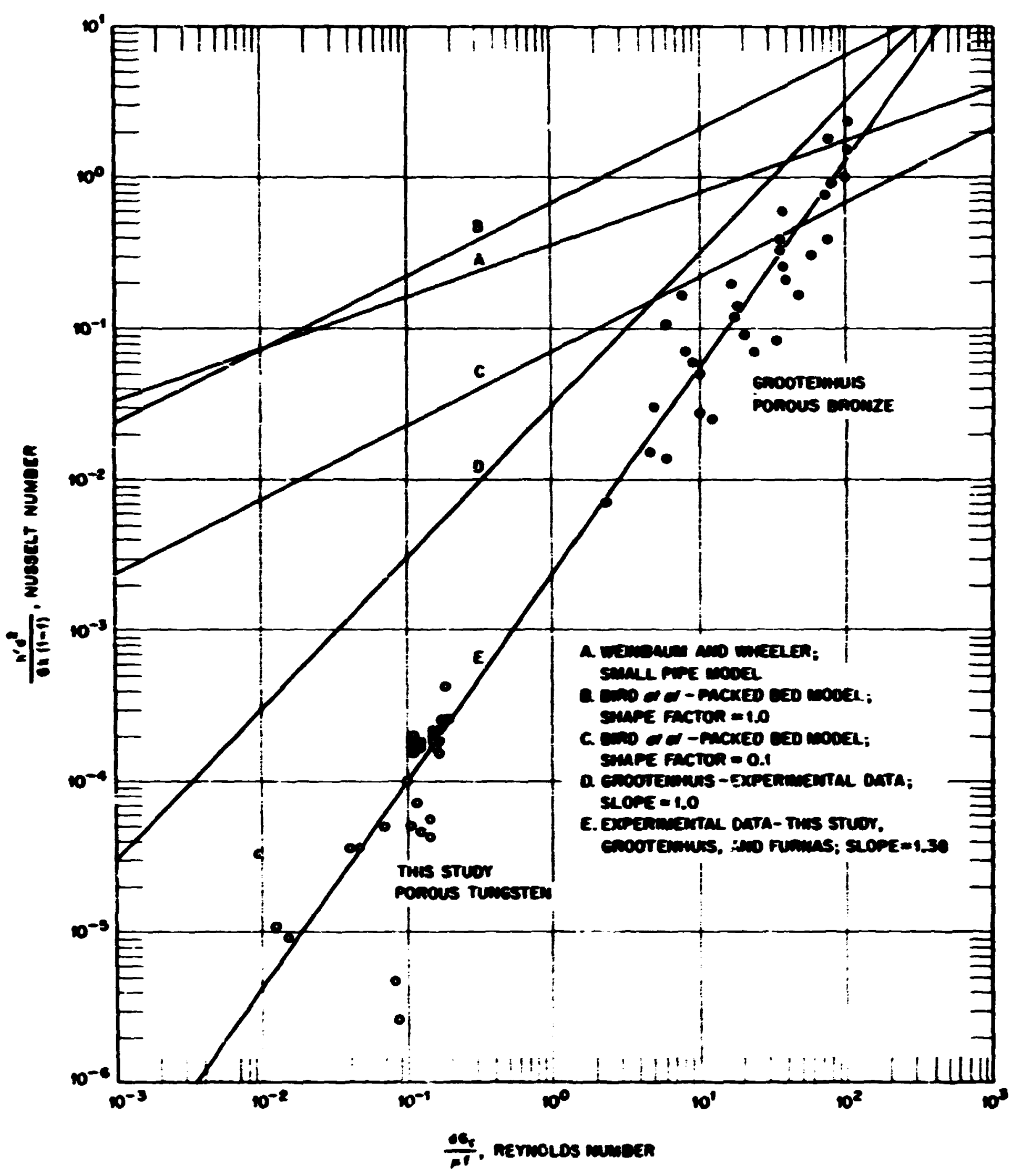

Pigure 17

Tusselt Number vs Reynolds Number for Systems of Porous Materials 
Nusselt-Reymolds Data Correlation

Figure 17 is a log-log plot of Nusselt number versus Reynolds number. The Nusselt number in this plot is $h^{\prime} d^{2} / 6 k(1-f)$ where $d$ is a measure of the particle size, $f$ is the porosity of the porous material, $k$ is the thermal conductivity of the gas passing through the porous witerial, and $h^{\prime}$ is the volumetric heat transfer coefficient i: B.t.l. $/$ hr.- - F-cu.ft.

The volumetric heat transfer coefficient, $h^{\prime}$, is equal to he where $h$ is the classical heat transfer coefficient in $B \cdot t \cdot u \cdot / h r .-s q \cdot f t .-{ }^{\circ}$ and c is the surface area within the pores of the naterial per unit volume measured on a bulk basis. The significance of $h^{\prime}$ is that it represents a quantity which can be measured directly, as in this study, without the need to know the internal surface area per unit volume of the porous material. There are wioe variety of techniques for the measuremit of the internal surface area of a porous material. Comparisons of heat transfer data using the classical $h$ can be difficult since the different techniques for the measuremen: of interial surface area can give different results. The use of mercury porosimetry for exalple, gives differen: values depending on the pressure used and the question then becomes which of these values in fact represent the effective aree for heat transfer. The reymolds number in this plot is $G_{c} \dot{d}^{\prime} / \mu f$ where $d$ is a measure of the particle size, $C_{q}$ is the mass flow rate per unit area of bulk porous material, $\mu$ is the viscosity of the ga passing through the porous material, and $f$ is the porosity of the porous material. The measure of particle sizz, $d$, is taken to be the size of the powde: used in the manifacture of the porous tuncisten. This value is used in boti, the Reynolds number a.1d 
the llusselt number. The justification For this choice will be presented shortly. The porosity term in the Reynolds number is introduced to give a Reynolds number based wore nearly on the true veloc!ty of the fluid in the pores of the porous tungsten. This correction has been made in other studies. $(17,11)$

Since $h^{\prime}$ is a volunetric hrat, transier coefficient, the conversion to the area based beat transfer coefriciert used in the lusselt number was accouplished by the lise of the term $6(1-f) / d$ wich is teken to be the surface area per unit volume of the porous material.

The particular forns of the Husselt and Reynolds numbers chosen fir Pigure 17 are designed to allow comarison or the experimentally deterained heat transfer coefficir:ts from this study with other work. The factor $6(1-f) / d$ does represent. the surface area per unit volune for a bed of spheres jacked tc obtain maxim porosity. It has been assuned frow the sature of the factor 1-f, that the surfece area per unit volume, basea on porosity alone, would vary linearly froa $\pi / d$ at the maximun porosity of approximately 0.476 to $6 / \mathrm{a}$ at zero porosity. While this factor is not designed to apply to porasities ajove 0.476 , the porosity of material in this study is close to the liait of this range, and this factor has been used in other work where the porosity was above 0.476 .

The use of the factor $6(1-f) / d$ gives a surface area per unit mass of approximateiy $0.0078 \mathrm{sq}$. weters/gx. for the porous tungsten used in this study. This corresponds with the experimentally measured surface area per unit mass of $0.0116 \mathrm{sq}$. neters/gr. For the porous tungsten. This surface area was determined by nitrogen adsorption. This is a good correspondence in light of the absence of any sphericity considerations which wouiù teind to increase the 0.0078 value. The agrecment 
mi the be consideres vesy food if the sphericity-porcsity correlation in Brown (4) is used. The sphericity value of 0.6 to. 0.7 for packed beds at a perusity of 0.5 would bring the value of 0.0078 into close agreement with the measured value.

Tise ticrmal conductivity, viscosioy, ana heat, capacity used in the IJusselt and Reymolds numbers were evaluated at the mean fluid temperature during the passines of the fluid through the porous tungsten. Th: Peymolds numbers studied in this work are on the order of $10^{-l}$. The Nusselt rumbers ccrresponding to this order of Fieynilds number are on the order of $10^{-4}$. The use of the measured surface area per unit mass of $0.0116 \mathrm{sq}$. meters/gr. gives haat transfer coefficients on the order of 0.1 z.t.u./hr.-sq. ft. $-^{\circ}$ F.

\section{Agreement with Other Fxne simental Data $^{+}$}

Figure 17 shows he results of this study along with other experimentally measured heat transfer ccofficients. The lata of Grootenhuis (17) for heat transfer from porrus bronze to air iz shown. This group of data rave Reynolds rumbers on the order of $10^{0}$ to $10^{2}$. The results found in this work give a correlation that agrees with the data of Groctenhuis. A line through the data fron this study and the data of Groutenhuis has a slope sijghtly greater than one. This is curve $\mathrm{E}$ in F:Eure 17. This line would also correlate well with other reported e.perimental aiata cited by Grootenhuis and in particulas with che data of Furnas ${ }^{1}$ on herat transfer from beds of iron and iron ore to air. Thess laiter points have Nusselt numbers on the order of $10^{2}$ and Reynolds

Cired by Grootenhuis (15). 
numbers on the order of $10^{3}$ and $10^{4}$.

The correlation line through the data of this study the data of Grootenhuis, and the data of Furnas has the equation

$$
N u=2.0 \times 10^{-3}(\mathrm{Re})^{1.38}
$$

where the Nusselt and Reynolds number are those described previously. Jrootenhuis suggests that a correlation line should not have a slope greater thal one which is presumably based on the Graetz analysis. Equation (21) is not a violation of this principle since the Graetz analysis is not particularly applicable to these porous systems as will be shown. In any event, equation (2l) should be considered an empirical correlation.

It is difficult to describe the flow regime in porous materials. Friction factor data on porous systems do not show a distinct transition from laminar to turbulent flow. It has been suggested that the rough nature of the flow channeis in porous material leads to a gradual increase in the numbin of channels which are in turbulent flow. The fact that the data on packed beds have a transition at a Reynolds number of 50 (1) suggests that a different type of flow regime has been acknowledged. It has been suggested that there are multiple transitions at Reynolds numbers around 42 and 1200 (11) for other data on packed beds.

The laminar nortion of tube or pipe friction factor curves are dependent, on $L / D$. It has teen fourd (22) thet for $L / D$ around 5 the laminar friction factor curve joins the turbulent friction factor curve with only a small transition. This same characteristic is seen in the continuous friction factor curve for porous materials. A poro:as 
material might therefor 2 be considered to have a small value of $L / D$, possibly as small as one.

Thus, to whatever exterit the flow in porous materials is laminar, the use of the Graetz analysis would still call for a uniform wall temperature, undistorted laminar flow, no viscosity dependence on temperasure, and some value for $L / D$ in a porous system.

Since it wuld probably be hard to meet these requirements, it would seem that a correlat: on with the Graetz analysis should not necessarily be the basis for accepting or rejecting a correlation line of slope greater than one.

In general the points in Figure 17 lie further below a line of slope one as the Reynolds number decreases. The particle diameter of the bronze particles is on the order of $10^{-3}$ to $10^{-4} \mathrm{ft}$. The particle ciameter of the tungsten particle is approximately $6.5 \times 10^{-5} \mathrm{ft}$. It has been suggested that the correlation line is actually of slope one but that the loss of surface area, ang the forming of porous materials, is greater for zarticles of smaller diameters. Thus, the factor $6(1-\mathrm{f}) / \mathrm{d}$ is an overestimate of the actual surface area with a resulting lowering of the Nusselt number values.

The bronze data vary in particle diameter over one order of magnitude and they do show an indication of this dependence on particle size. The iron ore data of Furnas have particle sizes on the order of $10^{-1} \mathrm{ft}$. The susselt values for the data of the present study do fall further below a correlation line of slope one than do data based on larger partic..e diameters. Curve $D$ in Figure 17 is a line of slope one that was used as a reference by Grootenhuis since it gave a good correlation with data $01^{\circ}$ Furnas and others at Reymolds numbers of $10^{2}$ and 
Nusselt numbers of $10^{3}$ to $10^{4}$.

It should also be noted that the ratio of wall and bulk viscosities has not been included in the evaluation of the ordinate in Figure 17 or in equation (21). The effect of this term as a multiplier of the Nusselt number would be to move the data points in this study closer to the correlation line of slope onc, curve $D$.

An evaluation of the wall viscosity in the porous tungsten was made at the average solid phase temperature. The viscosity correction factor, $\left(\mu_{w} / \mu_{b}\right)^{0.14}$ has been used for both laminar and turbulent flow. The correction which would be introduced by the ratio of the wall and bulk viscosities to the 0.14 power is on the order of 1.05 to 1.1 .

If, following Bird (1), the diameter to be used in the Reynolds number was evaluated as four times the hydraulic radius of the porous material the diameter would be approximately 13 percent smaller than the diameter used in the Revnolds number which was assumed to be the particle size of 20 microns. Also if the diameter used in the Fusselt number were evaluated as $6 / a_{v}$ where $a_{v}$ is the specific surface of the porous material, the diameter would be approximately 3z percent larger then the particle size diameter of 20 microns which was used in the Nusselt number. These corrections would lower the value of the Ktynolds number and raise the value of the Nusselt number. Both of these erfects would move the data points observed in this study toward the correlation line of slope one in Figure 17.

These evaluations were not made because their use would not cffect the evaluation of the heat iransfer coefficients and because there was no specific surface data available for the porous bronze and the iron ore. In addition, the use of a hydraulic radius is questionable for 
laminar flow and the Reynolds numbers in this study are in the laminar region.

Regarding the flow regime, the correlation line of equation (21) or even a correlation line in the vicinity of slope one offers sane indication that the nature of the flow in porous materials way be different from that found in pipes at Reynolds aumbers of $10^{-1}$. A correlation line with a slope arounci one would be expected for high Reynolds numbers, turbulent $\mathrm{flcw}$, and a large relative roughness speaking in the sense of flow in pipes. Porous materials shor friction factor correlations which correspond to low if not unitary I/D as the transition region is approached from the laminar region. Correspondingly, porous materials act in the turbulent region as if they were a pipe with a large relative roughnesz. Some friction factor correlations show relative roughnesses in the vicinity of 0.05 . A porous mate.ial may well have a relative roughness as large as the order of one.

The effect of the nature of porous materials on the friction factor correlation is to lower the Reynolds number at which the flow in a porous material begins to take on the aspects of turbulent flow. This should also be true to some extend and possibly even to a greater extent for heat transfer. This fact in conjunction with the correlation presented in Figure 17 suggests that flow in porous materials may contain elements oi turbulent flow and that Husselt-Reynolds correlations with a slope of one are more reasonable than corrclations based on laminar flow which postulate correlation lines with a slope of from $1 / 3$ to $1 / \hat{2}$. 


\section{Other Non-Experimental Correlations}

Figure 17 alsc shows curves which have been suggested as correlations that might be used to determine heat transier coefficients in porous materials.

Curve $A$ in Figure 17 is a Nusselt-Reymolds correlation based on the small pipe model for porous caterials used by Weinbaum and Ureeler. (34) This curve was evaluated using values for parameters typical of those found in this sturiy. The characteristic diameter of both the particles and the flow passages was 20 microns. The wall thickness or the equivalent pipe length was $1 / 16$ in. ar. 1 the Prandlt number was 0.705 . This curve was calculated by assuning, as did Weinbave and Wheeler, that the wall-bulk viscosity correction could be neglected.

The equation used in the correlation of Weinbave and theeler was the empirical ncdification of the Graetz theoretical temperature soluiion for fully developed laninar flow with constant wall temperature. Weinbaum and Wheeler reference McAdans (24) for their source of this equation. The slope or this correlation line is $1 / 3$. Figure 17 shows that this small pipe model does not describe the slope of heat transfer correiation determined in this st:idy. It also overestimates the heat transfer coefficient by approximately three orders of magnitude at Reynolds numbers of $10^{-1}$. The use of the correlation of curve $A$ for heat transfer in porous materials would not be recommended.

As has been noted previously, the use of the Graetz analysis is questionable in the case of porous materials since it is by no means clear that the nature of the flow in the pores satisfies the Graetz conditions. It is unclear how a value of $L / D$ would be evaluated for a 
porous system in the sense in which it is used in this analysis.

The Graetz correlation was not designed for the low range of Reymolds numbers encountered in this study. McAdans notes in his comentary on the us.? of this correlation that there are large deviations associated with the use of this correlation even in the cases being described. These cases include asphalt at temperatures of $300^{\circ} \mathrm{P}$ flowing in 1 in. tubes it $2 \mathrm{ft} . / \mathrm{sec}$. with heat transfer coefficients of 30 B.t.u./hr.-sq.ft.- P. Bird et al., (1) points out that there are significant uncertainties in the use of this correlation at values of the Graetz number less than 10.

The use of the correlation of Weinbaum and Wheeler could belp to propagate the idea that porous materials have essentially equal solid and fluid phase temperatures since the use of the mch overestimated heat transfer cofficients obtained from this correlation could indeed predict that the fluid temperature quickly reaches the temperature of the solid phase.

Curves $B$ and $C$ in Figure 17 are based on a packed bed nodel of a porous system that is described by Bird, et al., (1). Bird's correlation was based on heat and mass transfer data for packed beds and it was correlated in terms of the Colburn $j_{H}$ factor versus Reynolds number. Tisis correlation involved a particle shape factor, 1.0 for spheres and less for other shapes. Curve $B$ is based on a shape factor of 1.0 and Curve $C$ is bascd or a shape factor of 0.1 . In both cases a Prandlt number of 0.69 was assumed.

The slope of curves B and C on the Nusselt-Reynolds plot are 0.49 in a ranec of Reynolds number 1ess than 50. Curves $B$ and $\mathrm{C}$ have been chosen for comparison to the experimental data cited in this study 
because they suceest one of the larpest slopes proposed for the NusseltReynoljs correlation line in aterials of a porous nature.

From figurc 17 it can je seen that these two curves do not describe the dati points found in this study. Further, the slope of this correlation is still too low to jescribe the data observed in this work and by Grootenhuis and Furnas. Use of this correlation would alsc overestinate the heat iransier coefricient by two to three orders of magnitude at Reynolds numers of $10^{-1}$.

The correlation is presented in Bird et ai. as being based on large anounts of experimental data on both heat and mass transfer in packed beds. The prinary reierence to this datd is described as a private ccandiaication but the authors give a secaudary reference to charts by Houfer et al. 1 The charts give no indication as to how siall a value of Reynolds number could be described by their correlation. However, the particle dianeters explicitly discussed on the charts extend dom only to the or ier of $3.0 \times 10^{-4} \mathrm{ft}$. which is still an order of magnitude above the particle size in this stuay.

The fact that this correlation was designed for a vide range of data anả was seeking a correlation for not only heat transfer but alsci for mass transfer suggests that it would not be applicable to the small particle diameter and low Reynolds numbers found in this study.

Green (12) presents a correlation of heat and mass transfer data in terms of a plot of $j$-factor versus Reymolds number. The slope of this curve is on the order of -0.45 which would give a slope of 0.55 when presented on a Nusselt-Reynolds plot. The inadequacies of this

$\overline{1_{\text {cited by Bird et al. }}}$ (1) 
coriclation in describing data cited in this work are ssentially those of the correiation from Bird et al.

Grecn does note that trassient methods are generally used to measure heat transfer coefficionts in porous systems because of what he describes as the difficulty of measuring the heat, transfer coefficient in the porous aterial directly. He does note that there are frequently discussed errors in the use of the transient method of etaluating the heat transfer coefficient. Green cites, but does not use the data from Grootenhais in establishing his heat transfer correlation. The method of Grootenhuis had been to continuously supply radiant heat at one surface of a porous plate and thereby achieve a steady state system for tho measurement of the heat transfer coefficient in his apparatus. freer does however use the concept of the rolunetric heat transfer coefficient in his calculations wich was used by Grootenhuis.

A study by $\operatorname{Han}^{1}$ was considered by Green in estab:ishing his heat transfer correlation. It is interesting that Green rejected the data in this study on the basis chat it predicted heat transfer coefficients which he considered abnormally low by about two orders of agnitude. The results of this present work suggest that the heat transfer coefficient at Iow Reynolds numbers should be wach lower than those predicted by correlations of the type used by Weinbaum and Wheeler, Bird et al., ard Green.

As noted, curve $D$ in Figure 17 is a line of slope one which was used by Grooterhids t,o include the data or furnas and to serve as a suggested correlation line for the Nusse!t-Reynolds correlation of data

$\overline{\text { Icited by Gror:n (12). }}$ 
on heat transfer in porous materials.

Grootenhuis notes that his experimental data on beat transfer to porous bronze have fallen below this line. It is this line toward which he suggests his data could be moved if the loss of heat transfer surface during fabrication of the porous bronze could be taken into consideration.

The effect of sall corrections to the data of the present study would also tend to wove the data points as presently roported in the direction of curve D. These corrections have been cited and inclure tie effect of a viscosity correction, the evaluation of a nore precise hyarmulic ragius for use in the Rejnolds muber, and a nore precise average particle dianeter for use in the musselt numer. 
Heat Bal ances and Temperature Profiles

?igure 16 presents typical heat balances aroind the porous wall of ts. tuncsten cylinder. At any given axial position, the solid phase temperature profile through the wall of the cylinder is quite flat becalse of the high thermal conductivity of the tungsten and the low heat transfer cưfíicient. The solid phase temerature curve has a slight slope or is zero at the inside wall depending on wether or not the sheathed thermocouple is inserted into the interior of the tungsten cylinder. The slope of the temperature curve at the outside wall provides the weat lost by radiatiun to the enclosing warinite disks.

A significant amount of heating of the fluic flowing through the porous wall does take place within the porous wall but because of the low valu profile does not show the near step function of fluid beating proposed by Weinbau and wheeler. It can be seen from Pigure 16 that the assurption that the tecperatire of the solid and fluid phases are nearly identical would be in error for the porous systea used in this study.

The low value for the heat transfer coefficients found in this study and correzated with ctber experimenta: studies on heat transfer in porous systems suggest that errors, which may be as large as two orders of magnitude at Reynolds numbers of $10^{-1}$, may result fram the use of porous beat transfer correlations using Russe!t-Reynolds correlations with slopes of $1 / 3$ to $1 / 2$.

There is: $n$ additional exyrimental verification of the fact that the cas exiting from :he outside wall of the tungaten cylinder has not been heated to the leupreruture of the tuncsten wall. The stainless strel 
sheithed tirrmocouple number 16 was positioned at the axial position of the optical pyromter hole in Marinite disk number 6 on the opposite side of the tunesten cylinder from the optical pyroeser ani in contect with the outside wall of the tungsten cylinder. The thermocouple vas in this position during the experimental runs. The temperatures recorded by this thermocouple were generally found to be intermediate between that of the tunfsten wall with wich $i \dot{i}$ was in contact, and that of the calculc jed temperature of the gas leaving the tungsten surface. In addition the temperature of the Marinite wall through which the thermocouple was inserted ras generally above that of thernocouple numer 16 so that the existence of an exiting fluid belcu the wall temperature would be needed to explain these temperatures.

The effect of fluid phase heat conduction which has been neglected in this study was examined and found to contribute only about. 7 percent cf the heat transferred by fluid transport even at the low Reynolds numbers of this stidy. Heglecting this effect at higher flow rates would seem justified but studies at lower flow rates will need to take this efiect into account.

In order to justify the exclusion of the fluid conduction tern, differential equation (2) for the fluid phase heat transfer was nodified to include fluid conduction terms. The result was a fourth order differeniill equation. The resulting equations for the zolid and fluid temperature distributions now included four constants of integration and the operator equation now included the fluid conduction terms. The small magnitude of the fluid conduction terms could be ignored in the opsrator equation where they were nded to the existing terms. Howevar, since the operator equation was now of the fourth order, it wes uncertain whether 
or not the cour roct: resultine from the solution of the fourth order polynomial equation would desorile the samr: tempenature prufiles cbtidined with the thirl order operatcr equations. During the analysiz of eich rur, the root: of the fourth order operator equation were evaluated and compired to those of the third order equation. For two of the roots that were found to be essentially common between the third and fourth scder operator cquations, the diffurences were negiigible. While this subfested that ine temperature profiles described by the fourth order cquations might not differ significantly from those described by the third orrar "quations, the best verification of this fact through the use of the differential equations would be to solve the system of fourth orier equations and use an anvitional boundary condition to obtain resilts which could be compared to the results of the solution of the third order equation. The equatin $:$ involving fluid conduction are derived in Appendix A.

To avoid the difficulties associated with this problem an estimate of the magnitude of the heat flux from fluid conduction was made during the evaluation of the data from each run. A check had always been run on tine heat balance at the points $x=0, z=0$ and $x=l, z=0$. This check calculated the heat flux in B.t.u./hr, at these points for each of the heat transfer mechanisms of conduction ir. the tungsten, heat transport in the fluid, heat generation in the solid, and heat transfer from solid to fluid. The evaluation of the seat flux due to condiction in the fluid was added to these existing checks and the magitude of th:s effoct provided the most realistic measure of the justifization for ieaving the fiuid conduction effect out of the present calculations. 
The conclusiun reached in this study, that there is a large difference between the solid and fluid phase temperatures, should not be construed to be a conclusion that would be applicable to ill porous systems. There are probably many porous systems in which the solid phase temperature is approached cuite closely by the fluid phase tcmperature and it is this effect ir those systems that gives added weight to the ide: that this will be the case in all porous systems. Data for these systems arc usually at much larger Reynolds numbers than those considered in this study. An example of this would be the work of Koh and dei Casal (2lj with Reynolas numbers above 60. 


\section{Conduction Correction Factor}

The length-over-aria conduction correction factor was found to vary from approximately 0.45 for a new porous tungsten cylinder to approximat.:ly 0.22 1.0r a used porous tungsten cylinder. These values are presented in Table 7 .

It has been widely assumed that the conductivity, both electriral and thermal, of a porous materiai would be less than that of the solid material. The factor most comonly used to evaluate this reduction is the complement of the volumetric porositij. Grootenhuic uses this corncept and shows that points describing the thermal condictivity of porous bronze lie on a straight line running from the conductivity of solid bronze at zero porosity to zero thermal conductivity at a porosity of 0.476 . However he cives point out that certain data for porous stainless steels do not conform to this type of correlation and that another correlation would have to be expected for these stainless steels and other materials.

The condictance used in this work has bet: assumed to consist of the conductivily, the bulk area for conduction, one correction factor in the form of the complement of the volumetric porosity, and another correctic.s factor which is the length-over-area conduction correction factor described earlier in this work. Since the thermal conductivity of the porous tungsten could not be measured while the equipwent was running at the operating temperature, the electrical conductivity of the porous tungsten was measured under operating conditions and the conduction correction factor for the electrical condurtivity was assumed to apply to therwal conduction. 
As has been noted, this should be a good assumption becanse the electrical and thermal conductivity are known to be related through the Lorenz number. This relation has been verified experimentally for some porcus metals by ormienhilis.

The electrical resistivity of the portion of the tungsten cylinder between the voltage probes is proportional to the average solid phase temperature over that region, $\overline{\mathrm{T}}_{\mathrm{AB}}{ }^{*}$ Since the electrical resistivity of the tungsten is described as a pclynonial in temperature, the rosistance of this section of the tungsten cylinder car be found once the average teuperature of that section has been evaluated. As has been noted, the iteration to determine this value is carried out in the early stages of the determination of the razt transfer coefficient.

Tungsten cylinder $C$ showed conduction correction factors of approximately 0.44. This cylinder had been in use for development for some time when these data runs were made. Tungsten cylinder $D$, after being useci for some developinent work, gave a conduction correction factor of approximately 0.42 to 0.38 . Later, after being used at high temperatures and showing evidence of physical deformation and a definite oxide or nitride coating, this cylinder was found to have a conduction correction factor of approximately 0.22. Cylinder $E$ was used in essentially a brand new condition and initially showed a conduction correction factoi of approximately 0.45 but this value fell during the runs to approximately 0.41 .

Koh and iei Casal (21) take specific notice of the fact that the experimentally measured thermal conductivity of porous nickel Foametal is less than the value predicted by the use of the porosity correction 
factor (one minus the porosity) by a factor of about six. The conduction correction factor reported by Koh and del Casal for the nickel Foametal matrices range from a vaiue of 0.242 at a porosity of 0.42 to a value of $0 . i 51$ at a porosity of 0.735 . 


\section{Analysis of Experimental Errors}

\section{Divergent Data}

Two of the data points from this study which are shown in Figure 17 lie well below the main group of experimental data. There are also eight data runs which are tabulated in Appendix $\mathrm{C}$ which did not converge. That is, no value of the heat trarsfer coefficients was found from which a fourth boundary condition could be calculated corresponding to tire measured fourth boundary condition. The reasons for the scattered data points and the lack of convergence of the other data runs are understocil and are symptons of the major experimental difficulty encountered in this study.

The uncertainties in this study sten from problems associated with obtaining equilibrium conditions under which to take measurements of the system. The instability of the experimental system was due, in turn, largely to fluctuation in the electrical contact resistance at the interfaces between the tungsten, the graphite washers, and the piers.

The experimental system could be characterized as metastable. If the system was inicially stable with fairly uniform contact between the tungsten, g?'aphj te, and piers, the tungsten would heat rairly uniformly and a very good gas seal was obtained between the tungsten cylinder and the piers. However, as the run proceeded it is reasonable to assume that various thermal stresses developed throughout the experimental apparatus as its components were heated by the power being generated in the apparatus. Some stresses were handled oy the system of spring loaded stainless steel studs used to maintain pressure on the tungsten and the graphitr:. However, the metastable nature of the system appeared when $\therefore$ iscncoaxial load changed the pressuie and therefore the contact 
resistance around the circumference of one face of a graphite washes The increased pressure and the resulting reduced elect rical resistance at the pressure point would generate more heat at this point because power generation at constant voltage is inversely proportional to resi.itance. Thermal expansion at this point would then increase the magnitude of the hot spot. Gas leakage at points other than the hot spot would in turn selectively cool the balance of the circumference.

This pattern of operation was generally observed. In order to gather experimental data it was necessary to bring the system from a cold . :te into one operating near the desired conditions in a feriod on the order of several minutes. During the fairly short stable period of the apparatus it was necessary to take measurements, often while the system was still fluctuating. The experimental run was iuvariably terminated by the onset of the unstable conditions described previously. It was very difficult to shift the experiment to a region of a differen: gas flow rate or heat generation rate because this attempted shift generally terminated the run by initiating the onset of instability.

The two data points which lie approximately one order of magnitude below the main group of dat. points at a Reynolds number cf upproximately $10^{-1}$ are data points taken during the start of a series of runs when the experimental system had not yet approached irery close to iquilibrium.

In addition to the scattered data points there were two runs using nitrogen as the coolant which did not converge. One of these runs was made at a point in time edjactent to one of the runs which had Fioduced the scattercd data point. The same reasons wolld seem to explain why this run failed to converge. The second run using nitrogen which failed to converge was being made $z$ s the power and the temperature 
in the system were falling rapidly just before termination of the series of runs. There were six runs using helium gas as the coolant which failed to converge. Four of these runs were at very low gas flow rates of approximately 3 standard cubic feet per hour. These four runs vere the start-up runs for a series of runs and the system may not yet have been in equilibrium. The effect of gas conduction would have needed to have been considered in these runs since the run using helium at a flow rate of 8 standard cubic feet per hour showed gas conduction effects comparable tu the effect of heat transfer by fluid transport. The lowest flow rate in helium muns which did converge was approximately 8 standard cubic feet per hour which corresponded to a Reynolds number of approximately $10^{-2}$. The other two runs using helium which failed to converge had gas flow rates of approximately 30 standard cubic feet per hours. Since this series of runs was terminated just after these two runs due to the instability of the system described above, there is a strong suspicion that the high flow rates of these two runs represent the onset of leakize around the ends of the tungsten cylinder.

\section{Miscellaneous Justifications}

It has been noted that interparticle radiative heat transfer effects within the porous tungsten have been neglected due to the fact that the porous material forms a wall congosed of a large number of radiation shields. The neglect of the radiative contribution to thermal conductivity is further justified by evaluating a correlatior of

Demknhler ${ }^{1}$ that estimates the radiative contribution to thermal

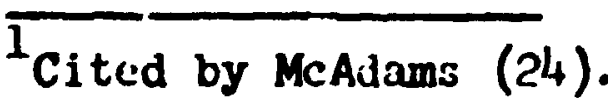


conducivity in a packed bed of known porosity and particle diameter at a given tcmperature. The radiative contribution to thermal conduction in this study would be 1.5 to 2 orders of magnitude smaller than the thermal conductivity of tingsten. Even by considering the thermal conductivity of the porous tungsten when reduced by the volumetric porosity factor and the conduction correction factor, the radiative contrilution to thermal conductivity would still be approximately an order of magnitude smaller than the residual thermal conductivity.

The temperature profile through the cylinder wall is quite flat. This fact contributes to the validity of the assumption that the coordinate transform from cylindrical to rectangular coordinates is justified. It has been previously noted that the hollow cylinder was sufficiently thin walled so that, the difference between the mean areas for cylindrical and rectangular conduction did not differ by two percent. The flat temperative profile through the wall suggests that there would not be any radial dependence on temperature in the solid phase.

The Reynolds number will drop as the gas flows radiully outward through the cylinder wall because the cross sectional area for flow at any given radius is increasing. The question then becomes whether or not the use of a mean value for the Reynolds number is a satisfactory method for deterwining the heat transfer coefficient.

While the heat transior coefficient will decrease as the gas flows outward through the wall, the volume of porous material avallable for heat transfer at any given radius will increase. The heat transferred by convective heat transfer at any radius will be proportional to the product of the heat transfer coefficient and the volume of the cylinder 
at that radius since the heat transfer coefficient is a volumetric heat transfer coefficient. For a slope of one on the nusselt-Reynolds correlation, the reduction in the heat transfer coefficient is offset by the increase in the volume with a resulting unifornity in the heat transfer at any given radius. Since the slope of the Fusselt-Reynolds correlation is close to one, the flux across the cylinder wall should have nearly the uniforaity of a flat wall.

The thinness of the cylinaier wall, the flat wall temperature proiile, and the nature of the volwetric heat transfer coefficient should all combint to justify the assuption that the cylinder wall can be replaced ty wh equivalent nat wall.

The axial temperature piorile was approximated by the first five t.erms of a Pcurier series. The use of this nuber of terms would seem tc be justified after examining the magnitude of the coefficients for each of the five terms or the Pourier serfes.

The fifin term of the series was found to be contributing only a few percent of the sum represented by the terms of the series. This would generally indicate that the major components of the series had been described by the first four terms and that no major change in the series would be expected by the inclusion of adustional terms.

\section{Effect of Errors in Selected Variables}

In order to determine the effect of experimental uncertainties on the results of this study, various components of the 'mput data for one run were altered by 10 to 50 percent in order to represent the effect of experimental errors. The effect of these changes on the calculated zeat. iransfer coefficient are corsidered. 
The temperature of thermocouple number 14 which was located inside the hollow tungsten cylinder was decreased by 10 percent which corresponded to a temperature reduction of approximately $109^{\circ} \mathrm{F}$. The effect of this change on the heat transfer coefficient was regligible. The value of the heat transfer coefficient was only reduced by 1 percent. This error of $109^{\circ} \mathrm{F}$ represents a much larger error than would be expected for the stainless steel shesthed thermocouple. However, it can be seen thet even for errors of this magnitude the effect on the heat transfer coefficient is quite swall.

The tesperature of this thermocouple does not uppear to be critical because the heat loss to this thermoccuple from the tungsten cylinder is relatizely swall in the overall heat balance, only about 7 percent of the heat. flux from the tungsten cylinder. The small significance of thermoco.jple number 14 should justify the runs in which this thermocouple was removed from the inside of the tungsten cylinder and an adiabatic Inside wall was assumed for the cylinder.

The tenyerature of therwocouple number 6 which was locatea near the outer eajge or the Marinite disks was decreasea oy 20 percent which corresponded to a temperature reduction of approximately $123^{\circ} \mathrm{P}$. The effect of this change was to reduce the heat transfer coefficient by

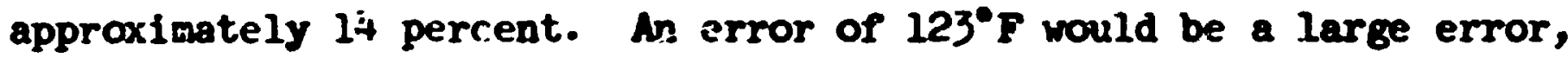
even for a bare thermocouple pail.. The significant effect of this paraneter in the value of the hest iransfer coefficiant would seem to be due io the fact that this temperature is used in the eraluation of the heat balance through the Marinite disks which is in turn related to the radiative heat loss from the outside wall of the tungsten cylinder. 
Since the radiative heat loss from the outer tungsten wall is approximately 37 percent of the heat flux from the tungsten cylinier, the parameters which play a part in the calculation of tinis heat flux could have a significant role in the determination of the heat transfer coefficient.

The average value used for the heat capacity of the gas during its passage through the porous tungsten was increased by 10 percent. The effect of this change was to reduce the calcuiated value of the heat trancfer coefficient by approximately 7 percent. This is not a particularly critical parameter since its value as a function of temperature is well known and it should be possible to construct models in which the temperature dependence of the heat capacity of the gas was taken into account.

The thermal conductivity of the tungsten was reduced by 10 percent. This resulted in a reduction in the calculated value of the heat transfer coefficient of approximately 15 percent. The sensitivity of the heat transfer coefficient to the thermal conductivity might seem strange in view of the very flat temperature profile within the wall of the tungsten cylinder. However, the therwal conductivity is directly involved in the determination of the temperature gradient at the walls of the tungsten cylinder. This does pcint up the need for more nearly aiiabatic walls on the porous material in order to reduce the dependency of the heat transfer coefficient on this value. In addition to the involvement of the thermal conductivity in boundary conditions at the inside and outside walls of the tungsten cylinder, in this particular run there is a heat flux into the cylinder from both piers which amounts to half of the heat flux from the tungsten cylinder. 
Accordingly the thermal conductivity is directly involved with the flow of this icat into the cylinder. Again, the point can be made tiat axial heat flows such as theie should be held to a winimum in order to recuce twe neea for consideration of such effects.

Sinc. che length-over-area conduction correction factor is always found in conjunction with the thermal conductivity the previous nbscr. vations regarding thermal conductivity are equaliy applicable to the conduction correction factor. The sensitivity of the heat transfer coefficient to these paraneters should further support the observations made in this study and cited elsewhere that there is a need for experimental data for the determination of what vilues should be used for conduction in porous materials.

It should be noted that the values of thermal conductivity used in this study, while taken as a constant value for the entire tungsten cylinder, were evaluated as a function of tei.perature based on the iverage temperature of the tungsten cylinder.

The amount of preheating that the incoming gas underwent in the lower stainless steel pier was increased by 50 percent based on the present pier exit temperature in ${ }^{\circ} \mathrm{F}$. This ircrease in preheating of the cas amounted to approximately $96^{\circ} \mathrm{s}$. The effect of ihis change was to caise the calculated value of the heat transfer sofficient by approximatiely 16 percert. The preheating normally experierced in the pier had been calculated to be i.pproximately $128^{\circ} \mathrm{F}$.

The incoming gas passed through a $1 / 8$ in. diameter pipe in its pasage into the interior of the tungsten cylinaer. This $1 / 8$ in. diameter pipe was approximateiy 5 to 6 inches long and consisted of the 
inside $c$ : the high pressure ritting on the lower bus biock, one inch of pessage through the bus block, and $1-3 / 4$ in. of the inside of the lower stainless steel pier. The Reynolds numbers for the flow through this pipe were on the order of $10^{-1}$.

While it would be difficult to sey what the effect or the flow would be of the various junciicns in the $1 / 8$ in. inlet passage it was assumed that iney wouid be negligible. Thus, the preheating considerations were based or the temperature profile of the last three incises of the $1 / 8$ in. pipe assuming that laminar flow had been developed in the first fe: inches of the pipe. The last three inches of the pipe were usea for the preheating calcuiation because there was no significant heating of the high pressure fitting wh: $\mathrm{ch}$ extended below the lower bus block. The heated three inches were assumed to start just as the gas putered the loser bus block.

Thic heat transfer coefficients under these conditions are described by McAdams and the viiues of $\mathrm{hD} / \mathrm{k}$ which are cited for the various modes of flow do not vary by more than a factor of two. The effect of the calculation lising an ircreased preheating value of $96^{\circ} \mathrm{F}$ may therefore be indicative of the effect that rariatioc in the heat transfer coefficient might; produce in the gas preheating.

The change in the heat transfer coefficient due to gas preheating effects is also indicative of the effect that $g a s$ absorption of the heat from thermocouple number 14 would have on the heat transfer coefficient. The increase in the temperature of the gas due to the absorption of the heat radiated to thermocouple number 14 is approxiantely $93^{\circ} \mathrm{P}$. This further suggests that the absenc. of therwocouple nuinber 14 is not only a just:ficd but a desirable condition. 
The effects of the changed heat transfer coefficient due to the increased gas preheating also s?ightly reduces the Reynolds number for the flow (dese to the higher viscosity during the passage through the porous tungsten) and increases the Russelt number. One result of such an adjustment wouid be to move the data points from this study toward alignment with curve D of slope one in Figure 17. However, such changes wou:d not change the order of magnitude of the heat transfer coefficient and in the sase of the helium runs, even with several hundred degrees of preheat, the heat transfer coefficients remain quite small. In these cases the effect of Iarge preheating effects does not appear to be altering the primary correlation jetween Nusselt number and Reynolds number that was found in this study.

The five optical pyrometer temperatures were increased by 10 percent which amounted to approximately $145^{\circ} \mathrm{F}$. The result of this change was that the caiculated value of the heat transfer coefficient was decreased by approximateiy 20 percent. A large change such as this would be expected since noarly all parameters in this study are dependent on the temperature of the tingsten. In addition, these temperatures control the radiative heat loss at the outside wall of the tungsten nylinder and it has been noted that this is a significant portion of tiic heat flux from the tungsten cyliuder.

However, an opiical pyrometer temperature error of this magnitude would require that the spectral emissivity of the porcus tungsten be much smaller than could be reasonably expected from a rough, oxidized surface. 
The effect of int. ducing simulated experimental error: into the calculation for this study s'aox that the evaluation of the heat transfer coefficient was subject to various uncertainties that could introduce errors that may be estimated to be on the order of 15 to 20 percent. However none of these experimental errors would aiter the magnitude of the heat transfer coefficients wich have been found in this study. The position of the data in the Musselt-Reynolds correlation show in Figure 17 would be essentially unchanged by errors that might reasconably be associsted with this study.

\section{Maximum Overall Brror Estimates}

A "worst case" error calculation was carried out by combining five of the individual exrors into one case where all of these errors combined to raise the calculated heat transfer coefficient. The effect of raising the calculated heat transfer coefficient was chosen because a major assertion of this study is that heat transfer coefficients in porous systems are (at low Reynolds numbers; significantly lower than would be predicted by other correlations in the literature. Thus, this "worst case" analysis would give some indication of the extent to which the conclusions of this study are dependent on experimental errors.

The following changes were arade for the "worst case" analysis. The temperature of thermocouple number 14 was increased by 10 percent. The terperature of thermocouple number 6 was increased by 20 percent. The average value of the fluid heat capacity during its passage through the porous tungsten was decreased by 10 percent. The thermal conductivity of tungsten was increased by 10 percent. The amount of gas preheating in the stainless steel pier was increased by 50 percent. 
No chan $\dot{B} \geq$ was made in the five observed optical pyrometer temperatures for the "worst case" analysis for the following reason. The five parameters that were perturbed for this analysis might reasonably be suspected of errors which could vary symetrically about the true value, i.e., errors might be either positive or negative. The possible errors ir the optical pyrometer temperatures would, however, be markedly asymetrical since the observed optical pjicmeter temperatures represent a lower limit from which the true vaiue could only vary upward. It would be extremely unlikely for the true surface temperature of the tungsten to be less than the observed value. Therefore, due to the nature of the optical pyrometer temperature measurements and the fact that increasing the observed uptical pyrometer temperatures would, in fact, decrease the calculated heat transfer coefficient, the least decrease in the calculated heat transfer coefficient can be obtained by not changing the observed optical pyrometer temperatures for the "worst case" analysis.

The result of the "worst case" was to raise the calculated heat transfer coefficient, by a factor of approximately 2.5.

Thus, as was observed for the individual errors, the results of the "worst case" error would stịl not change the magnitude of the heat transfer coefficients calculated in this study nor would it change the general nature of the heat transfer correlation for porous material that was determine: in this study. 


\section{Concussions}

It was possible to build and operite a simple experimental apparatis for studies involving heat generating porous mterials using porous tungsten heated by direct current. The major problem in the u.je of this apparatus was that of obtaining uniform and reproducible contact

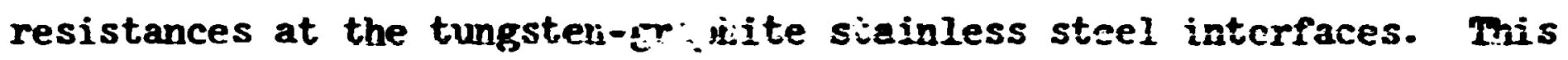
disadvantage was offset by ih? advantage of being able to use less expensive individual components for experimental studies. The use of separate tungsten, graphite, and pier comonents allored great flexibility. This would not have been possible if the porous tungsten had been welded or otherwise mechanically attached to the piers. In particular, the reduction of the axial teuperature gradient by the use of the graphite washers as combination heat sources and thermal conductivity insulators wiuld not have been possible.

The equations for heat transfer in a heat generating, fluid cooled, flat porous plate were derived. These equations were successfully extended to describe the hollow porous tungsten cylinder use: $\vec{a}$ in this study.

The heat transfer coefficients found in this study show good agreement with other experimental measurements of heat transfer in porous materializ. The data for the porouz materials examined in this study show tiat heat transfer coefficients on the order of $10^{-1}$ (for Nusselt. numbers on the order of $10^{-4}$ ) are found at Reynolds numbers on the order of $10^{-1}$. In comparison with other correlations for heat transfer in porous miterials which are extrapolated from heat transfer data in small tubes or in beds of granular material, th? results of this study 
found heat transfer cocfficients twu or three orders of monitude lowir than those predicted by these correlations. The use of correlations wich predict high values of heat transfer coefficients can continue to foster the basically incorrect idea that the temperature of the solid and fluid phase are essentially identical in porous materials. Differences of several hincred degrees $F$ between the solid and fluid temperatire are computed for the porous tungsten in this study.

The effects of fluid phase heat conduction which were neglected in the study were found to account for only a small percentage of the fluid beat transport effect in the majority of the cases studied.

It was possible to evaluate a length-over-area conduction correction factor in this study and to apply it to the determination of tive heat transfer coefficient in porous tungsten. The conduction correction factor that was computed indicates that the effective conduction of porous tungsten should be reduced by a factor of from 0.25 to 0.4 over and above corrections based on the volumetric porosity of the tungsten. 


\section{FUTUR WOR}

Juiure siudies should consider elininating the graphite washers from the axperimenial system. The graphite vasher did serve a useful purpose in providing a merharical seal and serving as a thermal barrier at the encs of the tungsten aglinder. Howevr, the probleas of fluctuating coitact resistances at these washers suggest that future studies should use large porous specimelis wich can be welded or otherwise mechanically attached to a supporting pier. Iarger porous specimens would be desirable since the welding process would wodify the porous structure adjacent to the weld and this modified region should occupy only a suall percentage of the porous specimen. Other techniques for obtaining a flit axial temperature profile, such as separate eicctrical heating circuits for the piers, should be considered.

The measurement of the surface temperature of porous materials by the use of optical pyrometry has eliminaicd any possibility that the nature of the portis medium was altered at the point of temperature measurement. However, in order to eliminate problems wich are associated with the operation of a porous system at high temperature, consideration should be given to the use of temperature measuring devices which could be attached to the surface of the porcus material and allow speration at a lower temperature.

If there is a need for operation of the porous system at hi in temperatures, the use of two color optical pyrometers would eliminate the need for eytensive emissivity corrections in temperature measurement and prnvide better values for use in radiative heat transfe: calculations. 
Direct weasuresent of the conduction correction factors for electrical and thermal conduction in porous speciens should be carried out prior to utilizing then in experiments. This irformation would be particularly useful if the apparatus was to be operated at temperatures wich ccrresponded to that at which the correction factor was measured. The use of heat generating porous materials as a device for the measurewent of the heat transfer coefficient should be continued and extended as this apparatus elininates the probless associated with the measurement of heat transfer coefficients by transient means. 
113

APPBDDXIX $A$

Derivation of Equetions 
All parmeters are independent $0 i^{*} T, t, x$, and 2 . The solid and fiuid temperatures are a nuction of $x$ and $z$.

$$
\begin{aligned}
& I=I(x, z) \\
& t=t(x, z)
\end{aligned}
$$

At steady state with no accumulation of beat the heat belance for the solid phase of she dx element in Pigare 1 is heat in = heat out. Wet heai in by conducticn $=u v_{2} \nabla^{2} T_{\text {. }}$. Heat in by Beneration $=r_{Y_{3}}$. Heat out by convective beat transfer $=\mathrm{ha}(\mathrm{T}-\mathrm{t})$.

$$
k r_{2} \nabla^{2} T+r_{Y_{3}}=h_{2}(T-t)
$$

At steady state with no accumulation of beat ibe beat balance for the fluid phase of the dx element in Figure 1 is beat in = beat out. Heat in by convective heat transfer $=$ he $(P-t)$. Wet heat out by fluid transport $=\mathrm{F} \mathrm{Cp}_{2} \mathrm{dt} / \mathrm{dx}$.

$$
h E(T-t)=P r_{3} \delta_{2} d t / d x
$$

The volumetr:c heat generation rate is expressed as a linear function of solid phase temperature.

$$
\Gamma_{Y_{z}}=G=G(T)=C_{0}+\alpha T(x, z)
$$

The volumetric heat generation rate is therefore $a$ function of $x$ and $z$. These functions are assumed to be separabie.

$$
G=G(x, z)=x(x) z(z)
$$

The following relations may be derived:

$$
\mathrm{T}=\mathrm{G} / \alpha-\mathrm{Go}_{0} / \alpha
$$




$$
\begin{aligned}
& \nabla^{2} \mathrm{I}=\nabla^{2} G / \alpha \\
& \nabla^{2} G=x^{m} Z+x z^{\prime \prime}
\end{aligned}
$$

Equation (24) now becones

$$
k y_{2} \nabla^{2} G+\infty a=h e(G-\omega o-\alpha t)
$$

and equatica (25) becones

$$
h_{e}(G-c o-a t)=a c^{2} \delta_{2} d t / d x
$$

Differentiation of equation (31) with respect to $x$ and the substitution of the $X$ and $Z$ components of $G$ gives

$$
k y_{2}\left(x^{m} z+x^{\prime} z^{\prime \prime}\right)+\alpha x \cdot z=b c\left(x^{\prime} z-\operatorname{adt} / a x\right)
$$

Solution of equation (33) for ct/ax gives

$$
\mathrm{dt} / \mathrm{dx}=\left(\frac{1}{a}-\frac{1}{b x}\right) x^{\prime} z-\frac{k \gamma_{2}}{\cos }\left(x^{m+n} z+x^{\prime} z^{n}\right)
$$

Substitution of $d t / d x$ from equation (34) into equation (32) gives upor rearrangewent

$$
x^{\prime \prime \prime} z+b X^{\prime \prime} Z-(c-a) X^{\prime} z+x^{\prime} Z^{n}+b a X z+b X Z^{n}=0
$$

where

$$
\begin{aligned}
& a=a_{i}^{\prime} k y_{2} \\
& b=h e / F C p \delta_{2}
\end{aligned}
$$

and

$$
c=h e / k y_{2}
$$


In order to scparate the $\mathrm{Z}$ function from equation (35) a form of $\mathrm{Z}$ runction is chosen which will satisfy the condition:

$$
z^{\prime \prime}=-\lambda^{2} z
$$

The Fourier series satisfies this condition. Substitution or equation (39) in equation (35) gives, after canceling $\mathrm{z}$,

$$
x^{\prime \prime \prime}+b X^{\prime \prime}-\left(c-a+\lambda^{2}\right) x^{\prime}-b\left(-a+\lambda^{2}\right) x=0
$$

The soiution of equation (40) is

$$
x=c_{1} e^{r_{1} x}+c_{2} e^{r_{2} x}+c_{3} e^{r_{3} x}
$$

where the $\mathbf{r}_{\mathbf{n}}$ are the roots of the operator equation

$$
m^{3}+b m^{2}-\left(c-a+\lambda^{2}\right) m-b\left(-a+\lambda^{2}\right)=0
$$

The Cs are the constants of intrgration.

One solution for $G$ in equation (27) is now

$$
G=x(x) z(z)=\left(c_{1} e^{r_{1} \ddot{x}}+c_{2} e^{r_{2} x}+c_{3} e^{r_{3} x}\right) z(z)
$$

or

$$
\approx=\left(\sum_{n=1}^{3} c_{n} e^{r_{n}^{y}}\right) z(z)
$$

Having found one of an infinity of solutions the general solution for $G$ is

$$
G=\sum_{i=1}^{\infty}\left(\sum_{n=1}^{3} c_{i n} e^{r_{i n} x}\right) z_{i}(z)
$$


where the $r_{i n}$ are the $n$ roots of the $i$ th operator equation using $\lambda_{i}$ where the first five $\lambda s$ are:

$$
\lambda_{1}=0 \quad \lambda_{2}=\lambda_{3}=\pi / L \quad \lambda_{4}=\lambda_{5}=2 \pi / L
$$

where $L$ is the $z$ length of the cylinder (wall) and where the first five $z_{i}$ are:

$$
\begin{aligned}
& z_{1}=1 \\
& z_{2}=\cos \lambda_{2} z \\
& z_{3}=\sin \lambda_{3} z \\
& z_{4}=\cos \lambda_{4} z \\
& z_{5}=\sin \lambda_{5} z
\end{aligned}
$$

Converting back to $\mathrm{T}$ and anproximating the Fourier series by the first five terms.

$$
\mathrm{i}=\sum_{\mathrm{i}=1}^{5}\left(\sum_{n=1}^{3} c_{\text {in }} e^{\mathrm{r}_{\text {in }} \mathrm{x}}\right) \mathrm{z}_{\mathrm{i}}(\mathrm{z})-\cos ^{\prime} \alpha
$$

By a similar process a solution for $t$ is found to be

$$
t=\sum_{i=1}^{5}\left(x_{i}^{*} z_{i}\right)-G_{0} / a
$$

where

$$
x_{i}^{*}=B_{i 1} e^{r_{i 1} x}+B_{i 2} e^{r_{i 2} x}+B_{i 3} \epsilon^{r_{j 3} x}
$$


The relation between the coefficients of the $t$ equation and the $T$ equation is found by substituting the solution of the $T$ equation back into equation (24). This shows that

$$
B_{\text {in }}=C_{i n}\left(c-a+\lambda_{i}^{2}-r_{i n}^{2}\right) / c
$$

or that

$$
B_{\text {in }}=c_{\text {in }} b /\left(r_{\text {in }}+b\right)
$$

Equation (49) thus becomes

$$
t=\sum_{i=1}^{5}\left(\sum_{n=i}^{3}\left(\frac{b}{r_{i n}+b}\right) c_{i n} e^{r_{i n} x}\right) z_{i}(c)-c_{0} / \alpha
$$

The evaluation of the conduction correction factor, $f_{L / A}$, is based on the following analysis. The volunitric heat generation rate is expressed in the following:

$$
\mathrm{G}=\mathrm{JIv}=\mathrm{JI}^{2} \mathrm{R}
$$

and

$$
G=J I^{2}\left(\frac{p_{L L f} / A}{A\left(1-S_{3}\right)}+\frac{\alpha^{\prime} L f_{I_{1} / A} \bar{T}}{A\left(1-S_{3}\right)}\right)
$$

Soliution of equation (26) is connection with equation (55) shows inat

$$
\alpha=\frac{\alpha^{\prime} J 1^{2} L f_{L / A}}{A\left(1-S_{3}\right)}
$$


Since

$$
\alpha=\frac{G}{\frac{C_{0}}{\alpha}+T}=\frac{J I v_{A B}}{\frac{p^{\prime}}{\alpha^{\prime}}+\bar{T}_{A B}}
$$

The value of $f_{L / A}$ can be found from equation (57) once the arriage value of the solid phase temerature beiveen voltage probe $S A$ and $B$ can be found.

When thermal conduction effects in the fluid are included, equation (25) becomes

$$
h e(T-t)=P \text { Cp dt/dx }-k_{\text {fluid }} \delta_{e} d^{2} t / d x^{2}
$$

Equation (140) then becomes

$$
\begin{aligned}
\left(b / c^{\prime}\right) x^{m+n}+x^{m}+b\left(i+\left(c-a+\lambda^{2}\right) / c^{\prime}\right) x^{n} \\
-\left(c-c+\lambda^{2}\right) x^{\prime}-b\left(-a+\lambda^{2}\right) x=0
\end{aligned}
$$

where

$$
c^{\prime}=\mathbf{h e} / \mathbf{k}_{\text {fluid }} \delta_{2}
$$

This equation differs from equation (40) only in thcse terms which involve $c^{\prime}$ and in the fact that this is now a fourth order equigtion. 
APPOTDIX B

Experimentai Data

Common Vaiues and Physical Constants 

Tabiz 1

Comar: Parameters and Physical Constants

Rectifier Current Shint Factor 120. amperes/millivolt

Stefan-3oltzmann constant $0.1712 \times 10^{-8}$ B.t.u./sq.ft. $-h r .-{ }^{-} R^{4}$

Total Enissivity of Thernocouple number 140.95

Total Enissivity of tunfsten 1.0

Total Bnisivity of Marinite 0.8

Spectral Emissivity of tungsten at 1.0

Spectral Emissivity of Marinite at

0.65 wicron wave length 0.8

Yarinite Disks:

Thermal Conductivity B.t.u./hr.-ft.- ${ }^{\bullet} \quad 0.12+5.0 \times 10^{-5}$ TPP

Inside Dianeter

Outside Diameter

$0.5 \mathrm{in}$.

Therwocouple number 7 - radius position

Thermocouple number 6 - radius position

1.75 in.

0.302 in.

0.750 in.

Tungsten:

Density of Solid Tungsten

$19.3 \mathrm{gr} \cdot / \mathrm{cu} \cdot \mathrm{cm}$.

coefficient of ther dal expansion

Elestrical resistivity (ohm-ft.)

$0.1479+4.378 \times 10^{-4} T^{0} F+3.725 \times 10^{-8} T^{0} P^{2}-2.094 \times 10^{-12} T^{0} P^{3}$

Thermal Conductivity (B.t.u./hr.-ft.- ${ }^{\bullet}$ )

$\mathbf{T}^{\circ} \mathbf{K}$

1100

$78.52-.0099\left(\mathrm{~T}^{\circ} \mathrm{K}\right)$

1200

1300

$76.96-.0086\left(T^{\circ} \mathrm{K}\right)$

$140077.87-.0093\left(T^{\circ} \mathrm{K}\right)$

$150077.73-.0092\left(\mathrm{~T}^{\circ} \mathrm{K}\right)$

1600

$\tau 8.81-.0099\left(\mathrm{~T}^{\circ} \mathrm{K}\right)$ 
123

Table 1 (Continued)

Porous Tungsten:

Measured internal area by gas adsorption 0.0116 sq. neters/gr.

Original Powder Size $\quad 2 n$ micron $=6 . j 6 \times 10^{-5} \mathrm{ft}$.

0.06726 1b.-mass/Standard Civic Foot - Nitrogen

0.01034 1b.-mass/standard Cubic Foot - Helium

Viscosity:

$$
\begin{aligned}
& \left.\mu_{2}\left(1 b_{0}-\text { massif. } j^{-h r}\right)=0.04 \operatorname{cl} 7\left(\left(t^{*} F / 49\right) .7\right)+0.9349\right)^{0.756} \\
& H_{\text {He }}\left(1 b .-\operatorname{eass} / 2 t .-\mathrm{mr}_{\cdot}\right)=0.04525\left(\left(\mathrm{t}^{\bullet} \mathrm{P} / 491 . i\right)+0.934 .9 j^{\mathrm{C} .647}\right.
\end{aligned}
$$

Beat Capacity (B.t.u./SCP-`P at constant Pressure)

$$
\begin{aligned}
& C_{p} \text { (nitrogen) }=1.513 \times 10^{-2}+2.426 \times 10^{-6} \mathrm{t}^{\circ} \mathrm{R}-2.557 \times 10^{-10} \mathrm{t}^{\circ} \mathrm{R}^{2} \\
& C_{p} \text { (́belium) }=1.389 \times 10^{-2}
\end{aligned}
$$

Thermal Conductivity - at $t^{\bullet} \mathrm{P}$ :

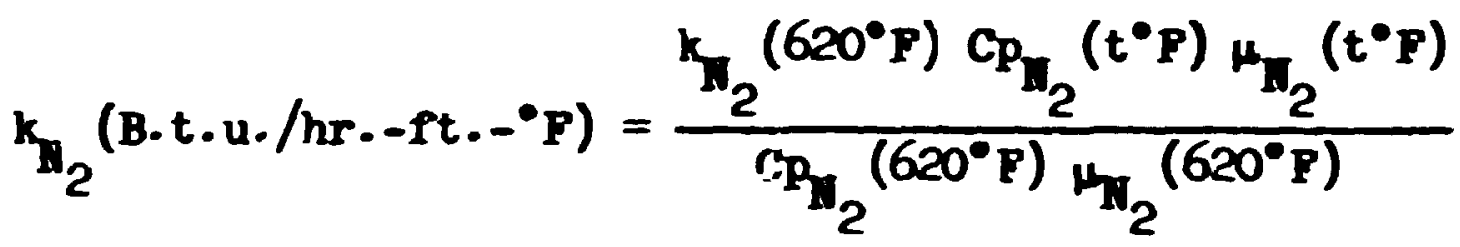

$$
\begin{aligned}
& k_{\mathrm{He}}\left(\mathrm{B} \cdot \mathrm{t} \cdot \mathrm{u} \cdot / \mathrm{hr} \cdot-\mathrm{ft.--^{ \circ } \mathrm { F } )}=\frac{\mathrm{k}_{\mathrm{He}}\left(620^{\circ} \mathrm{F}\right) \mu_{\mathrm{He}}\left(t^{\circ} \mathrm{P}\right)}{H_{\mathrm{He}}\left(620^{\circ} \mathrm{F}\right)}\right.
\end{aligned}
$$


APPENDIX C

Experimental Data

Individual Run Data 
BLANK PAGE 
TABLE 2

INOIVIDUAL RUM DATA

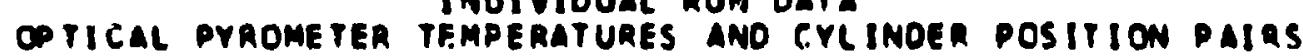

POSITION OY TUMGSTEN CYIINOER IN CM.

OPTICAL iYROAETER TEMPERATURES -- DEgREES C

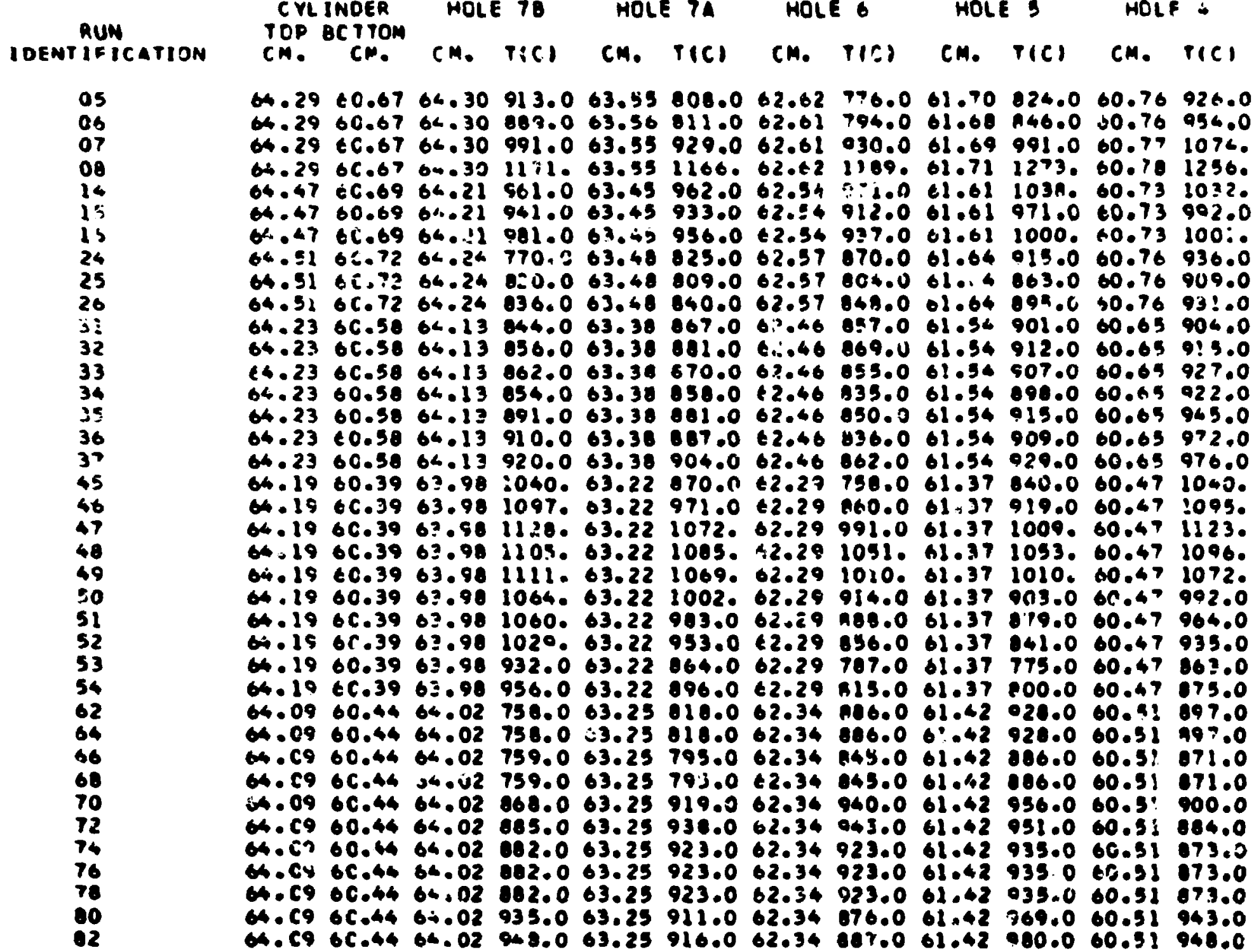


TABLE 3

INDIVIOUAL RUN DATA

THERMOMETER ANO THERMOCOUPLE READINGS

all rempeqATUOES IN DEGREFS F

THER MOC OUPLES-D.
LOWER PIER TEMPERATURES

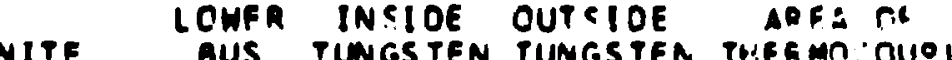
RUN POOM INLET GAS
IOENTIFICATIUN TEMPEAATURE TEMPERATURE DUTER IMTER INTER BLOCK CYLINOER CYLINOEF MUMBEP

\begin{tabular}{|c|c|c|}
\hline $\begin{array}{l}05 \\
06 \\
07 \\
08 \\
14 \\
15 \\
16 \\
24 \\
25 \\
26 \\
38 \\
32 \\
33 \\
36 \\
35 \\
36 \\
37 \\
45 \\
46 \\
47 \\
68 \\
69 \\
50 \\
51 \\
52 \\
53 \\
54 \\
62 \\
64 \\
56 \\
68 \\
70 \\
72 \\
74 \\
76 \\
78 \\
00 \\
82\end{array}$ & 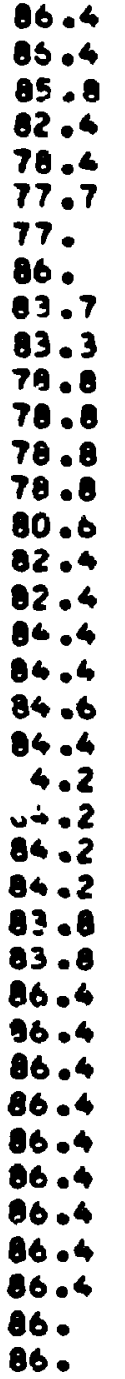 & 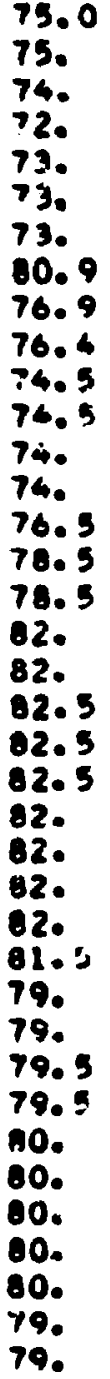 \\
\hline
\end{tabular}

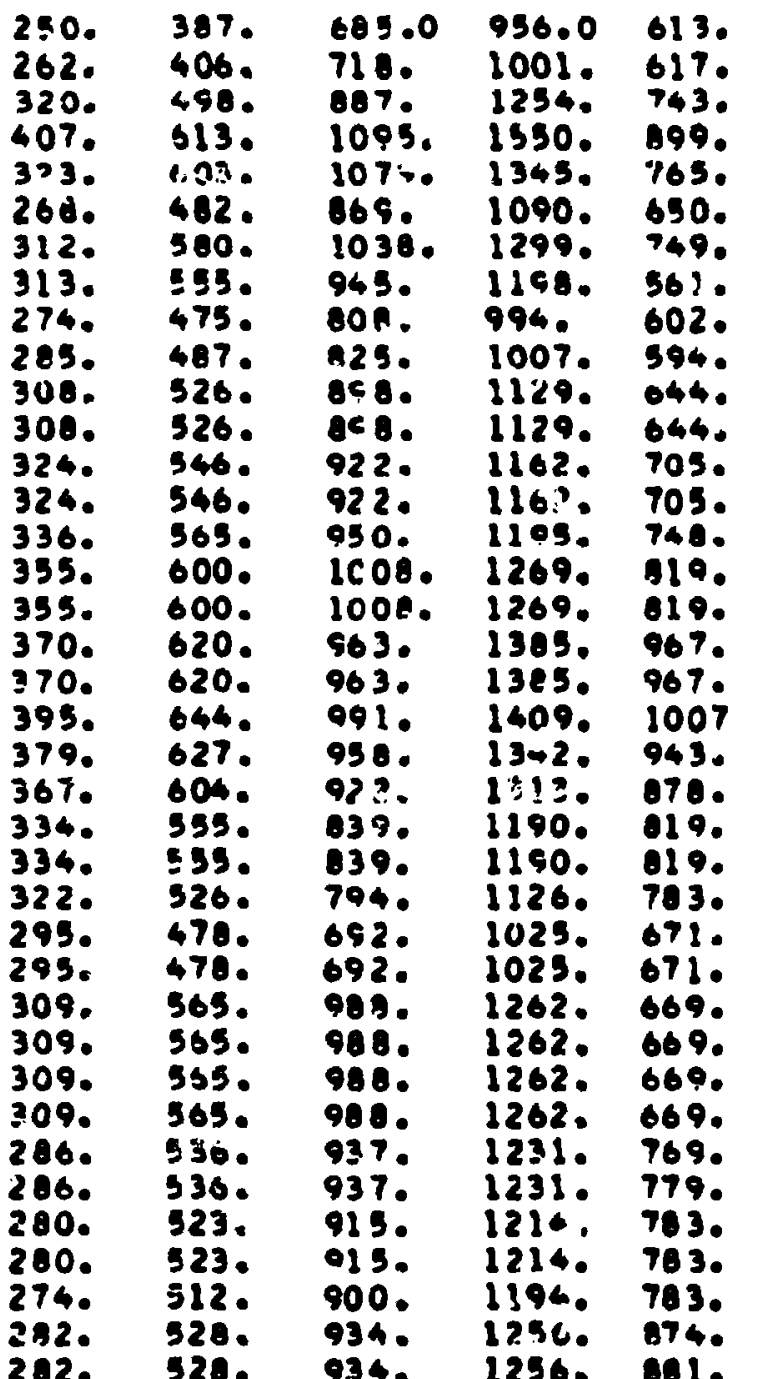

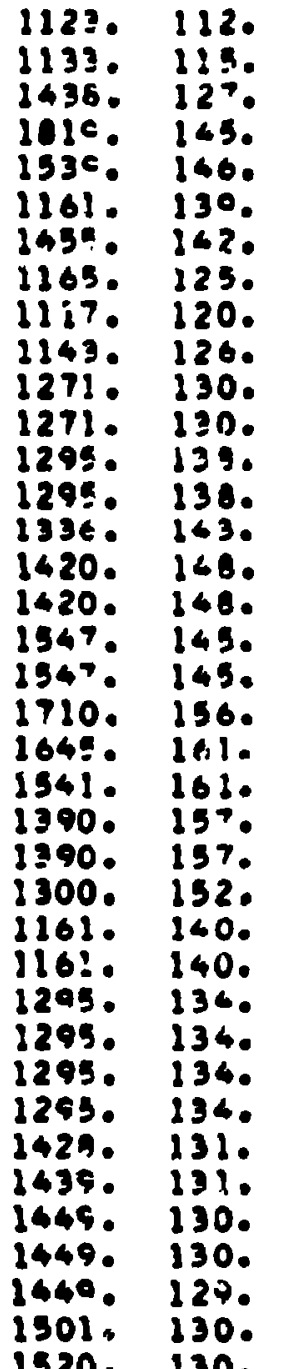

1080.

NC. 6 (SO.FT.)

331. $22 !: 0 \quad 001023$

1735.2009 .000

13:6. 1600.

$933 \circ \quad 1220^{\circ} \quad .0 \mathrm{0} .02$ ?

l:e7. 1+82. .0010?:

1251. 1201. .001 त?

1043. $1260 . \quad .00: 02:$

$1169.005 .00102=$

1350 1350.001023

13.0.

036.1330 .001023

40.1350 .001023

85. 1620. $00102:$

657. 14?0. .00102?

1920.09400

1014.1779 . 0

1034. 1792: 0

1036. $17020^{\circ}$

jiv? 1602

1754.1496.

i rop, 9630 .

1585. 3200.

1555. 1204.

1716. 12-0.

ile. 1370 .

1736.136 !.

i.24. !361.

1601. 145?

520. 1465.

1484.1680.

:484. 1460

1196.1440.

$1+90$. 
TAEle 4

CrINDER SPECIFICATIONS. FEAT GENERATION AND FLIIIO FLOH

\begin{tabular}{|c|c|c|c|c|c|c|c|c|c|c|c|}
\hline $\begin{array}{l}\text { CVI } \\
\text { :CEN }\end{array}$ & $\begin{array}{l}\text { RUN } \\
\text { CATION }\end{array}$ & $\begin{array}{l}\text { CYLINDFR } \\
\text { LENGT:1 } \\
\text { IIN.I }\end{array}$ & $\begin{array}{l}\text { SPECIFIS } \\
\text { MASS } \\
\text { (GR.) }\end{array}$ & $\begin{array}{l}\text { IONS } \\
\text { O.D. } \\
\text { IIN.I }\end{array}$ & 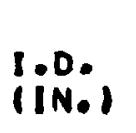 & $\begin{array}{l}\text { HEAY } \\
\text { AMMETER SHUNT } \\
\text { MILLIVOLT OROP }\end{array}$ & $\begin{array}{l}\text { GENERATION } \\
\text { CYLINDER PPOBE } \\
\text { YOLT TAGE OROP }\end{array}$ & $\begin{array}{c}\text { VCLTAGE } \\
\text { 2-PDSITI } \\
\text { A }\end{array}$ & $\begin{array}{c}\text { DPOBE } \\
\text { ONIFT. } \\
\text { R }\end{array}$ & $\begin{array}{c}\text { CLCW-? } \\
\text { CU. } F\end{array}$ & $\begin{array}{l}\text { IAN SAFE } \\
7.100 .\end{array}$ \\
\hline $\begin{array}{l}C \\
C \\
C \\
C \\
D \\
D \\
D \\
D \\
D \\
D \\
D \\
D \\
D \\
D \\
D \\
D \\
D \\
E \\
E \\
E \\
E \\
E \\
E \\
E \\
E \\
E \\
E \\
D \\
D \\
D \\
D \\
D \\
D \\
D \\
D \\
D \\
D \\
D\end{array}$ & $\begin{array}{l}05 \\
06 \\
07 \\
08 \\
14 \\
15 \\
16 \\
24 \\
25 \\
26 \\
31 \\
32 \\
33 \\
34 \\
35 \\
36 \\
37 \\
45 \\
46 \\
47 \\
48 \\
49 \\
50 \\
51 \\
52 \\
53 \\
54 \\
62 \\
64 \\
66 \\
68 \\
70 \\
72 \\
74 \\
76 \\
70 \\
80 \\
02\end{array}$ & $\begin{array}{l}1.431 \\
1.431 \\
1.431 \\
1.431 \\
1.492 \\
1.492 \\
1.432 \\
1.447 \\
1.499 \\
1.487 \\
1.434 \\
1.434 \\
1.434 \\
1.434 \\
1.434 \\
1.434 \\
1.434 \\
1.504 \\
1.504 \\
1.304 \\
1.504 \\
1.504 \\
1.504 \\
1.504 \\
1.504 \\
1.504 \\
1.304 \\
1.434 \\
1.434 \\
1.434 \\
1.434 \\
1.434 \\
1.434 \\
1.434 \\
1.434 \\
1.434 \\
1.434 \\
1.434\end{array}$ & 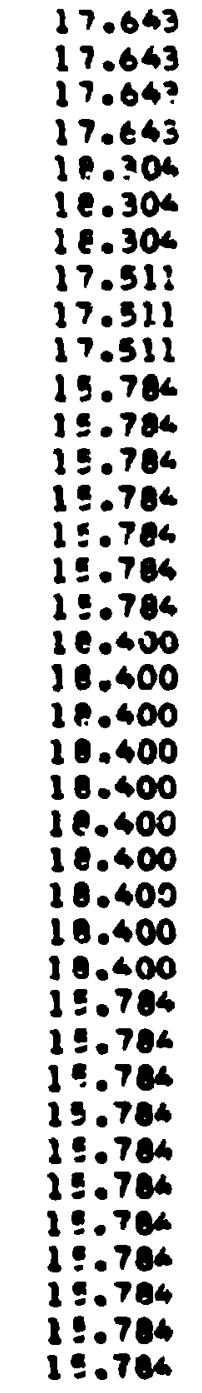 & $\begin{array}{l}.416 \\
.416 \\
.416 \\
.416 \\
.416 \\
.416 \\
.416 \\
.411 \\
.411 \\
.411 \\
.405 \\
.405 \\
.405 \\
.405 \\
.405 \\
.405 \\
.405 \\
.416 \\
.416 \\
.416 \\
.416 \\
.416 \\
.416 \\
.416 \\
.416 \\
.416 \\
.416 \\
.405 \\
.405 \\
.405 \\
.405 \\
.405 \\
.405 \\
.405 \\
.405 \\
.405 \\
.405 \\
.405\end{array}$ & $\begin{array}{l}.276 \\
.276 \\
.276 \\
.276 \\
.270 \\
.276 \\
.276 \\
.276 \\
.276 \\
.276 \\
.277 \\
.277 \\
.277 \\
.277 \\
.277 \\
.277 \\
.277 \\
.275 \\
.275 \\
.275 \\
.275 \\
.275 \\
.275 \\
.275 \\
.275 \\
.275 \\
.275 \\
.279 \\
.279 \\
.279 \\
.279 \\
.277 \\
.279 \\
.279 \\
.277 \\
.277 \\
.271 \\
.277\end{array}$ & $\begin{array}{l}1.616 \\
1.649 \\
2.150 \\
2.896 \\
2.199 \\
2.296 \\
1.949 \\
1.502 \\
1.752 \\
1.722 \\
1.763 \\
1.763 \\
1.806 \\
1.804 \\
2.049 \\
2.266 \\
2.346 \\
2.411 \\
2.411 \\
2.897 \\
2.389 \\
2.396 \\
2.353 \\
2.353 \\
2.289 \\
2.103 \\
2.116 \\
1.285 \\
1.246 \\
1.209 \\
1.209 \\
1.411 \\
1.341 \\
1.213 \\
1.18 \\
1.196 \\
1.823 \\
1.821\end{array}$ & 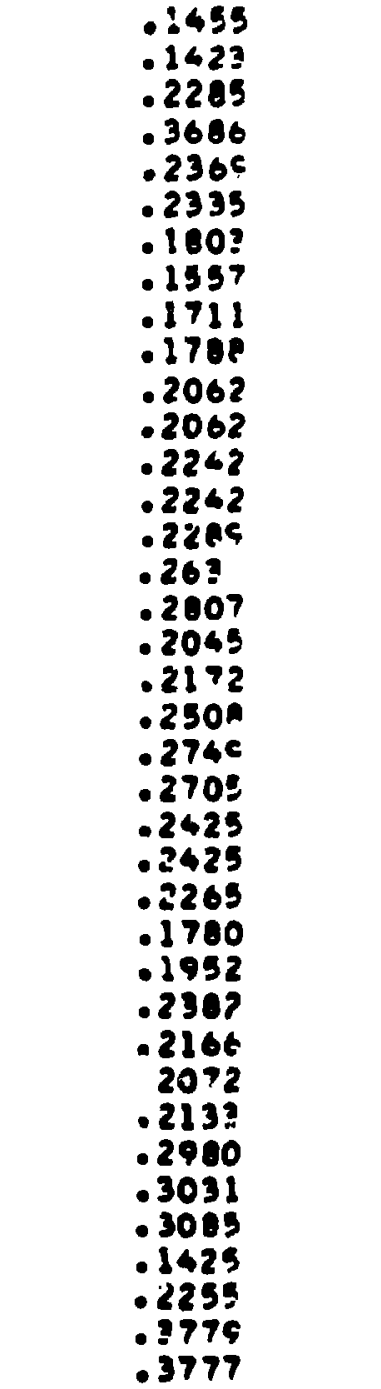 & 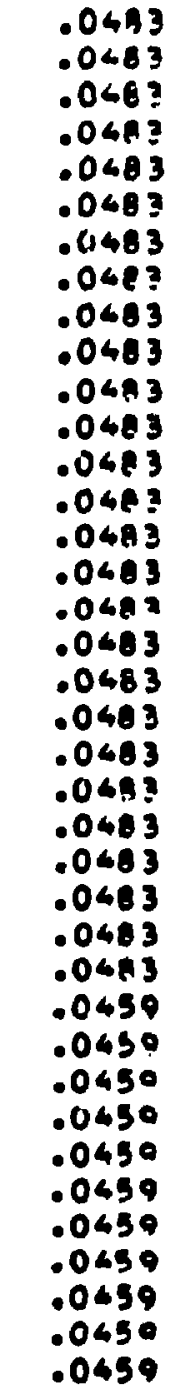 & 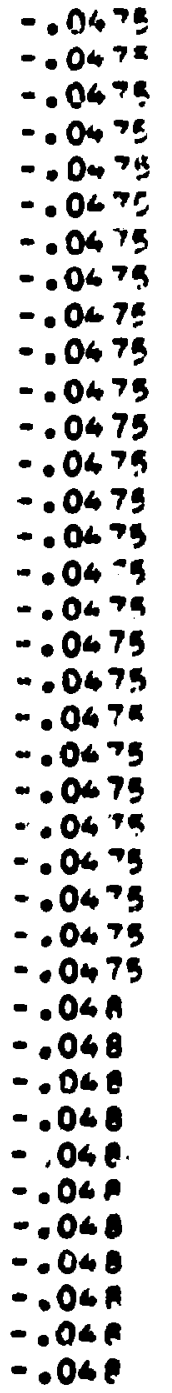 & 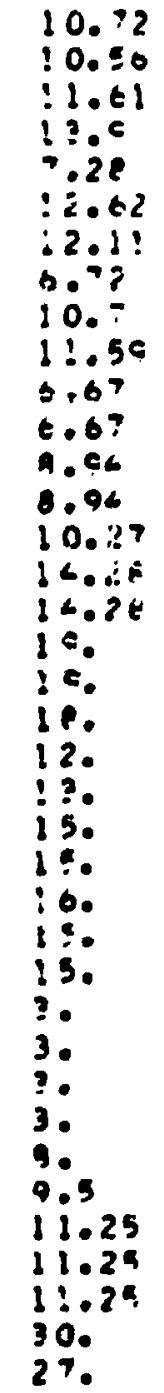 & 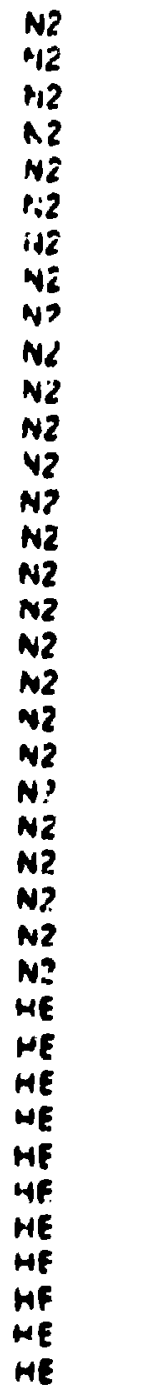 \\
\hline
\end{tabular}


APPERDIX D

Results of Individual Run Analysis 
TABLE 3

IMOI VIOUAL RUN AMALYS IS

HEAT OAL ANCES

ALL PEAT FLUXES(O) IN B.T.U. IHA.

- generated in cylinder + O Into crimofr ltop and oottomi

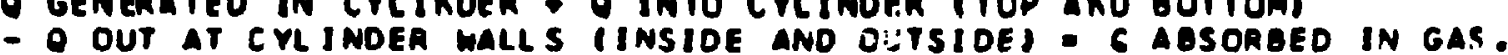

JOENTIFICATION DIGEVERATEOI OIIN TOPI OIV

05
06
07
08
14
15
24
25
26
31
33
34
35
36
37
43
46
47
48
49
30
51
52
53
56
70
72
76
80
82

\begin{tabular}{|c|c|c|}
\hline 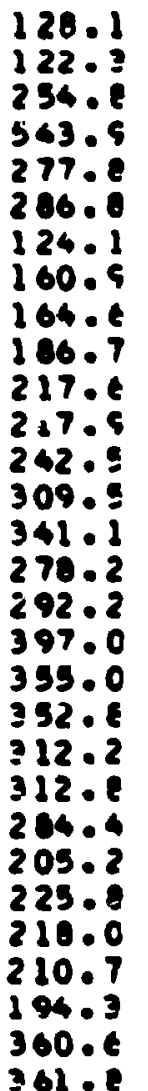 & 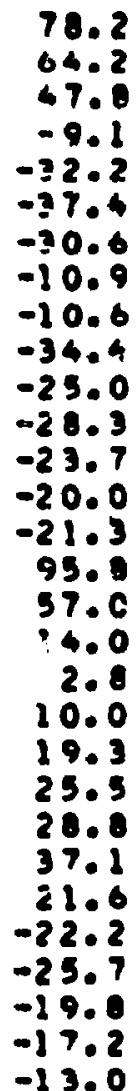 & 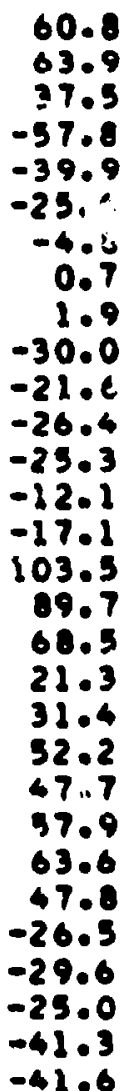 \\
\hline
\end{tabular}

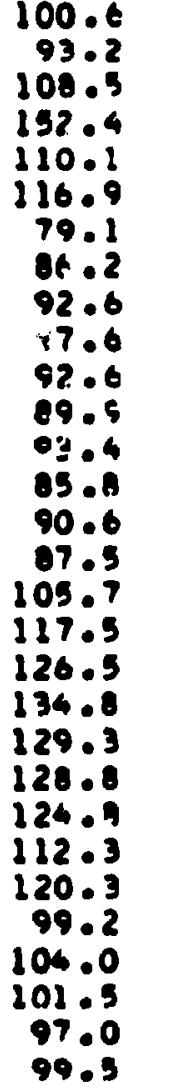

10.1
17.3
23.5
47.2
28.2
32.4
6.0
17.0
17.8
19.8
25.0
23.7
27.5
27.5
29.5
-0.0
0.0
-0.0
0.0
-0.0
-0.0
-0.0
-0.0
-0.0
0.0
6.4
10.3
11.4
24.2
24.9

150.3

140.0

277.1

67.3

2.7

4.5

33.9

49.9

73.1

146.2

102.7

390.4

333.1

362.3

252.8

259.1

$25+1$

246.3

193.8

174.8

40.8

37.0

182.7 
TAQLE 6

INOI VIOUAL RUN ANALYS IS

\begin{tabular}{|c|c|c|c|c|c|c|c|}
\hline IDEMTIFICATION & $\begin{array}{l}\text { ALL TEMPERG } \\
\text { TUNGS TEN } \\
\text { WALL AT } \\
\text { THERMO. NO. IE }\end{array}$ & $\begin{array}{l}\text { TUPES ARE IN } \\
\text { THERMOCOUPLE } \\
\text { NUABER I6 }\end{array}$ & $\begin{array}{l}\text { OEGREES F - } \\
\text { INSIDE WALL } \\
\text { MARINT TE }\end{array}$ & $\begin{array}{l}\text { EXIT GAS } \\
\text { THERMO. NO. } 16\end{array}$ & $\begin{array}{l}\text { INLET GAS } \\
\text { BELCW } \\
\text { PIER }\end{array}$ & $\begin{array}{l}\text { GAS AFTER } \\
\text { PREHEATING } \\
\text { IN PIER }\end{array}$ & $\begin{array}{l}\text { GAS AFTER HFAT } \\
\text { ABSORAEO ER JM } \\
\text { THEAMO. NO. IL }\end{array}$ \\
\hline $\begin{array}{l}05 \\
06 \\
07 \\
08 \\
14 \\
15 \\
24 \\
25 \\
26 \\
31 \\
33 \\
34 \\
35 \\
36 \\
37 \\
45 \\
46 \\
47 \\
46 \\
49 \\
30 \\
31 \\
32 \\
33 \\
54 \\
70 \\
72 \\
74 \\
80 \\
12\end{array}$ & $\begin{array}{l}1425 . \\
1461 . \\
1706 . \\
2172 . \\
1780 . \\
1674 . \\
1598 . \\
1479 . \\
1558 . \\
1575 . \\
1571 . \\
1539 . \\
1562 . \\
1537 . \\
1504 . \\
1396 . \\
1580 . \\
1816 . \\
1924 . \\
1850 . \\
1679 . \\
1630 . \\
1973 . \\
1445 . \\
1695 . \\
1724 . \\
1729 . \\
1693 . \\
1609 . \\
1629 .\end{array}$ & $\begin{array}{l}1210 . \\
1211 . \\
1545 . \\
2008 . \\
1600 . \\
1229 . \\
1291 . \\
1260 . \\
1303 . \\
1358 . \\
1333 . \\
1333 . \\
1390 . \\
1420 . \\
1420 . \\
1574 . \\
1574 . \\
1777 . \\
1732 . \\
1662 . \\
1494 . \\
1494 . \\
1430 . \\
1800 . \\
2200 . \\
1461 . \\
1465 . \\
1400 . \\
1460 . \\
1490 .\end{array}$ & $\begin{array}{l}1356 . \\
1306 . \\
1545 . \\
2025 . \\
1570 . \\
1514 . \\
1145 . \\
1239 . \\
1279 . \\
1365 . \\
1309 . \\
1370 . \\
1438 . \\
1451 . \\
1409 . \\
1613 . \\
1748 . \\
1975 . \\
1879 . \\
1874 . \\
1776 . \\
1770 . \\
1705 . \\
1901 . \\
1980 . \\
1502 . \\
1547 . \\
1533 . \\
1591 . \\
1616 .\end{array}$ & $\begin{array}{l}1061 . \\
1041 . \\
1335 . \\
1326 . \\
1039 . \\
685 . \\
392 . \\
612 . \\
322 . \\
513 . \\
739 . \\
722 . \\
793 . \\
944 . \\
1032 . \\
1169 . \\
1074 . \\
1273 . \\
1430 . \\
1339 . \\
1136 . \\
1133 . \\
1093 . \\
901 . \\
934 . \\
1644 . \\
1327 . \\
1196 . \\
935 . \\
1030 .\end{array}$ & 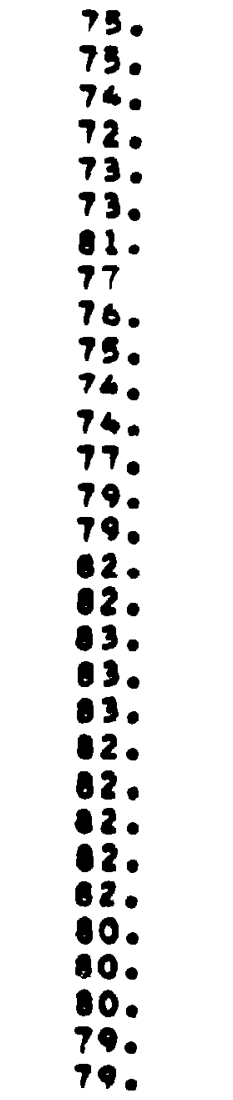 & 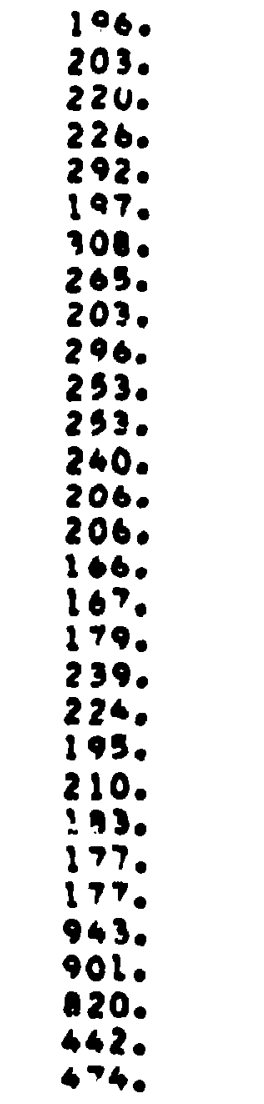 & 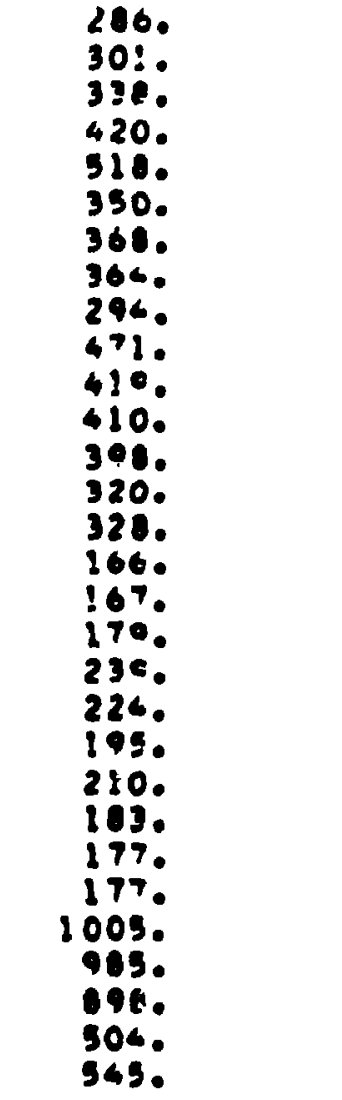 \\
\hline
\end{tabular}


TABLE 7

INDIVIDUAL RUN GinaLYS IS
HEAT TRANSFER COEFFICIENTS AND CONOUCTION CORACTION FACTOR

PUN
IDENT IFICAT

05
06
07
08
14
15
24
25
26
31
33
34
35
36
37
45
46
47
48
49
50
51
52
53
34
70
72
74
00
02

RE YNOLOS

NUMB ER

.1112

.1101

.1225

0693

1435

oet4

.1250

1651
.0823

.0823

.1021

ilez

0.1163

.1562

1832

.1939

.1744

.1104

.1220

.1318

.1458

.1681

.1642

.1710

.0056

.0122

.019

.0468
.0466
NUSSELT

NUSSELT
NUMBER

.0001678

.0001487

0.000024

00005s

.00045

000047

000052

.000049

.0000902

.0001633

.0001800

.0004193

.0002585

.0002503

.0001744

.0001801

.000197

.0002107

.0001825

.000011

.0000090

.0000350
.0000364 heat taAnSFER coefficients

B.T.U.

CLASSICAL CORRECTION FACTOR

3189

2809.

-.- SO.FT. FOR CONDUCTION

.09470 .4445

$.1123 \quad .4330$

$.0204 \quad .4201$

.0272

il7. $\quad .0010 \quad 0213 \quad .4121$

611.01110007000

919. $\quad .0270 \quad .3818$

951. $\quad .0250 \quad .3765$

$1248.0 \quad .0367 \quad .4080$

3438. 1019

8506. $\quad 2484 \quad .4525$

4918. .1435

5063. $\quad .1475 \quad .5343$

3754. $.1094 \quad .4153$

3756.

3792.0 .2106

$4104 . \quad 01190 \quad 04078$

3786. $.1105 \quad .4110$

3135. $\quad 0916 \quad .4444$

2553. $\quad .07 \% 66$

i $301 . \quad 030$ ?

985. $\quad .0289 \quad .1834$

$\begin{array}{lll}3310 . & .0976 & .2230 \\ 3500 . & .1032 & .2260\end{array}$ 


\section{TABLE OF NOWENCLATURE}

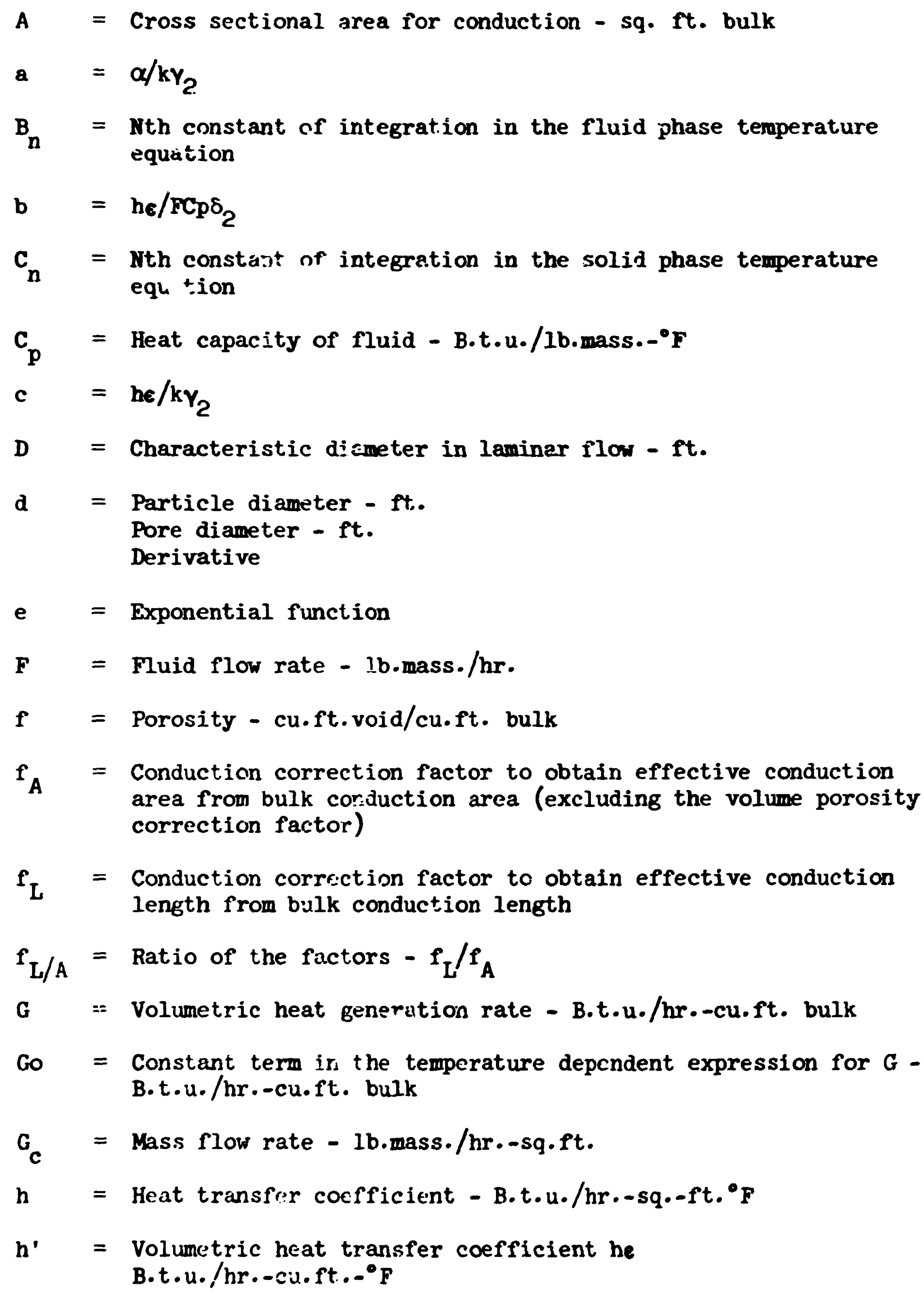




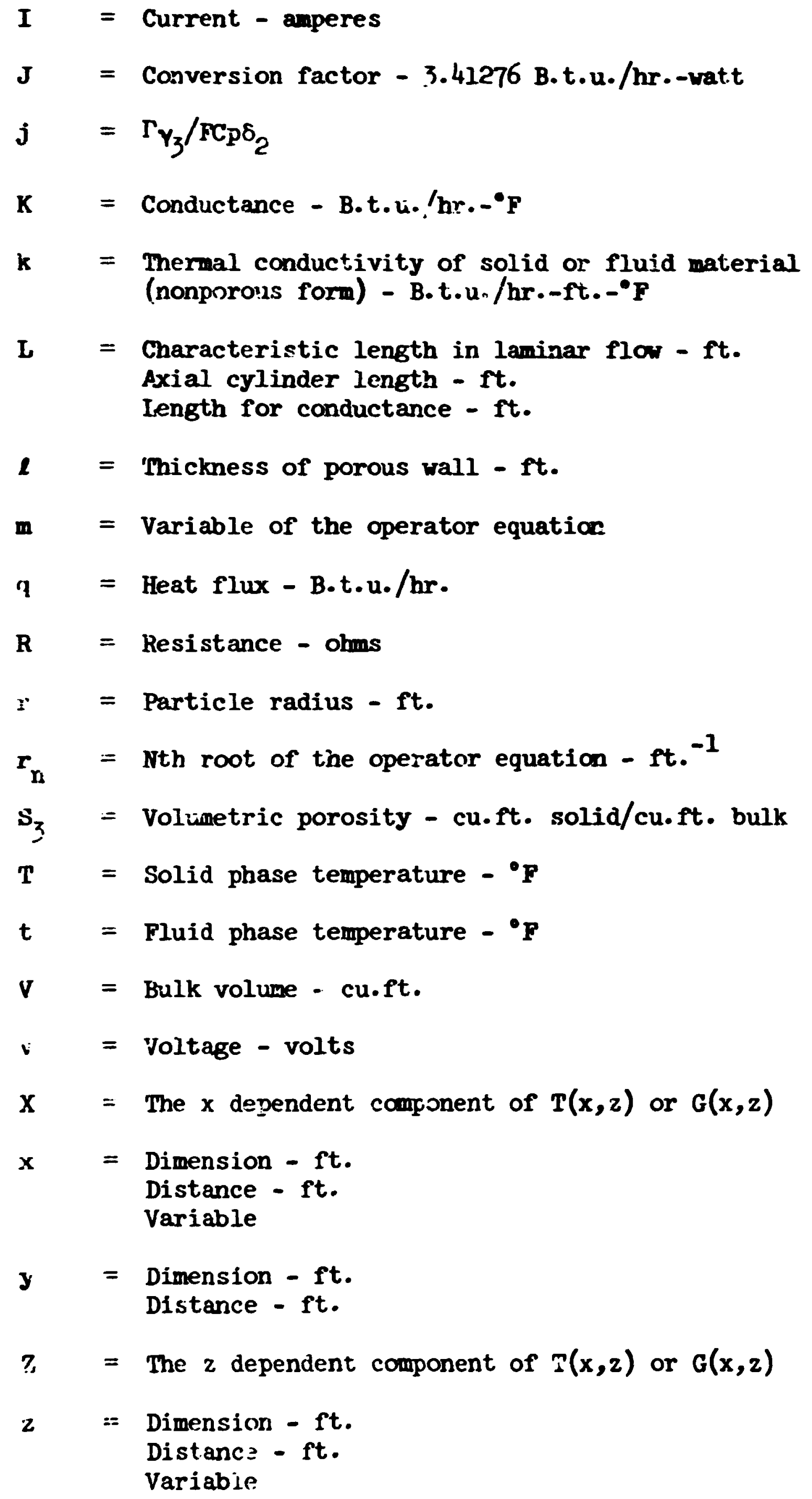




\section{Subscripts}

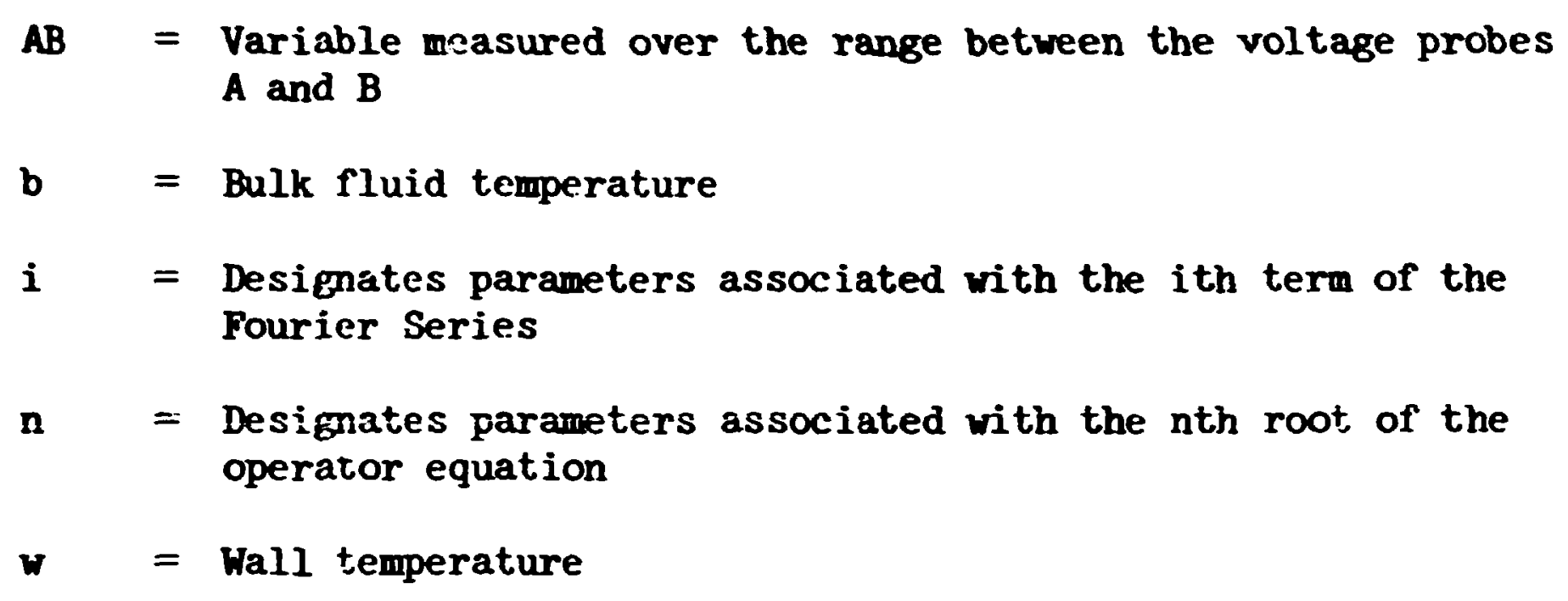

\section{Superscripts}
- = Designates the derivative with respect to the single variable of the function
- $\quad=$ Indicates an average value of the function

\section{Greek Letters}

$$
\begin{aligned}
& \alpha=\text { Coefficient of temperature dependence in } \mathbf{G} \\
& \text { B.t.u./hr.-cu.ft. }{ }^{\circ} \mathrm{F} \\
& \alpha^{\prime}=\text { Coefficient of temperature dependence in } \rho-\text { ohms/ft.- }{ }^{\circ} \mathrm{F} \\
& \Gamma \quad=\text { volumetric heat generation rate } \\
& \text { B.t.u./hr.-cu.ft. solid } \\
& \gamma_{2}=\text { Effective area for solid phase heat and electric } \\
& \text { conduction - sq. ft. solid/sq.ft. bulk } \\
& \gamma_{3}=\underset{\text { Effective volume for heat generation - cu.ft. solid/cu.ft. }}{\text { bulk }} \\
& \delta_{2}=\begin{array}{l}
\text { Effective area for fluid flow - sq. ft. flow area/sq.ft. } \\
\text { bulk }
\end{array} \\
& \text { - = Internal surface area of porous material } \\
& \text { sq. ft. area/cu.ft. bulk } \\
& \lambda_{n}=\text { Coefficient in the argument of the Fourier series - } n \pi / L \\
& \mu=\text { Gas viscosity - lb.mass./ft. }-\mathrm{hr} \text {. }
\end{aligned}
$$




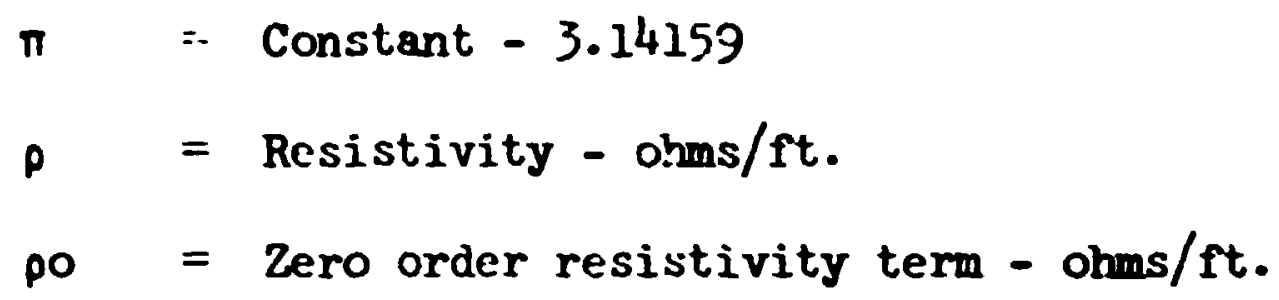

Special Symbols

$\nabla \quad=$ Nabla operator 


\section{BIBLIOGRAPHY}

1. Bird, R. B., Stewart, W. E. Lightfooi, E. N., "Transport Phenomena," John Wiley, Naw Yo:k, (1960).

2. Bland, D. R., Proceedings of the Royal Society of London, 221, pp. 1-28, (1954).

3. Boucher, D. F., Alves, G. E., Chemical Engineering Progress, 55, No. 9, pp. 55-64, (1959).

4. Brown, G. G. and Associates, "Unit Operations," John Wiley, New York, (1950).

5. Brownell, L. E., and Katz, D. L., Chemical Engineering Progress, 43, No. 10, pp. 537-545, (1947).

6. Burgess, E., "Rocket Propulsion," Chapman and Hall, London, (1554).

7. Bussard, R. W., and DeLauer, R. D., "Tuclear Rocket Propulsion," McGraw-Hill, New York, (1958).

8. Cheung, H., "A Critical Reveiw of Heat Pipe Theory and Applications," UCRL-50453, University of California, Livermore, California, (1968).

9. Eastman, G. Y., Scientific American, 218, humber 5, pp. 38-1+6, (1968).

10. Farber, J., Chemical Reaction in an Electrically Heated Porcus Medium, Ph.D. Thesis, The Pennsylvania State University, 1966.

11. Gelperin, J. J., and Kagan, A. M., Proceedings of the Third International Heat Transfer Conference, Chicago, I]lincis, August 7-12, Volume IV, pp. 308-321, (1966).

12. Green, L. Jr., ASME-AIChE Heat Transfer Conference, Universi iy Park, Pa., August 11-15, 1957.

13. Green, L. Jr., Journal of Applied Mechanics, Trans. ASWE, 19, pp. 173-178, (1952).

34. Grootenhuis, P. and Moore, N. P. W., Special Report of the Iron and Steel Institute, I nndon, Number 43, p. 281, (1951).

15. Grootenhuis, P., Proceediags of General Discussior on Heat Transfer, Institution of Mechanical Engineers, pp. 363-366, (:951).

16. Grootenhuis, P., Powell, R. W., and Tye, R. P., Proceedinge of thic Physical Society, B, London, 65, p. 502, (1952).

17. Grootcnhuis, P., Journal of The Royal Aeronautical Socisty, iz, No. 578, pp. 73-89, (1959). 
18. Jakob, M., "Heat Transfer," Volume II, John Wiley, New York, (2957).

19. Keyser, C. A., "Basic Engineering Metallurgy," Prentice-Hall, New York, (1.952).

20. Knudsen, J. G., Katz, D. I.., "Fluid Dynsmics and Heat Transfer," McGraw-Hill, New Ycrk, (1958).

21. Koh, J. C. Y., and del Casal, E., Prociecaings of the 1965 Heat. Transfer and Fluid Mechanics Iistitute, LosAngeles, California, June 21-23, pp. 26;-281, (1965).

22. Kroll, C. L., Thesis in Chemical Engineering, Massachusetts Institute of Techrolcsy, (1951).

23. Ley, W., "Rockets, Missiles, and Space Travel," Viking, New York, (1951).

24. McAdams; W. H., "Heat Transmission," McGraw-Hill, New York, (1954).

25. Mickley, H. S., Sherwood, T. $K_{.}$, and Reed, C. E., "Applied Mathematics in Ch2mical Engineering," McGraw-4ill, New York, (1957).

26. Musikat, M., "The Flow of Homogeneous Fluids Through Porcus Media," J. W. Edwards, Ine., Ann Arbor, Michigan, (1946).

27. Perry, J. H., Editcr, "Chemical Engineers' Handbook," McGraw-Hill, New York, (1950).

28. Schneider, P. J., "Concuction Heal Transfer," Addison-Wesley, Cambrilige, Mass., (1955).

29, Simmons, J. T., "The Physical and Thermounnamic Properties of Helium," Technical Repori D-3027. Wm. R. Whittaker Co., Los Angeles, (1957).

30. Sutton, G. P., "Rocket Propulsion Elements," John Wiley, New York, (1949).

31. Tungsten Data Sheet, Sylvania Electrical Products, Towanda, Pennsylvania.

32. Walas, S. M., "Reaction Kinetics for Chemical Engineers," McGrawHill, New York, (1959).

33. Weber, R. L., "Heat and Temperature Measurement," Prentice-Hall, New York, (1950).

34. Weinbaum, S., and Wholler, H. L. Jr., Journal cf Applied Physics, 20, pp. 113-122, (19/4).

35. Veiner, M. M., and Edwards, D. K., Proceeaings of the 1963 Hcat Trancfer and Fiadid Mechanies institute, Pasadena, Caljforria, June 12-14, pp. 236-250, (196;). 